Trust, Happiness, and Pro-social Behavior

Stefano Carattini and Matthias Roesti

September 2020 Discussion Paper no. 2020-15

School of Economics and Political Science, Department of Economics 


$\begin{array}{ll}\text { Editor: } & \text { Vanessa Pischulti } \\ & \text { University of St.Gallen } \\ & \text { School of Economics and Political Science } \\ & \text { Department of Economics } \\ & \text { Müller-Friedberg-Strasse 6/8 } \\ & \text { CH-9000 St.Gallen } \\ & \text { Phone +4171 224 23 07 } \\ & \text { Email seps@unisg.ch } \\ & \text { School of Economics and Political Science } \\ & \text { Department of Economics } \\ & \text { University of St.Gallen } \\ \text { Publisher: } & \text { Müller-Friedberg-Strasse 6/8 } \\ & \text { CH-9000 St.Gallen } \\ & \text { Phone +41 71 224 23 07 } \\ & \text { http://www.seps.unisg.ch }\end{array}$




\title{
Trust, Happiness, and Pro-social Behavior ${ }^{1}$
}

\author{
Stefano Carattini ${ }^{2}$ and Matthias Roesti
}

Authors' address:

Dr. Stefano Carattini

Swiss Institute for International Economics and

Applied Economic Research (SIAW)

University of St.Gallen

Bodanstrasse 8

$\mathrm{CH}-9000$ St.Gallen

Phone +41712242577

Email stefano.carattini@unisg.ch

Website

\author{
Matthias Roesti \\ Swiss Institute for International Economics and \\ Applied Economic Research (SIAW) \\ University of St.Gallen \\ Bodanstrasse 8 \\ $\mathrm{CH}-9000$ St.Gallen \\ Phone +41712243159 \\ Email matthias.roesti@unisg.ch \\ Website
}

\footnotetext{
${ }^{1}$ We are grateful to Louis-Gaëtan Giraudet, Roland Hodler, Linus Mattauch, Mirko Moro, Richard Norgaard, David Ribar, and participants of various seminars for helpful comments. The usual disclaimer applies.

Carattini acknowledges support from the Grantham Foundation for the Protection of the Environment through the Grantham Research Institute on Climate Change and the Environment and from the ESRC Centre for Climate Change Economics and Policy as well as from the Swiss National Science Foundation, grant number PZ00P1_180006/1. This study has been realised using data collected by the Swiss Household Panel (SHP), which is based at the Swiss Centre of Expertise in the Social Sciences FORS. The project is supported by the Swiss National Science Foundation.

${ }^{2}$ Stefano Carattini's main affiliation is with the Department of Economics, Andrew Young School of Policy Studies, Georgia State University. He is also affiliated with CESifo and the Grantham Research Institute on Climate Change and the Environment and the ESRC Centre for Climate Change Economics and Policy, London School of Economics and Political Science.
} 


\begin{abstract}
This paper combines several large-scale surveys with different identification strategies to shed new light on the determinants of cooperative behavior. We provide evidence indicating that the well-being maximizing level of trust is above the income maximizing level. Higher trust is also linked to more cooperative and pro-social behaviors, including the private provision of global public goods such as climate change mitigation. Consistent with "warm glow" theories of pro-social behavior, our results show that individuals may enjoy being more cooperative than what would lead them to maximize their income, which is reflected in higher levels of well-being.
\end{abstract}

\title{
Keywords
}

Cooperation, generalized trust, pro-social behavior, pro-environmental behavior, well-being JEL Classification

Q50, H41, I31, D64 
"It is better to suffer wrong than to do it, and happier to be sometimes cheated than not to trust." - Samuel Johnson

\section{Introduction}

One of the most important contributions of experimental economics has been to document the fact that in real-life situations people tend to be more cooperative than theory allowed (Dawes and Thaler, 1988; Ostrom, 2000). Although cooperative behavior was considered an "anomaly" at first, the idea that the concept of homo economicus only very imperfectly explains human behavior is nowadays widely accepted in the discipline, as recognized by the Nobel prizes awarded to Elinor Ostrom and Richard Thaler. Yet, cooperative behavior still attracts the attention of many economists and social scientists, who try to expand our understanding of its drivers and rationales (Tomasello, 2009; Sigmund, 2010).

Recently, a study by Butler et al. (2016) identified an inverse U-shape relationship between generalized trust and income, according to which each society has an income maximizing level of trust. Individuals with too little trust, thus located to the left of the income maximizing level of trust, may miss out on profitable opportunities. Individuals being too trusting - i.e. whose trust beliefs are above the income maximizing level - may have others taking advantage of them. While the former may not realize that they are missing out on additional income, people with very high trust beliefs should realize that they are being "overly trusting", making their "excessively" cooperative behavior particularly intriguing.

Hence, in this paper, we are especially interested in the mass of "overly trusting" individuals that Butler et al. (2016) documented. We posit and show that the wellbeing maximizing level of trust is consistently higher than the income maximizing 
level of trust. We show, with different identification strategies, that higher trust tends to lead to higher well-being, and not necessarily the other way around. Rather than just being the product of individual errors, e.g. due to a false consensus about the average trustworthiness of others (see Butler et al., 2015, 2016), high levels of trust can be rationalized if we allow such individuals to consider their own well-being rather than just their potential income. Further, we find that higher trust relates to a higher proclivity to engage in pro-social and pro-environmental behavior.

Our results are consistent with the idea that individuals may maximize along dimensions other than income, with corresponding implications for the measurement of prosperity and the evaluation of economic policy more generally (Diener, 2000; Kahneman and Krueger, 2006; Benjamin et al., 2012). Our results are also consistent with a warm glow of pro-social behavior (Andreoni, 1990). Individuals may enjoy being more cooperative than what would exactly lead them to maximize their income and that is reflected in their higher levels of well-being. As far as pro-environmental behavior is concerned, our results are consistent with evidence showing that lessons on cooperative behavior from the local commons (Ostrom, 1990) may also extend to the global commons (see Carattini et al., 2019).

Our multilayered approach is as follows. First, we replicate the original finding of Butler et al. (2016) with extended data from the European Social Survey as well as richer data for Sweden and Switzerland from the Society Opinion Media and the Swiss Household Panel, respectively. With all datasets, we identify an income maximizing level of trust, as well as an important mass of "overly trusting" individuals to the right of the maximum. Second, with each of the three datasets, we analyze the trusthappiness relationship. We find that happiness maximizing trust lies beyond the level a pure income maximizer would likely choose. The positive relationship between trust and subjective well-being is robust to many specification changes. To further 
support our results, we show that considerable exogenous shocks to happiness have no discernible effects on trust, by comparing individuals who lost their spouse with similar individuals who did not. Third, with the three datasets, we investigate the mechanisms behind the trust-happiness relationship. Building on the considerable body of evidence on the existence of a "warm glow" of contributing to a public good, we hypothesize that one important channel through which trust affects wellbeing is via pro-social behaviors. Our data are consistent with this channel. In particular, we document the role of trust as a vital component in fostering cooperative behavior and attitudes. Analyzing a wide range of pro-social and pro-environmental behaviors from the three surveys, including voluntary contributions to global public goods such as climate change mitigation, we provide evidence of a strongly cooperative role of high-trust individuals. We further verify our findings with an instrumental variable approach based on a measure of inherited trust for individuals with migration background (inspired by Algan and Cahuc, 2010) as an instrument for trust. Finally, we provide a battery of additional robustness tests, supporting our results.

In sum, our paper provides an explanation for why an important mass of individuals displays levels of trust that exceed the income maximizing optimum: they are happier. If anything, our findings raise the question of why we observe that some individuals are willing to forgo a happiness bump to maximize income. Our paper also points to an important mechanism driving our results: high-trust individuals are more likely to engage in pro-social behaviors, from which they may derive extra happiness through the warm glow of giving. Our findings support calls for measures aimed at promoting trust in new generations, which may not only be beneficial for society but also for the individuals who would have been educated to trust more (Tabellini 2008; Dixit and Levin 2017). Further, our findings point to the importance of leveraging people's proclivity to engage in pro-social behaviors and enjoyment in doing so, to 
further address local and global issues requiring pro-sociality and collective action.

Our paper contributes to four different strands of literature. First, we add to the literature analyzing the determinants of prosperity and in particular the role of informal institutions such as trust. Seminal contributions from political science and sociology (Fukuyama, 1995; Putnam, 2000) have stressed the importance of trust, as well as social capital more generally, for economic prosperity. A large economics literature subsequently added quantitative evidence to these early studies. Trust is positively associated with economic development across countries (Knack and Keefer, 1997; Zak and Knack, 2001), and the effect persists if a measure of inherited trust or historical information on literacy rates and political institutions are used as exogenous trust shifters to account for endogeneity concerns (Algan and Cahuc, 2010; Tabellini, 2010; Algan and Cahuc, 2014). Other beneficial impacts of trust suggested by the literature relate to financial development, stock market participation, and entrepreneurship (Guiso et al., 2004, 2006, 2008; Algan and Cahuc, 2014).

The second strand of literature relates to the role of trust in collective action. Early work has highlighted the role of trust in contributing to the successful management of common pool resources and the prevention of the tragedy of the commons (Ostrom, 1990). Additional evidence has been provided by studies leveraging surveys, field, and lab experiments (see e.g. Uslaner, 2002; Gächter et al., 2004; Ostrom, 2009; Poteete et al., 2010). A common theme in these studies is that people tend to cooperate to a much higher degree than standard economic theory based on a narrow definition of individual rationality would predict (Sen, 1977; Dawes and Thaler, 1988; Ostrom, 2000). Such "anomalous" levels of cooperation have also been observed in the climate commons (see Carattini et al., 2019, for a review).

The third strand of literature focuses on the determinants of pro-social behavior and their interlinkages with subjective well-being through forms of kindness. In par- 
ticular, we refer to work showing that pro-social behavior tends to increase subjective well-being, underpinning the theory of the "warm glow of giving" (Andreoni, 1990). In such a framework of impure altruism, the act of contributing to a public good directly enters the utility function, which improves the ability of economic models to explain patterns from experimental data and real-life observations (Kahneman and Knetsch, 1992; Andreoni, 1993; Ribar and Wilhelm, 2002; Andreoni, 2006; Andreoni and Payne, 2013). Further, we also relate to studies aiming at rationalizing masses of altruistic behavior, which potentially dominate in number selfish money-maximizers (Andreoni and Miller, 2002), and showing that while individuals understand free riding, they intentionally choose to act pro-socially (Andreoni, 1995). The concept of a "warm glow of giving" is also consistent with additional studies using brain imaging to study brain reactions to potentially altruistic decisions, for instance during an ultimatum game, or studies tracking hormone production (Sanfey et al., 2003; Zak et al., 2004), which physiologically measure the extent of "warm glow". Other studies, correlational in spirit, have shown positive associations between various measures of social capital and reported well-being (Helliwell, 2003; Bjørnskov, 2003; Helliwell and Wang, 2011; Helliwell et al., 2018).

The fourth strand of literature focuses on the measurement of well-being, as well as on its importance compared to other indicators of prosperity. While material payoff maximization remains a good proxy for human behavior in a wide range of settings, there is increasing evidence highlighting the limits of relying only on economic motives in understanding how individuals maximize utility, and the related important implications for policymaking and the measurement of prosperity (Easterlin, 2003; Kahneman et al., 2006). In particular, recent contributions have emphasized that well-being, along with other non-pecuniary outcomes, is deserving of a greater role in the assessment of how society fares as a whole (Frank, 2005; Kahneman and Krueger, 
2006; Layard, 2006; Frank, 2008; Fleurbaey, 2009; Jones and Klenow, 2016; Stiglitz et al., 2018). This body of work relies largely on survey questions, which have been shown in several contexts to provide reliable proxies for well-being (e.g. Frey and Stutzer, 2002; Frey, 2008; Kahneman and Krueger, 2006; Diener et al., 2009, 2018).

\section{Data and empirical strategy}

In what follows, we present our multilayered approach, which builds on three complementary surveys, providing rich data and a diverse selection of respondents, and includes two different identification strategies providing additional robustness to our results. Our three data sources are as follows.

First, we use data from the European Social Survey (ESS), a large-scale biennial cross-section of European countries. The ESS provides us with a large sample size, representing a vast underlying population covering many European countries. It also allows us to directly compare our results with those in Butler et al. (2016).

Second, we use data from the Swiss Household Panel (SHP), a rich panel of Swiss residents. The Swiss data are especially useful for the following reasons. Switzerland is a country with relatively high average trust, where about $30 \%$ of respondents in the sample report trust levels of 8 or higher. This yields plenty of observations in this upper area of the trust distribution, which is important for the purposes of our study. Swiss data are also ideally suited for our identification strategies, as they contain both data on spousal deaths (from a country with an extremely low murder rate of about 0.5 per 100,000 residents, see SFOS, 2020) as well as a very large number of individuals with a migration background. At the population level, about 38\% of Swiss residents aged 15 or older have a migration background, ${ }^{1}$ providing suitable conditions for the

\footnotetext{
${ }^{1}$ See https://www.bfs.admin.ch/bfs/en/home/statistics/population/migration-integration/by-
} 
implementation of the identification strategy relying on inherited trust. Further, the SHP covers a wide variety of pro-social and pro-environmental behaviors. In the SHP, survey questions on donations do not only measure the extensive margin, i.e. whether people donate to charities or not, but also the intensive margin, i.e. the extent of their donations. In Switzerland, more than half of the donations are targeted to foreign countries (ZEWO, 2019), which allows us to consider them as private provisions of both local and global public goods. Switzerland is also well-known for its semi-direct democratic tradition, where voting several times a year on a wide variety of issues is the norm. On average, Swiss people vote on about 10 issues per year at the federal level, to which one should add cantonal and municipal ballots (Kriesi and Trechsel, 2008). This provides us with another measure of civic engagement. Finally, the SHP contains more fine-grained income data than comparable surveys, which is useful for our replication of Butler et al. (2016).

The third data source we consider is the Swedish Society Opinion Media (SOM) survey, an annual cross-section of Swedish residents. The main specificity of the SOM data is that it contains an extensive set of pro-social outcomes, including one of the broadest ranges of environmentally-friendly behaviors and attitudes among comparable surveys.

Building on our baseline results, for which we test consistency over the three data sources, we also employ two specific identification strategies, which we implement with the SHP data. First, following Liberini et al. (2017), we exploit exogenous negative shocks to well-being due to the death of a spouse to further isolate our relationship of interest. Second, following Algan and Cahuc (2010), we implement an instrumental variable approach leveraging the variation in inherited trust endowments among individuals with migration background, with the aim of providing additional migration-status.html (last accessed on June 18, 2020). 
evidence on the causal nature of the observed relationship between trust and wellbeing as well as between trust and cooperative outcomes.

In what follows, we briefly describe the ESS and SHP data. Further details are presented in Appendix A and B, respectively. The SOM data (SOM-Institute, 2018) are presented in Appendix C. Table 1 contains descriptive statistics of the main variables in the ESS and SHP. From the ESS, we use waves 1-8, spanning 2002-2016 (European Social Survey, 2018). In the SHP, trust is available from 2002 onward, leaving us with waves 4-19, covering 2002-2017. We remove all observations with missing information on one or more of our baseline controls and observations of minors. In the ESS data baseline controls include age, sex, marital status, household income, years of education, unemployment status, labor force participation, reported altruism, risk tolerance, whether one resides in a big or small city (or neither), and whether the father only has basic education. In the SHP data, the corresponding outcome variables are age, sex, education, and household income.

In both the ESS and the SHP, trust is based on a question of the form "Do you think most people can be trusted or you can't be too careful?", which goes back to Rosenberg (1956). The answer is determined by choosing a value on an integer 0-10 scale ranging from 0 ("you can’t be too careful") to 10 ("most people can be trusted"). Based on this question, our concept of trust consists in what the literature considers to be "generalized trust" and captures individual beliefs about the trustworthiness of others, including strangers. It represents one of the main pillars of social capital (bridging social capital) and is conceptually distinguished from "particularized trust" (bonding social capital), which is directed at a much smaller number of people with which an individual is more closely associated, for example through kinship (see Putnam, 2000; Uslaner, 2002). Evidence from both lab experiments and field studies, including the famous "lost wallet experiment", show 
that the survey-based measure is closely linked to what economists try to capture when measuring trust and trustworthiness (Knack and Keefer, 1997; Glaeser et al., 2000; Poteete et al., 2010).

Subjective well-being is captured by two main items in the ESS data, which we term "happiness" and "life satisfaction": (i) "How happy are you?", ranging from 0 ("extremely unhappy") to 10 ("extremely happy"); and (ii) satisfaction with life as a whole, ranging from 0 ("extremely dissatisfied") to 10 ("extremely satisfied"). The SHP primarily focuses on life satisfaction, asking about the satisfaction with life in general, ranging from 0 ("not at all satisfied") to 10 ("completely satisfied"). For comparability reasons across datasets, we focus on reported life satisfaction, but the qualitative results are independent of that choice (see also Section 3.3).

For our baseline estimates, we use a regression specification which includes a set of 10 trust dummies. This avoids any a priori imposition of a specific functional form between trust and the outcome variable. Our baseline estimates are supplemented with two additional identification strategies. First, we use the death of a spouse as an exogenous shock on well-being to further isolate the relationship of interest. Second, we employ an instrumental variable (IV) strategy based on the notion that trust has a sizable inherited component dependent on the country of origin of immigrants. This identification strategy, which we adapted to our context from Algan and Cahuc (2010), relies on the following intuition. Empirical studies have shown that trust has considerable geographic variation, is highly persistent, and a sizable part is passed on by their parents to their offspring (Bjørnskov, 2007; Algan and Cahuc, 2010, 2014). The prevailing trust level in the country of origin is therefore correlated with the "trust endowments" of people with migration background - either via their parents or because their socialization took place in the country of origin some decades ago. We implement the IV approach as follows. First, we estimate inherited trust as the shared 
Table 1: Summary statistics - ESS and SHP

(a) ESS

\begin{tabular}{lccccc}
\hline \hline Statistic & $\mathrm{N}$ & Mean & St. Dev. & Min & Max \\
\hline Trust & 231,844 & 5.154 & 2.447 & 0 & 10 \\
Happiness & 230,974 & 7.285 & 1.964 & 0 & 10 \\
Life satisfaction & 231,844 & 6.969 & 2.253 & 0 & 10 \\
Age & 231,844 & 49.106 & 17.441 & 18 & 99 \\
Male & 231,844 & 0.473 & 0.499 & 0 & 1 \\
Married & 231,844 & 0.554 & 0.497 & 0 & 1 \\
Log of household income & 231,844 & 9.784 & 1.075 & 6.068 & 12.374 \\
Education (years) & 231,844 & 12.639 & 4.100 & 0 & 54 \\
Potential experience & 231,844 & 30.478 & 19.017 & 0 & 92 \\
Father basic education & 231,844 & 0.330 & 0.470 & 0 & 1 \\
Unemployed & 231,844 & 0.055 & 0.227 & 0 & 1 \\
Out of labor force & 231,844 & 0.390 & 0.488 & 0 & 1 \\
Big city & 231,844 & 0.335 & 0.472 & 0 & 1 \\
Small city & 231,844 & 0.303 & 0.460 & 0 & 1 \\
Risk tolerance & 231,844 & 3.051 & 1.428 & 1 & 6 \\
Altruism & 231,844 & 5.078 & 0.899 & 1 & 6 \\
Religiosity & 230,655 & 4.702 & 3.006 & 0 & 10 \\
Health & 231,692 & 3.788 & 0.917 & 1 & 5 \\
Immigrant & 231,844 & 0.091 & 0.288 & 0 & 1 \\
Crime victim & 231,364 & 0.180 & 0.384 & 0 & 1 \\
\hline
\end{tabular}

(b) SHP

\begin{tabular}{lccccc}
\hline \hline Statistic & $\mathrm{N}$ & Mean & St. Dev. & Min & Max \\
\hline Trust & 111,196 & 6.154 & 2.253 & 0 & 10 \\
Life satisfaction & 111,196 & 8.040 & 1.398 & 0 & 10 \\
Log of net personal income & 106,668 & 10.634 & 0.965 & 2.303 & 15.521 \\
Log of net household income & 111,195 & 11.510 & 0.589 & 4.605 & 15.638 \\
Age & 111,196 & 49.269 & 17.302 & 18 & 100 \\
Male & 111,196 & 0.443 & 0.497 & 0 & 1 \\
Unemployed & 111,196 & 0.016 & 0.127 & 0 & 1 \\
Out of labor force & 111,196 & 0.294 & 0.456 & 0 & 1 \\
Married & 111,196 & 0.594 & 0.491 & 0 & 1 \\
Divorced & 111,196 & 0.101 & 0.301 & 0 & 1 \\
Full time & 111,132 & 0.347 & 0.476 & 0 & 1 \\
In training & 111,132 & 0.080 & 0.271 & 0 & 1 \\
Household size & 111,196 & 2.771 & 1.322 & 1 & 12 \\
Number of children & 109,875 & 1.559 & 1.319 & 0 & 14 \\
Health & 111,196 & 4.029 & 0.655 & 1 & 5 \\
Education (years) & 111,196 & 13.464 & 3.065 & 8 & 21 \\
Potential experience & 111,196 & 29.812 & 17.590 & 0 & 84 \\
Death of relative & 111,142 & 1.772 & 0.420 & 1 & 2 \\
Charity member & 71,963 & 0.337 & 0.596 & 0 & 2 \\
Donated & 21,920 & 0.677 & 0.467 & 0 & 1 \\
ln(Donation) & 14,166 & 5.889 & 1.316 & 0 & 12.429 \\
Voluntary work & 86,400 & 0.472 & 0.499 & 0 & 1 \\
Voting frequency & 61,709 & 7.720 & 3.054 & 0 & 10 \\
Envir. org. member & 71,973 & 0.222 & 0.469 & 0 & 2 \\
Buy eco-friendly & 21,792 & 5.786 & 2.544 & 0 & 10 \\
Buy seasonal fruit/veg. & 21,863 & 7.514 & 2.221 & 0 & 10 \\
More envir. spending & 21,530 & 0.603 & 0.548 & -1 & 1 \\
Environment > growth & 65,648 & 0.345 & 0.742 & -1 & 1 \\
\hline
\end{tabular}


trust component by country of origin for three different age cohorts of individuals with migration background in our sample using a series of auxiliary regressions. Then, in a second step, we use our estimates for inherited trust as an instrument for trust in a two-stage least squares model to examine the effect of trust on the outcomes of interest.

Additional details about our empirical approach are provided in Appendix Sections A.2, B.2, and C.2.

\section{Results}

This section is organized as follows. First, we replicate the original results by Butler et al. (2016) on the trust-income relationship with all three datasets. Then, we focus on our main relationship of interest, between trust and well-being, where we complement our baseline results with two additional identification strategies which exploit exogenous variation due to the death of a spouse and varying endowments of inherited trust. Finally, we explore an important channel underlying the relationship between trust and well-being, with the goal of shedding light on the mechanisms behind our relationship of interest. We then proceed with a battery of robustness tests on all these findings.

\subsection{Trust, income, and well-being}

In what follows, we first present aggregate evidence on the trust-income and trustwell-being relationship for a wide variety of European countries from the ESS. Subsequently, we examine these questions leveraging the rich data from the SHP, which also allows us to take a closer look at the implications of high levels of trust for a wider range of cooperative and pro-social outcomes. We also proceed with the same 
analyses using SOM data. Estimates from the SOM are presented in Appendix C.3.

Based on data from the ESS, Figure 1a displays effects of trust (on a 0-10 scale) on household income (in logs) and reported life satisfaction (see Table A.3 in Appendix A.3 for more details). To put these results into context, it is worth noting that the median trust in the ESS is 5 .

The left panel of Figure 1a highlights two stylized facts. First, there is a humpshaped relationship between trust and income, in line with earlier findings, which were obtained with a smaller number of ESS rounds (Butler et al., 2016). Second, a sizable share of respondents exhibits trust levels above the income maximizing level suggested by the point estimates on display. Roughly $18.5 \%$ of respondents in our sample report trust levels of 8 or higher. Deviating from prevailing levels to this extent does not yield any benefits in terms of income, and likely increases the chance of being taken advantage of, as indicated by the downward sloping segment of the trust-income curves (and as suggested by IV and experimental evidence in Butler et al., 2015, 2016).

One possible interpretation of this observation is that high-trust individuals are simply mistaken in their choice to confide in others either by misjudging the trustworthiness of their peers (a "false consensus", see e.g. Butler et al., 2015) or a lack of awareness of the extent of the repercussions in terms of income (or both). The amount of such mistakes, however, would have to be very high to produce the observed distribution of trust, suggesting that other important factors might be at work as well, and even possibly dominate any income considerations. Well-being is our top candidate.

Indeed, the second graph in Figure 1a reveals a strong positive relationship between trust and reported life satisfaction. We find no clear indication of a humpshaped relationship between trust and life satisfaction, and in any case not in the 

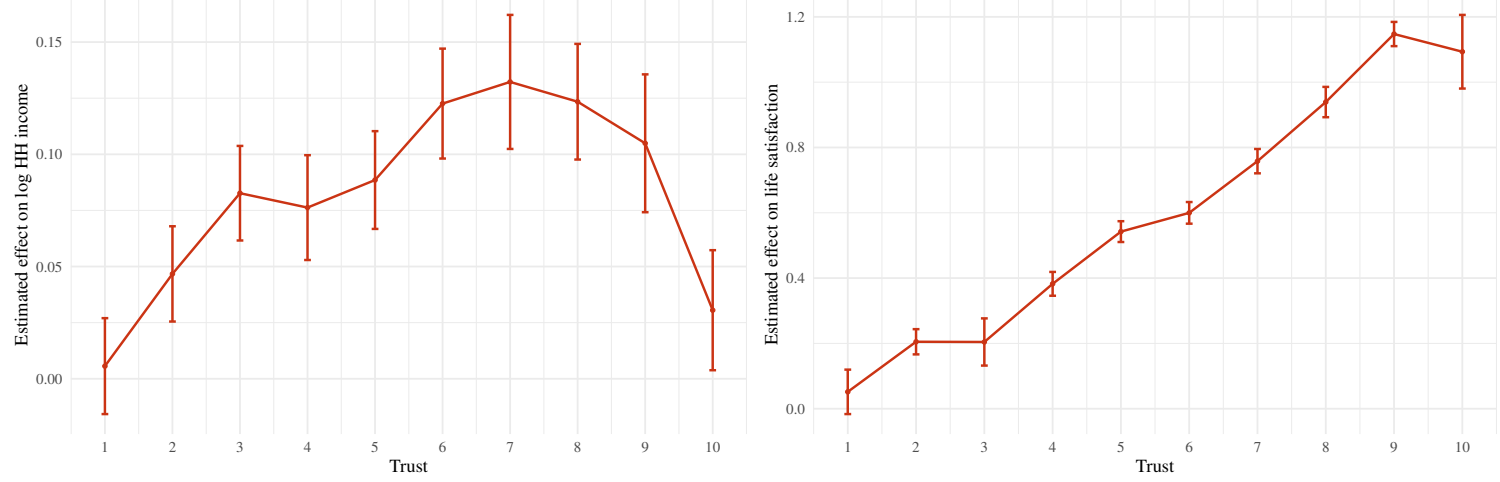

(a) Coefficient plots of trust and income (left) vs. trust and life satisfaction (right) in the ESS.
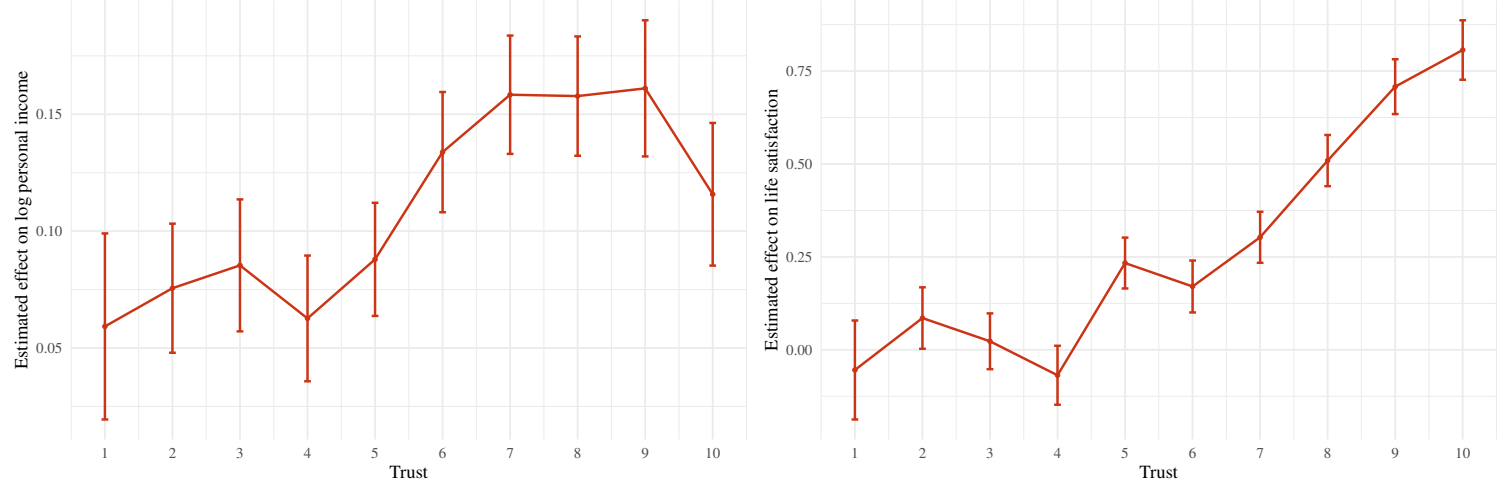

(b) Trust and income (left) vs. trust and life satisfaction (right) in the SHP.

Figure 1: Trust and income vs. trust and life satisfaction in the ESS (top) and SHP (bottom) surveys.

Controls include a broad set of socioeconomic and demographic variables. Displayed standard errors are clustered at the country (ESS) and individual (SHP) level. Estimates are based on linear regressions using post-stratification and population weights (ESS) and cross-sectional sampling weights (SHP) to account for differences in sampling across countries and individual backgrounds. Corresponding regression tables are in Appendix A.3 (ESS) and Appendix B.3 (SHP). 
range of income maximizing levels. Consequently, the well-being maximizing level of trust is much higher than the income maximizing level. Correspondingly, as high-trust individuals consistently report higher levels of subjective well-being, the interpretation that high trust is simply the result of some mistake is not fully convincing. On the contrary, if the effects are taken at face value, it would be far more questionable to choose the income maximizing level of trust and forego a huge well-being bump in return. The estimated difference in life satisfaction between a trust level of 7 and a trust level of 10 is 0.335 , which is in the same order of magnitude as the difference typically observed between married and unmarried individuals (the unmarried being unhappier, see e.g. Helliwell, 2003). At an estimated cost of about $10 \%$ of household income, this is a trade-off where giving preference to well-being does not need to stem from an obvious lapse in judgment, but can be incorporated into a framework where individuals care not only about material consumption, but derive utility from other sources as well. The "warm glow of giving" framework of Andreoni (1990) is a good case in point.

Given that the data used in Figure 1a are pooled from different countries, we extend our analysis further and look at the same relationship in a single country setting. Specifically, we examine data from the SHP in Figure 1b to test the robustness of the patterns observed in the ESS (see Table B.3 in the Appendix for the corresponding regressions). When revisiting the trust-income and trust-life satisfaction relationships in this national context, the plots from the SHP show a picture very similar to the ESS data: the income maximizing level of trust is somewhere between 7 and 9, and the point estimates again follow a hump shape along the trust distribution. The results for trust and life satisfaction are equally consistent with the ESS data: increasing trust from 7 to 10 is projected to elevate life satisfaction by 0.504 points on a $0-10$ scale, and a loss in personal income of about $4 \%$. When using the instrumental 
variable approach described in Section 2, we also find both statistically and economically meaningful effects of trust on well-being. Table B.7 in Appendix B.3 reports the corresponding estimates. In another section in the Appendix, namely Appendix C.3, we also apply this approach to the Swedish National Society-Opinion-Media (SOM) survey. As shown in Table C.3, we find very similar patterns both qualitatively and quantitatively as we obtained with the SHP and ESS data as displayed in Figure 1.

In light of these considerable effects on life satisfaction, we further isolate the causal relationship of interest by leveraging exogenous well-being shocks. Specifically, we exploit the strong negative shock to life satisfaction caused by the death of a spouse, which, as mentioned, is overwhelmingly due to natural causes in Switzerland. Following an approach employed by Liberini et al. (2017), we compare individuals confronted with the death of their spouse to similar respondents who were spared this fate in the period in question. As expected, spousal death has a strong negative effect on reported life satisfaction in the year after the event $(\mathrm{p}=0.00)$ relative to the pre-treatment period, but there is no difference in trust between those who lost their spouse and individuals who did not $(\mathrm{p}=0.73)$. On average, the magnitude of the wellbeing impact pushes the treated into the unhappiest $15 \%$ of our sample. Naturally, the loss of a spouse has profound impacts on other dimensions as well (e.g. financial, social). The fact that we do not observe any impacts on trust despite these additional sources of disruption further supports our approach. Hence, we conclude that trust is persistent and unaffected by a strong well-being shock, supporting our analysis of the effect of trust on subjective well-being. Appendix B.3.2 provides additional details on this test. 


\subsection{Mechanisms}

After having documented the positive relationship between trust and reported life satisfaction, we investigate the channels responsible for this persistent pattern in the data. By nature, cooperation involves helping others in particular or the community in general, which, in the spirit of "doing the right thing", is likely to feel good in itself through some form of "warm glow" (Andreoni, 1990). To the extent that trust fosters pro-social behavior and attitudes, any positive well-being effect tied to such actions can be viewed as a potential channel between trust and life satisfaction.

Returning to the SHP data, which allows us to implement our IV approach, we look at various forms of pro-social or cooperative behavior. First, we look at reported engagement in voluntary work and reported donations. In 2018, an estimated $52 \%$ of Swiss donations to certified charities benefited internationally active non-profit organizations, implying that a majority of funds are intended to contribute to address more global rather than local social dilemmas (ZEWO, 2019). Second, we consider the reported frequency of voting, which is a very salient indicator of civic duty, leveraging the fact that popular votes on political initiatives take place several times a year in Switzerland. Third, we extend to pro-environmental behavior in the form of membership of an environmental organization as well as the reported frequency of purchasing seasonal and eco-friendly products. Fourth, we look at pro-environmental attitudes, including preferences for government spending for environmental purposes and preferences over social priorities between economic growth and environmental protection.

To further motivate the important nexus among trust, cooperative behavior, and well-being, we provide in Figure 2 descriptive evidence indicating that individuals who report the highest life satisfaction also tend to score high in both trust and pro-social 
behavior. The latter is measured as donations and the frequency of voting, as these two continuous measures lend themselves very well to our graphical analysis, but we find similar patterns for the frequency of purchasing seasonal produce and eco-friendly products as well (see Figure B.3 in Appendix B.4). As expected, the surfaces tend to be sloped more steeply along the cooperation than along the trust axis, consistent with the notion that the observed effect of trust on well-being is to a considerable extent channeled through these forms of pro-social and pro environmental behaviors.

Building on Figure 2, in Table 2 we analyze the relationship between trust and cooperative behaviors in a systematic manner. Table 2 shows a consistent positive relationship between all these dimensions and trust, consistent across both the baseline regressions (top) and our IV approach (bottom of the table): higher levels of trust are associated with more cooperation, both in terms of charitable activities, voting frequency, pro-environmental behaviors and attitudes. Importantly, this relationship does not taper off once the typical level of trust in Switzerland - where the income benefits of more trust start to vanish or turn negative - is reached. People at the upper end of the trust distribution are significantly more cooperative than individuals who report trust levels of 7 , the Swiss median, consistent with the trust-life satisfaction relationship. For example, a trust level of 7 is estimated to increase the reported frequency of buying eco-friendly products by about 1.25 points on a 10-point scale relative to a trust level of 0 . Moving up to trust $=10$ adds another 0.5 points to this difference based on our dummy specification, which is significantly higher ( $\mathrm{p}$ $=0.000)$ than our estimate for trust $=7$. In Appendix A.4, we provide a set of very similar estimates from the ESS data, for which trust positively affects variables capturing pro-social and pro-environmental behaviors such as membership in environmental/peace/animal rights organizations, the propensity to donate, and the reported frequency of work for a voluntary/charitable association, as well as pro-environmental 

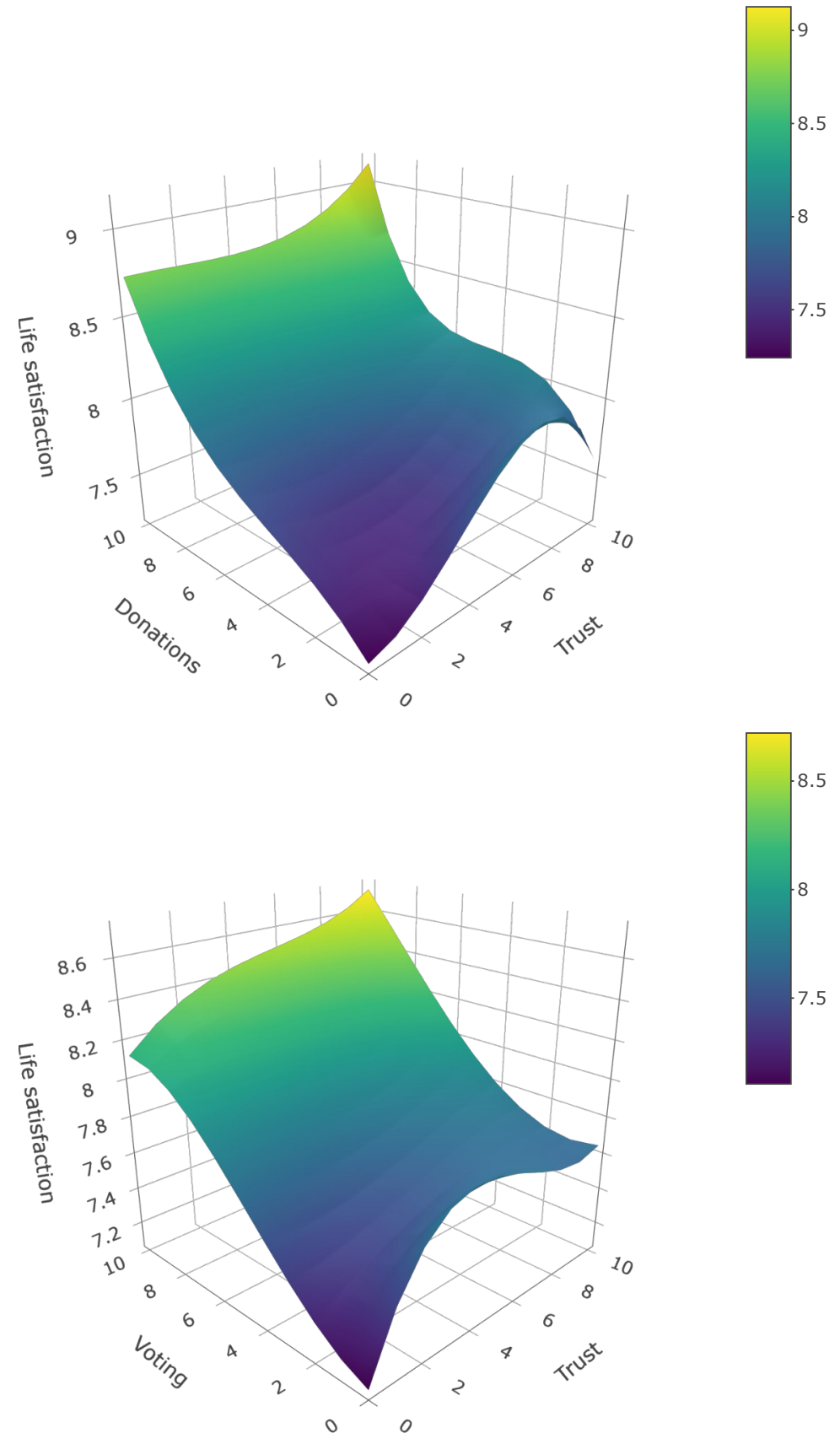

Figure 2: Pro-social behavior, trust and life satisfaction in the SHP data.

The top panel shows the descriptive relationship between trust, the amount of donations to charity (discretized into 11 categories of similar size in terms of number of observations) and reported life satisfaction. The bottom panel indicates the corresponding relationship between trust, the reported frequency of voting, and life satisfaction. The graphs are constructed using smoothed means of life satisfaction across the trust/pro-social behavior grid, based on a third order polynomial (and corresponding two-way interaction terms) of trust and the respective pro-social behavior. 
attitudes, such as support for a fuel tax, the importance attached to the environment, the degree to which combating climate change is viewed as a personal responsibility and, finally, the degree of confidence about the individual ability to save energy and mitigate climate change. These results also translate to the Swedish SOM data, for which we display a set of similar outcomes in Appendix C.4. In the SOM, higher trust is associated with a higher likelihood to be a member of a humanitarian/aid organization and a higher reported frequency of helping such an organization either through voluntary work or donations. Importantly, the extensive margin of donations is measured in terms of frequency of donating, which complements the measure provided by the SHP. Further, higher trust increases the estimated likelihood of environmental organization membership as well as the reported frequency of using alternative transport and sorting of waste for environmental reasons. Lastly, we also see a positive association between trust and attitudes on the degree to which an environmentally friendly society and an increased carbon tax are favored as well as on the importance attached to reducing energy consumption by households.

In sum, the evidence strongly supports the notion that high-trust individuals have a higher propensity to engage in a wide range of cooperative and pro-social behaviors. This includes not only more localized forms of cooperation such as engagement in voluntary work, but also contributions to larger scale outcomes via donations or pro-environmental behavior. The latter outcomes in particular deserve attention as they relate to the private provision of a global public good, which is climate change mitigation. This link helps to explain why we tend to observe more climate action than the standard theories of international environmental agreements would predict (see e.g. de Zeeuw, 2015), and provides further empirical support for earlier work, which points to local social norms as an important driver of cooperation in the climate commons (see Carattini et al., 2019, for a review). 


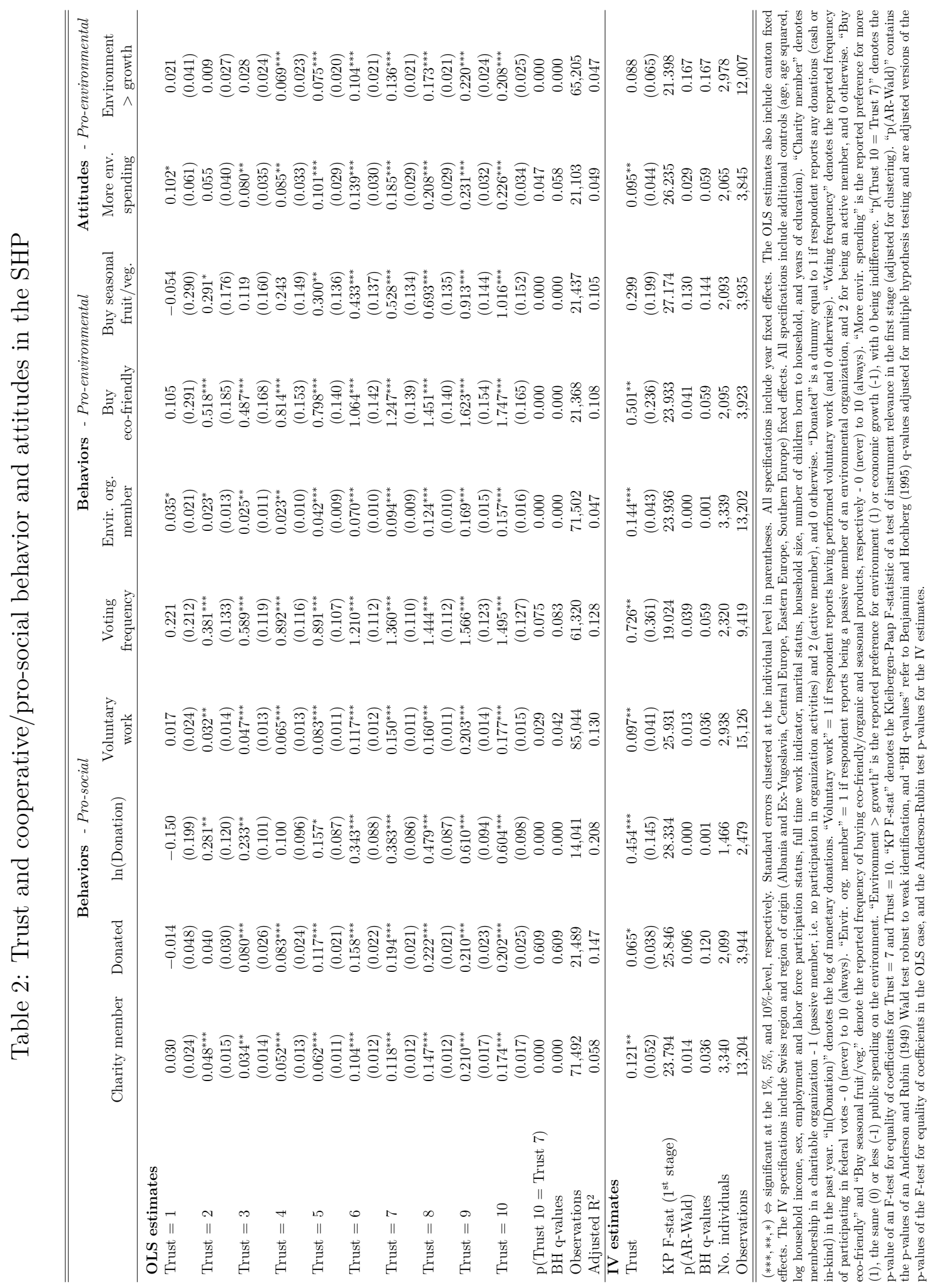




\subsection{Additional sensitivity tests}

In this section, we further examine the robustness of our key results. First, we incorporate a set of additional controls to supplement our baseline specification. Second, we consider the impact of sampling weights. Third, we examine the robustness of our results to the definition and scaling of the dependent variable. Our results remain robust across all these additional specifications.

For the ESS, the set of additional controls includes trust in the police, the legal system, politicians and parliament as well as additional covariates capturing factors such as being a member of an ethnic minority, being impaired by a disability, health, or mental health condition, and whether the respondent has someone with whom to discuss intimate problems. We further estimate a specification where we control for a series of items measuring affective well-being, namely how often the respondent felt (i) like having a lot of energy, (ii) calm, and/or (iii) anxious during the last week, (iv) the degree to which one feels positive about oneself, and (v) the agreement on the statement that it is hard to be hopeful for the future of this world. For the SHP, the additional controls include variables such as trust in the federal government, religious affiliation, and the frequency of church attendance. Controlling for these covariates also does not alter the nature of the observed relationship between trust and cooperative outcomes in both OLS and IV regressions displayed in Table 2. Our results from the SHP are also robust to the addition of a battery of items capturing big five personality traits. We further include five types of trust in other institutions/groups and an indicator of religiosity in our SOM estimates, and in a separate specification control for a set of questions related to negative affect, overtime work, and social activities (included under "controlling for affect" in Figure 3). The corresponding results are provided, for the ESS in Figures A.1 and A.2 of Appendix A.5; for the 


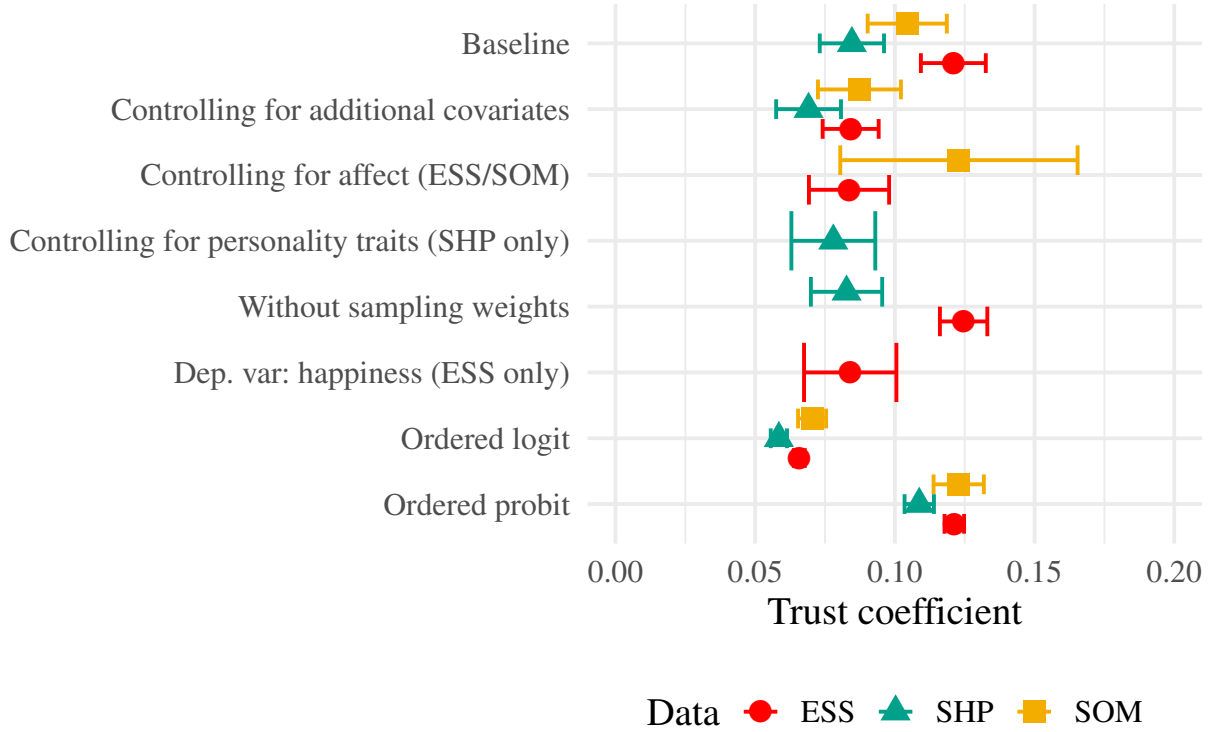

Figure 3: Sensitivity of the effect of trust on life satisfaction.

Estimates are based on a linear trust model and the same baseline covariates as in Figure 1 for the SHP/ESS, and Table C.3 (Appendix C.3) for the SOM data. Error bars denote 95\% confidence intervals.

SHP in Figures B.4 and B.5 as well as Tables B.15 and B.16 of Appendix B.5; and for the SOM in Figures C.1 and C.2 of Appendix C.5.

Furthermore, the nature of our results is also unaffected by whether we use sampling weights or not. The corresponding results are provided, for the ESS in Figure A.3 of Appendix A.5; and for the SHP, in Figure B.6 and Table B.23 of Appendix B.5.

Switching the dependent variable from life satisfaction to happiness in the ESS slightly changes the estimate for the effect of trust, but not in an economically meaningful way.

Our results also carry over when we estimate ordered probit and logit models to check whether the linear interval scale imposed on the outcome variable has an effect on the estimated trust-life satisfaction relationship. We do not find this to be the case. For example, we estimate both statistically and economically significant 
effects of trust on the estimated probability of being in the highest life-satisfaction category (see Tables A.6, A.7, B.21, B.22, C.6, and C.7 in Appendix A.5, B.5, and C.5, respectively).

\section{Conclusion}

Cooperative behavior is essential for societies to thrive and for humanity to address local and global social dilemmas. Modern democratic societies would not be functioning without the cooperativeness of their members, who show up to vote in elections, offer countless hours as volunteers, and donate to advance important causes. Explaining cooperative behavior in local and global social dilemmas represents, however, an area that still attracts important research efforts in search of an alternative paradigm to oppose to the standard concept of homo economicus. While many of these efforts are recent, they are not without tradition. Indeed, Adam Smith himself already expressed a more nuanced view of individual selfishness in his "Theory of Moral Sentiments" than what his contemporary portrayal often suggests, including the following words: "How selfish soever man may be supposed, there are evidently some principles in his nature, which interest him in the fortune of others, and render their happiness necessary to him, though he derives nothing from it except the pleasure of seeing it" (Smith 1822:1). In the present paper, we investigate why many individuals report trust levels above the income maximizing optimum. This apparent puzzle can be resolved once we allow for non-monetary returns to trust, namely positive effects in terms of well-being. Part of this positive well-being effect can be explained in terms of a "warm glow of cooperation", as high trust individuals consistently report a higher degree of cooperative behavior. The range of cooperative outcomes that we consider in this paper extends beyond the local context. Specifically, we also observe more 
cooperation towards global commons such as the state of our climate. This finding has immediate implications relating to how policymakers and practitioners may approach local and global social dilemmas. First, cultural traits such as trust are rather slow to change over time, but change can happen over generations if trust is effectively instilled in pupils (Tabellini, 2008; Dixit and Levin, 2017). Instilling trust in pupils may not only be good for society, but may also make them happier adults. Second, our results point to an untapped potential in terms of measures leveraging the fact that individuals enjoy being cooperative. Solutions to social dilemmas that require great amounts of cooperation, including climate change mitigation, may be more successful if they make use of such proclivity to sustain cooperation. 


\section{References}

Algan, Y. and P. Cahuc (2010). Inherited Trust and Growth. American Economic Review 100(5), 2060-2092.

Algan, Y. and P. Cahuc (2014). Trust, Growth, and Well-Being: New Evidence and Policy Implications. In P. Aghion and S. N. Durlauf (Eds.), Handbook of Economic Growth, Volume 2 of Handbook of Economic Growth, pp. 49-120. Elsevier.

Anderson, T. W. and H. Rubin (1949). Estimation of the Parameters of a Single Equation in a Complete System of Stochastic Equations. The Annals of Mathematical Statistics 20(1), 46-63.

Andreoni, J. (1990). Impure Altruism and Donations to Public Goods: A Theory of Warm-Glow Giving. The Economic Journal 100(401), 464-477.

Andreoni, J. (1993). An Experimental Test of the Public-Goods Crowding-Out Hypothesis. The American Economic Review, 1317-1327.

Andreoni, J. (1995). Cooperation in Public-Goods Experiments: Kindness or Confusion? The American Economic Review 85(4), 891-904.

Andreoni, J. (2006). Philanthropy. In S.-C. Kolm and J. M. Ythier (Eds.), Handbook of the Economics of Giving, Altruism and Reciprocity, Volume 2, Chapter 18, pp. 1201-1269. Elsevier.

Andreoni, J. and J. Miller (2002). Giving According to GARP: An Experimental Test of the Consistency of Preferences for Altruism. Econometrica 70(2), 737-753.

Andreoni, J. and A. A. Payne (2013). Charitable Giving. In A. J. Auerbach, R. Chetty, 
M. Feldstein, and E. Saez (Eds.), Handbook of Public Economics, Volume 5, pp. 1-50. Elsevier.

Benjamin, D. J., O. Heffetz, M. S. Kimball, and A. Rees-Jones (2012). What Do You Think Would Make You Happier? What Do You Think You Would Choose? American Economic Review 102(5), 2083-2110.

Benjamini, Y. and Y. Hochberg (1995). Controlling the False Discovery Rate: a Practical and Powerful Approach to Multiple Testing. Journal of the Royal Statistical Society: Series B (Methodological) 57(1), 289-300.

Bjørnskov, C. (2003). The Happy Few: Cross-Country Evidence on Social Capital and Life Satisfaction. Kyklos 56(1), 3-16.

Bjørnskov, C. (2007). Determinants of Generalized Trust: A Cross-Country Comparison. Public Choice 130(1-2), 1-21.

Butler, J. V., P. Giuliano, and L. Guiso (2015). Trust, Values, and False Consensus. International Economic Review 56(3), 889-915.

Butler, J. V., P. Giuliano, and L. Guiso (2016). The Right Amount of Trust. Journal of the European Economic Association 14(5), 1155-1180.

Carattini, S., S. Levin, and A. Tavoni (2019). Cooperation in the Climate Commons. Review of Environmental Economics and Policy 13(2), 227-247.

Dawes, R. M. and R. H. Thaler (1988). Anomalies: Cooperation. Journal of Economic Perspectives 2(3), 187-197.

de Zeeuw, A. (2015). International Environmental Agreements. Annual Review of Resource Economics 7(1), 151-168. 
Diener, E. (2000). Subjective Well-being: The Science of Happiness and a Proposal for a National Index. American Psychologist 55(1), 34.

Diener, E., R. Lucas, J. F. Helliwell, and U. Schimmack (2009). Well-Being for Public Policy. Oxford, United Kingdom: Oxford University Press.

Diener, E., S. Oishi, and L. Tay (2018). Advances in Subjective Well-being Research. Nature Human Behaviour 2(4), 253.

Dixit, A. and S. Levin (2017). Social Creation of Pro-social Preferences for Collective Action. In The Theory of Externalities and Public Goods, pp. 127-143. Springer, Cham.

Easterlin, R. A. (2003). Explaining Happiness. Proceedings of the National Academy of Sciences 100(19), 11176-11183.

European Social Survey (2018). Cumulative File, ESS 1-8, Data file edition 1.0. NSD - Norwegian Centre for Research Data, Norway - Data Archive and distributor of ESS data for ESS ERIC, doi:10.21338/NSD-ESS-CUMULATIVE.

Fleurbaey, M. (2009). Beyond GDP: The Quest for a Measure of Social Welfare. Journal of Economic Literature 47(4), 1029-1075.

Frank, R. H. (2005). Positional Externalities Cause Large and Preventable Welfare Losses. American Economic Review 95(2), 137-141.

Frank, R. H. (2008). Should Public Policy Respond to Positional Externalities? Journal of Public Economics 92(8-9), 1777-1786.

Frey, B. S. (2008). Happiness: A Revolution in Economics. Cambridge, MA; London, United Kingdom: MIT Press. 
Frey, B. S. and A. Stutzer (2002). What Can Economists Learn from Happiness Research? Journal of Economic Literature 40(2), 402-435.

Fukuyama, F. (1995). Trust: The Social Virtues and the Creation of Prosperity. New York, NY: Free Press.

Gächter, S., B. Herrmann, and C. Thöni (2004). Trust, Voluntary Cooperation, and Socio-Economic Background: Survey and Experimental Evidence. Journal of Economic Behavior and Organization 55(4), 505-531.

Glaeser, E. L., D. I. Laibson, J. A. Scheinkman, and C. L. Soutter (2000). Measuring Trust. The Quarterly Journal of Economics 115(3), 811-846.

Guiso, L., P. Sapienza, and L. Zingales (2004). The Role of Social Capital in Financial Development. American Economic Review 94(3), 526-556.

Guiso, L., P. Sapienza, and L. Zingales (2006). Does Culture Affect Economic Outcomes? Journal of Economic Perspectives 20(2), 23-48.

Guiso, L., P. Sapienza, and L. Zingales (2008). Trusting the Stock Market. Journal of Finance 63(6), 2557-2600.

Helliwell, J. F. (2003). How's life? Combining Individual and National Variables to Explain Subjective Well-Being. Economic Modelling 20(2), 331-360.

Helliwell, J. F., H. Huang, and S. Wang (2018). New Evidence on Trust and Wellbeing. In E. M. Uslaner (Ed.), The Oxford Handbook of Social and Political Trust, Chapter 18, pp. 409-446. Oxford, United Kingdom: Oxford University Press.

Helliwell, J. F. and S. Wang (2011). Trust and Wellbeing. International Journal of Wellbeing 1(1), 42-78. 
Jones, C. I. and P. J. Klenow (2016). Beyond GDP? Welfare Across Countries and Time. American Economic Review 106 (9), 2426-2457.

Kahneman, D. and J. L. Knetsch (1992). Valuing Public Goods: The Purchase of Moral Satisfaction. Journal of Environmental Economics and Management 22(1), $57-70$.

Kahneman, D. and A. B. Krueger (2006). Developments in the Measurement of Subjective Well-Being. Journal of Economic Perspectives 20(1), 3-24.

Kahneman, D., A. B. Krueger, D. Schkade, N. Schwarz, and A. A. Stone (2006). Would You Be Happier if You Were Richer? A Focusing Illusion. Science 312(5782), 1908-1910.

Knack, S. and P. Keefer (1997). Does Social Capital Have an Economic Payoff? A Cross-Country Investigation. Quarterly Journal of Economics 112(4), 1251-1288.

Kriesi, H. and A. H. Trechsel (2008). The Politics of Switzerland: Continuity and Change in a Consensus Democracy. Cambridge, United Kingdom: Cambridge University Press.

Layard, R. (2006). Happiness and Public Policy: A Challenge to the Profession. The Economic Journal 116(510), C24-C33.

Liberini, F., M. Redoano, and E. Proto (2017). Happy Voters. Journal of Public Economics 146, 41-57.

Ostrom, E. (1990). Governing the Commons: The Evolution of Institutions for Collective Action. Cambridge, United Kingdom: Cambridge University Press.

Ostrom, E. (2000). Collective Action and the Evolution of Social Norms. Journal of Economic Perspectives 14(3), 137-158. 
Ostrom, E. (2009). A Polycentric Approach for Coping with Climate Change. World Bank Policy Research Working Paper 5095.

Poteete, A. R., M. A. Janssen, and E. Ostrom (2010). Working Together: Collective Action, the Commons, and Multiple Methods in Practice. Princeton, NJ: Princeton University Press.

Putnam, R. D. (2000). Bowling Alone: The Collapse and Revival of American Community. New York, NY: Simon and Schuster.

Ribar, D. C. and M. O. Wilhelm (2002). Altruistic and Joy-of-Giving Motivations in Charitable Behavior. Journal of Political Economy 110(2), 425-457.

Rosenberg, M. (1956). Misanthropy and Political Ideology. American Sociological Review 21 (6), 690-695.

Sanfey, A. G., J. K. Rilling, J. A. Aronson, L. E. Nystrom, and J. D. Cohen (2003). The Neural Basis of Economic Decision-Making in the Ultimatum Game. Science $300(5626)$, 1755-1758.

Sen, A. K. (1977). Rational Fools: A Critique of the Behavioral Foundations of Economic Theory. Philosophy and Public Affairs 6(4), 317-344.

SFOS (2020). Polizeiliche Kriminalstatistik (PKS) - Jahresbericht 2019 der Polizeilich Registrierten Straftaten. Swiss Federal Office of Statistics.

Sigmund, K. (2010). The Calculus of Selfishness. Princeton, NJ: Princeton University Press.

Smith, A. (1822). The Theory of Moral Sentiments. London, United Kingdom: J. Richardson and Co. 
SOM-Institute (2018). The SOM Institute Cumulative Dataset 1986-2017 v2018.1. University of Gothenburg: SOM Institute.

Stern, P. C. (1999). Information, Incentives, and Proenvironmental Consumer Behavior. Journal of Consumer Policy 22(4), 461-478.

Stern, P. C. (2000). Toward a Coherent Theory of Environmentally Significant Behavior. Journal of Social Issues 56(3), 407-424.

Stiglitz, J., J. Fitoussi, and M. Durand (2018). Beyond GDP: Measuring What Counts for Economic and Social Performance. Paris, France: OECD Publishing.

Tabellini, G. (2008). The Scope of Cooperation: Values and Incentives. The Quarterly Journal of Economics 123(3), 905-950.

Tabellini, G. (2010). Culture and Institutions: Economic Development in the Regions of Europe. Journal of the European Economic Association 8(4), 677-716.

Tomasello, M. (2009). Why We Cooperate. Cambridge, MA: MIT Press.

Uslaner, E. M. (2002). The Moral Foundations of Trust. Cambridge, United Kingdom: Cambridge University Press.

World Bank (2020). State and Trends of Carbon Pricing - 2020. Technical report, Washington, DC.

Zak, P. J. and S. Knack (2001). Trust and Growth. Economic Journal 111(470), 295-321.

Zak, P. J., R. Kurzban, and W. T. Matzner (2004). The Neurobiology of Trust. Annals of the New York Academy of Sciences 1032(1), 224-227. 
ZEWO (2019). Die Schweizer Bevölkerung Spendet Grosszügig - ZewoSpendenstatistik 2018. Zewoforum 3/2019, 6-9. 


\section{Appendix}

\section{A Additional information and results for the ESS data}

\section{A.1 Variable description}

In what follows, we describe the ESS variables that we used for our analyses. All income variables were converted into Euros using the prevailing exchange rate at the time of the survey data collection, which is virtually always contained in the official ESS documentation. More details on the imputation procedure used to convert income brackets into single income values are provided in the variable description. Table A.2 provides descriptive statistics for all ESS variables. The average trust level in our sample is about 5 on the $0-10$ scale, and both happiness and life satisfaction have means around 7.

Table A.1: Description of ESS variables used

\begin{tabular}{|c|c|c|}
\hline & Description/Encoding & $\begin{array}{l}\text { Underlying } \\
\text { ESS Variable }\end{array}$ \\
\hline \multicolumn{3}{|l|}{ Main variables } \\
\hline Trust & $\begin{array}{l}\text { Most people can be trusted (10) or you can't be too careful (0), } \\
11 \text { discrete values }\end{array}$ & ppltrst \\
\hline Happiness & $\begin{array}{l}\text { Taking all things together, how happy would you say you are? - } \\
\text { ranges from } 0 \text { (extremely unhappy) to } 10 \text { (extremely happy), } 11 \\
\text { discrete values }\end{array}$ & happy \\
\hline Life satisfaction & $\begin{array}{l}\text { All things considered, how satisfied are you with your life as a } \\
\text { whole nowadays? Ranges from } 0 \text { (extremely dissatisfied) to } 10 \\
\text { (extremely satisfied) }\end{array}$ & stflife \\
\hline
\end{tabular}


Log of household income

Demo./econ. variables

Age

Male

Immigrant

Minority

Married

Education (years)

Potential experience

Father_ISCED_x

Father basic education

Unemployed

Out of labor force

Big city

Small city

Professions

Professional

Technician

Clerk

Service worker

Agricultural worker

Craft worker
Log of annualized household income in Euros based on mean values of income categories (there are fixed overall categories in first three waves, which changes to country/year specific thresholds from wave 4 onward). Top coded income values were inferred via censored maximum likelihood - assuming a log-normal distribution of income - for each country/year combination using the post-stratification weights provided (variable "pspwght", but the outcome is very similar with and without weights). For BG, EE, RU, and UA, a total of 6 top income values could not be determined via maximum likelihood for an early wave, due to a low (or 0 in case of RU) observation count in the top income bracket. In these cases, we assigned an income of 160,000 Euros, which is based on the mean of our estimates for the other countries in the same waves

Age in years

1 if male, 0 otherwise

1 if not born in country where interview took place, 0 otherwise Belonging to ethnic minority in country - 1 if yes, 0 if no/refusal 1 if married (incl. civil union/partnership), 0 otherwise

Years of completed full-time education

Potential experience, calculated as the maximum between Age years of education -6 and 0

Father's highest level of education, by ISCED category - coded as set of dummies

Father's highest level of education is ISCED category 0 or 1 $=1$ if unemployed and wanting employment, regardless of whether person is actively looking for a job or not, 0 otherwise $=1$ if main activity in last 7 days was education, retirement, community/military service, housework, disability or "other" $=1$ if ind. lives in a "big city" or a suburb thereof, 0 otherwise $=1$ if ind. lives in a "small city", 0 otherwise

$=1$ if ISCO $88 / \mathrm{ISCO} 08=2 \mathrm{XXX}, 0$ otherwise

$=1$ if ISCO $88 /$ ISCO0 $8=3$ XXX, 0 otherwise

$=1$ if ISCO $88 / \mathrm{ISCO} 08=4 \mathrm{XXX}, 0$ otherwise

$=1$ if ISCO $88 / \mathrm{ISCO} 08=5 \mathrm{XXX}, 0$ otherwise

$=1$ if ISCO $88 / \mathrm{ISCO} 08=6 \mathrm{XXX}, 0$ otherwise

$=1$ if ISCO $88 / \mathrm{ISCO} 08=7 \mathrm{XXX}, 0$ otherwise hinctnt, hinctnta

agea

gndr

brncntr

blgetmg

marital,

maritala,

maritalb

eduyrs

edulvlfa

edulvlfa

mnactic

mnactic

domicil

domicil

iscoco, isco08

iscoco, isco08

iscoco, isco08

iscoco, isco08

iscoco, isco08

iscoco, isco08 


\begin{tabular}{|c|c|c|}
\hline $\begin{array}{l}\text { Plant mach. worker } \\
\text { Elementary occupation } \\
\text { Well-being factors }\end{array}$ & $\begin{array}{l}=1 \text { if ISCO } 88 / \text { ISCO } 08=8 \text { XXX, } 0 \text { otherwise } \\
=1 \text { if ISCO } 88 / \text { ISCO0 } 8=9 \text { XXX, } 0 \text { otherwise }\end{array}$ & $\begin{array}{l}\text { iscoco, isco08 } \\
\text { iscoco, isco08 }\end{array}$ \\
\hline Health & How is your health in general? - 1 (very bad) to 5 (very good) & health \\
\hline Impaired & $\begin{array}{l}1 \text { if hampered a lot in daily activities by } \\
\text { illness/disability/infirmity/mental problem, } 0 \text { otherwise }\end{array}$ & hlthhmp \\
\hline Feel positive & $\begin{array}{l}\text { In general feel very positive about myself - } 1 \text { (strongly disagree) } \\
\text { to } 5 \text { (strongly agree) }\end{array}$ & pstvms \\
\hline Have energy & $\begin{array}{l}\text { Had lot of energy, how often past week - } 1 \text { (none), } 2 \text { (some), } 3 \\
\text { (most) to } 4 \text { (all the time) }\end{array}$ & enrglot \\
\hline Felt anxious & $\begin{array}{l}\text { Felt anxious, how often past week - } 1 \text { (none), } 2 \text { (some), } 3 \text { (most) } \\
\text { to } 4 \text { (all the time) }\end{array}$ & fltanx \\
\hline Felt calm & $\begin{array}{l}\text { Felt calm and peaceful, how often past week - } 1 \text { (none), } 2 \\
\text { (some), } 3 \text { (most) to } 4 \text { (all the time) }\end{array}$ & fltpcfl \\
\hline No hope for world & $\begin{array}{l}\text { Hard to be hopeful about the future of the world - } 1 \text { (disagree } \\
\text { strongly) to } 5 \text { (agree strongly) }\end{array}$ & nhpftr \\
\hline Social activity - absolute & $\begin{array}{l}\text { How often subject socially meets with friends, from } 1 \text { (never) to } \\
7 \text { (every day) }\end{array}$ & sclmeet \\
\hline $\begin{array}{l}\text { Social activity - relative to } \\
\text { peer group }\end{array}$ & $\begin{array}{l}\text { Engagement in social activities relative to others at the same } \\
\text { age - from } 1 \text { (much less than most) to } 5 \text { (much more than most) }\end{array}$ & sclact \\
\hline Intimate discussion & $\begin{array}{l}\text { Dummy on whether there is someone to discuss } \\
\text { intimate/personal matters with - } 1 \text { if yes and } 0 \text { if not }\end{array}$ & inmdisc, inprdsc \\
\hline Crime victim & $\begin{array}{l}1 \text { if household was victim of burglary or assault in past } 5 \text { years, } \\
0 \text { otherwise }\end{array}$ & crmvct \\
\hline Religiosity & $\begin{array}{l}\text { Regardless of whether you belong to a particular religion, how } \\
\text { religious would you say you are? } 1 \text { (not at all religious) to } 10 \\
\text { (very religious) }\end{array}$ & rlgdgr \\
\hline Risk tolerance & $\begin{array}{l}\text { Important to seek adventures and have an exciting life - } 1 \text { (not } \\
\text { like me at all) to } 6 \text { (very much like me). Analogous to Butler } \\
\text { et al. (2016). }\end{array}$ & ipadvnt \\
\hline Altruism & $\begin{array}{l}\text { Important to be loyal to friends and devote to people close to } \\
\text { oneself - } 1 \text { (not like me at all) to } 6 \text { (very much like me). } \\
\text { Analogous to Butler et al. (2016). }\end{array}$ & iplylfr \\
\hline Trust parliament & Trust in parliament - 0 (no trust) to 10 (complete trust) & trstprl \\
\hline Trust legal system & Trust in the legal system - 0 (no trust) to 10 (complete trust) & trstlgl \\
\hline Trust police & Trust in the police - 0 (no trust) to 10 (complete trust) & trstplc \\
\hline Trust politician & Trust in politicians - 0 (no trust) to 10 (complete trust) & trstplt \\
\hline \multicolumn{3}{|l|}{ Citizen involvement variables } \\
\hline Envir. org. member & $\begin{array}{l}\text { Environmental/peace/animal organization, last } 12 \text { months: } \\
\text { member - } 1 \text { if either participated or member, } 2 \text { if both, } 0 \text { if } \\
\text { no/NA }\end{array}$ & $\begin{array}{l}\text { epaommb, } \\
\text { epaoptp }\end{array}$ \\
\hline
\end{tabular}


Volunt. work

Donated

Charity work

Environmental variables

Importance envir.

Could red. energy

CC resp.

I can red. cc

Supports fuel tax

Supports enregy subs.

\section{Admin variables}

Wave

Country

Sampling weight
1 if performed voluntary work for any of the following organizations in the last 12 months: Sports, cultural, union, professional, consumer, humanitarian, environmental, religious, political party, science, other. 0 otherwise

1 if donated to any of the following organizations in the last 12 months: Sports, cultural, union, professional, consumer,

humanitarian, environmental, religious, political party, science, other. 0 otherwise

Involved in work for voluntary or charitable organizations, how often past 12 months - from 1 (never) to 6 (at least once a week)

Important to care for nature and environment - 1 (not at all like me) to 6 (very much like me)

How confident you could use less energy than now - 0 (not at all) to 10 (completely confident)

To what extent feel personal responsibility to reduce climate change - 0 (not at all) to 10 (a great deal)

How likely that limiting own energy use will reduce climate change - 0 (not at all) to 10 (extremely likely)

Favor increase taxes on fossil fuels to reduce climate change -

from 1 (strongly against) to 5 (strongly in favor)

Favor subsidize renewable energy to reduce climate change -

from 1 (strongly against) to 5 (strongly in favor)

ESS wave number (1-8)

Country, 2-character strings

Combines post-stratification with population weights (both contained in the ESS) sptcrw, cltovw, truvw, prfovw, cnsovw, hmnovw, epaovw, rlgovw, prtyvw, setovw, sclcrw, othvvw sptcdm, cltodm, trudm, prfodm, cnsodm, hmnodm, epaodm, rlgodm, prtydm, setodm, sclcdm, othvdm wkvlorg

impenv

cflsenr

ccrdprs

ownrdcc

inctxff

sbsrnen

essround

cntry

pspweight,

pweight 
Table A.2: Summary statistics - ESS (full)

\begin{tabular}{|c|c|c|c|c|c|}
\hline Statistic & $\mathrm{N}$ & Mean & St. Dev. & Min & $\operatorname{Max}$ \\
\hline Trust & 231,844 & 5.154 & 2.447 & 0 & 10 \\
\hline Happiness & 230,974 & 7.285 & 1.964 & 0 & 10 \\
\hline Life satisfaction & 231,844 & 6.969 & 2.253 & 0 & 10 \\
\hline Age & 231,844 & 49.106 & 17.441 & 18 & 99 \\
\hline Male & 231,844 & 0.473 & 0.499 & 0 & 1 \\
\hline Married & 231,844 & 0.554 & 0.497 & 0 & 1 \\
\hline Log of household income & 231,844 & 9.784 & 1.075 & 6.068 & 12.374 \\
\hline Education (years) & 231,844 & 12.639 & 4.100 & 0 & 54 \\
\hline Potential experience & 231,844 & 30.478 & 19.017 & 0 & 92 \\
\hline Father basic education & 231,844 & 0.330 & 0.470 & 0 & 1 \\
\hline Unemployed & 231,844 & 0.055 & 0.227 & 0 & 1 \\
\hline Out of labor force & 231,844 & 0.390 & 0.488 & 0 & 1 \\
\hline Big city & 231,844 & 0.335 & 0.472 & 0 & 1 \\
\hline Small city & 231,844 & 0.303 & 0.460 & 0 & 1 \\
\hline Risk tolerance & 231,844 & 3.051 & 1.428 & 1 & 6 \\
\hline Altruism & 231,844 & 5.078 & 0.899 & 1 & 6 \\
\hline Religiosity & 230,655 & 4.702 & 3.006 & 0 & 10 \\
\hline Health & 231,692 & 3.788 & 0.917 & 1 & 5 \\
\hline Impaired & 231,085 & 0.060 & 0.238 & 0 & 1 \\
\hline Immigrant & 231,844 & 0.091 & 0.288 & 0 & 1 \\
\hline Crime victim & 231,364 & 0.180 & 0.384 & 0 & 1 \\
\hline Minority & 228,999 & 0.054 & 0.225 & 0 & 1 \\
\hline Professional & 231,844 & 0.155 & 0.362 & 0 & 1 \\
\hline Technician & 231,844 & 0.147 & 0.354 & 0 & 1 \\
\hline Clerk & 231,844 & 0.091 & 0.287 & 0 & 1 \\
\hline Service worker & 231,844 & 0.145 & 0.352 & 0 & 1 \\
\hline Agricultural worker & 231,844 & 0.029 & 0.168 & 0 & 1 \\
\hline Craft worker & 231,844 & 0.113 & 0.317 & 0 & 1 \\
\hline Plant mach. worker & 231,844 & 0.075 & 0.264 & 0 & 1 \\
\hline Elementary occupation & 231,844 & 0.091 & 0.288 & 0 & 1 \\
\hline Feel positive & 60,377 & 3.858 & 0.793 & 1 & 5 \\
\hline Have energy & 60,279 & 2.609 & 0.855 & 1 & 4 \\
\hline Felt anxious & 60,326 & 1.628 & 0.737 & 1 & 4 \\
\hline Felt calm & 60,250 & 2.745 & 0.827 & 1 & 4 \\
\hline No hope for world & 59,895 & 3.270 & 1.051 & 1 & 5 \\
\hline Social activity - absolute & 231,017 & 4.855 & 1.553 & 1 & 7 \\
\hline Social activity - relative & 228,615 & 2.724 & 0.936 & 1 & 5 \\
\hline Intimate discussion & 230,195 & 0.923 & 0.267 & 0 & 1 \\
\hline Trust parliament & 227,819 & 4.524 & 2.585 & 0 & 10 \\
\hline Trust legal system & 227,897 & 5.244 & 2.676 & 0 & 10 \\
\hline Trust police & 230,119 & 6.061 & 2.556 & 0 & 10 \\
\hline Trust politician & 228,905 & 3.620 & 2.384 & 0 & 10 \\
\hline Envir. org. member & 20,865 & 0.069 & 0.253 & 0 & 1 \\
\hline Volunt. work & 20,865 & 0.190 & 0.392 & 0 & 1 \\
\hline Donated & 20,865 & 0.301 & 0.459 & 0 & 1 \\
\hline Charity work & 60,272 & 2.079 & 1.658 & 1 & 6 \\
\hline Importance envir. & 231,263 & 4.894 & 1.013 & 1 & 6 \\
\hline Could red. energy & 30,713 & 6.145 & 2.608 & 0 & 10 \\
\hline CC resp. & 29,771 & 5.706 & 2.693 & 0 & 10 \\
\hline I can red. CC & 29,680 & 4.347 & 2.644 & 0 & 10 \\
\hline Supports fuel tax & 30,208 & 2.815 & 1.240 & 1 & 5 \\
\hline Supports energy subs. & 30,528 & 3.979 & 1.049 & 1 & 5 \\
\hline
\end{tabular}




\section{A.2 Empirical approach}

Our estimation equations for the ESS data are of the form

$$
y_{i c}=\beta_{0}+\sum_{k=1}^{10} \beta_{k} \mathbb{1}\left(\text { Trust }_{i c}=k\right)+\delta X_{i c}+\eta_{c t}+\epsilon_{i c}
$$

where $y_{i c}$ denotes the outcomes of interest (income, cooperative attitudes and behaviors, and happiness) for individual $i$ in country $c, \eta_{c t}$ are country-year fixed effects, and $X_{i c}$ is a vector of individual controls. Trust enters as a series of dummies, which allows us to avoid an a priori imposition of a particular functional relationship between trust and the outcome variable. 


\section{A.3 Trust and income/life satisfaction}

In Table A.3, we provide the full regression table corresponding to our estimates for the relationship between trust and log household income/life satisfaction in the ESS as displayed in Figure 1a. An F-test strongly rejects equality of coefficients for Trust $=7$ and Trust $=10$ for both income and life satisfaction, which supports our observation that the income maximizing level of trust is around 7, while the well-being optimum is located beyond this value. 
Table A.3: Estimates for trust and income/life satisfaction corresponding to Figure $1 \mathrm{a}$

\begin{tabular}{|c|c|c|}
\hline & $\begin{array}{c}\ln (\mathrm{HH} \text { inc. }) \\
(1)\end{array}$ & $\begin{array}{c}\text { Lf satisf. } \\
(2)\end{array}$ \\
\hline Trust $=1$ & $0.006(0.021)$ & $0.052(0.068)$ \\
\hline Trust $=2$ & $0.047^{* *}(0.021)$ & $0.205^{* * *}(0.039)$ \\
\hline Trust $=3$ & $0.083^{* * *}(0.021)$ & $0.204^{* * *}(0.072)$ \\
\hline Trust $=4$ & $0.076^{* * *}(0.023)$ & $0.382^{* * *}(0.036)$ \\
\hline Trust $=5$ & $0.089^{* * *}(0.022)$ & $0.542^{* * *}(0.032)$ \\
\hline Trust $=6$ & $0.123^{* * *}(0.024)$ & $0.600^{* * *}(0.033)$ \\
\hline Trust $=7$ & $0.132^{* * *}(0.030)$ & $0.758^{* * *}(0.037)$ \\
\hline Trust $=8$ & $0.123^{* * *}(0.026)$ & $0.939^{* * *}(0.046)$ \\
\hline Trust $=9$ & $0.105^{* * *}(0.031)$ & $1.147^{* * *}(0.037)$ \\
\hline Trust $=10$ & $0.031(0.027)$ & $1.093^{* * *}(0.113)$ \\
\hline Age & $0.003(0.024)$ & $0.011(0.057)$ \\
\hline $\mathrm{Age}^{2}$ & $0.0001(0.0001)$ & $0.001^{* * *}(0.0001)$ \\
\hline Unemployed & $-0.526^{* * *}(0.021)$ & $-0.747^{* * *}(0.068)$ \\
\hline Out of labor force & $-0.213^{* * *}(0.020)$ & $0.127^{* * *}(0.015)$ \\
\hline Health & $0.085^{* * *}(0.010)$ & $0.580^{* * *}(0.033)$ \\
\hline Immigrant & $-0.118^{* * *}(0.016)$ & $-0.120^{* * *}(0.023)$ \\
\hline Married & $0.326^{* * *}(0.022)$ & $0.399^{* * *}(0.024)$ \\
\hline Father basic educ. & $-0.117^{* * *}(0.016)$ & $0.006(0.048)$ \\
\hline Education (years) & $0.016(0.017)$ & $-0.077(0.051)$ \\
\hline Big city/suburb & $0.106(0.070)$ & $-0.136^{* * *}(0.024)$ \\
\hline Small city & $0.036(0.033)$ & $-0.107^{* * *}(0.017)$ \\
\hline Risk tolerance & $0.016^{* * *}(0.005)$ & $-0.010(0.009)$ \\
\hline Altruism & $0.009^{* * *}(0.004)$ & $0.077^{* * *}(0.016)$ \\
\hline Social activity - absolute $=2$ & & $0.158(0.123)$ \\
\hline Social activity - absolute $=3$ & & $0.408^{* * *}(0.122)$ \\
\hline Social activity - absolute $=4$ & & $0.545^{* * *}(0.123)$ \\
\hline Social activity - absolute $=5$ & & $0.591^{* * *}(0.112)$ \\
\hline Social activity - absolute $=6$ & & $0.677^{* * *}(0.117)$ \\
\hline Social activity - absolute $=7$ & & $0.788^{* * *}(0.118)$ \\
\hline Social activity - rel. to peer group $=2$ & & $0.259^{* * *}(0.047)$ \\
\hline Social activity - rel. to peer group $=3$ & & $0.478 * * *(0.039)$ \\
\hline Social activity - rel. to peer group $=4$ & & $0.580^{* * *}(0.052)$ \\
\hline Social activity - rel. to peer group $=5$ & & $0.523^{* * *}(0.094)$ \\
\hline Religiosity & & $0.059^{* * *}(0.008)$ \\
\hline Crime victim & & $-0.222^{* * *}(0.055)$ \\
\hline Country-year FE & Yes & Yes \\
\hline 7 Occupation FE & Yes & Yes \\
\hline $\mathrm{p}($ Trust $7=$ Trust 10$)$ & 0.00 & 0.00 \\
\hline Observations & 231,692 & 226,407 \\
\hline Adjusted $\mathrm{R}^{2}$ & 0.695 & 0.295 \\
\hline
\end{tabular}

$(* * *, * *, *) \Leftrightarrow$ significant at the $1 \%, 5 \%$, and $10 \%$-level, respectively. Standard errors clustered at the country level in parentheses. Estimates are generated using poststratification and population weights. "p(Trust $7=$ Trust 10$)$ " denotes the p-value of an F-test for equality of coefficients for Trust $=7$ and Trust $=10$. 


\section{A.4 Trust and cooperative outcomes}

In this section, we focus on three measures of the extensive margin of participation in pro-social and pro-environmental activities through membership in an environmental organization, engagement in voluntary work, and whether or not the respondent has made any donations in the past 12 months. For all these outcomes, we see increasing coefficients as we move from the average level of trust (trust $=5$ ) toward trust $=9$, which produced the highest estimate in terms of the effect on well-being in Figure 1a. The difference in point estimates is also statistically significant at the $10 \%$-level or lower, with only one exception, which is voluntary work (see Table A.4). Hence, we further consider an intensive measure of the extent of voluntary work for charitable and other voluntary organizations performed in the past 12 months, where we also find that trust has a strong positive effect on reported engagement in this form of cooperative activity (Tables A.4 and A.5). In addition, we consider a range of attitudes towards the environment and climate change comprising the degree of support for increased fuel taxes, energy subsidies, and the general importance attached to the environment. We, again, find larger coefficients as we move up the trust scale. Finally, we also include three items inquiring on one's perspective about individual behavior in presence of social dilemmas: (i) do I feel that reducing climate change is a personal responsibility, (ii) how likely is it that limiting my own energy use can reduce climate change, and ultimately (iii) the confidence about the own ability to reduce energy consumption. These questions refer to the concepts of "ascription of responsibility" and "awareness of consequences", both considered important motivators of socially, and environmentally desirable behavior in the social psychology literature (Stern 1999, 2000). Here we also find a very consistent pattern: high-trust individuals are more likely to think that they should, and actually can, do something 
against climate change (Table A.5).

Table A.4: Regression estimates for pro-social and pro-environmental outcomes I

\begin{tabular}{|c|c|c|c|c|c|}
\hline & $\begin{array}{l}\text { Envir. org. member } \\
\text { (1) }\end{array}$ & $\begin{array}{c}\text { Voluntary work } \\
(2)\end{array}$ & $\begin{array}{c}\text { Donated } \\
(3) \\
\end{array}$ & $\begin{array}{c}\text { Char. work } \\
\text { (4) }\end{array}$ & $\begin{array}{l}\text { Supports fuel tax } \\
(5)\end{array}$ \\
\hline Trust $=1$ & $-0.022^{*}(0.013)$ & $0.022(0.016)$ & $0.007(0.024)$ & $0.099^{* * *}(0.030)$ & $-0.076(0.121)$ \\
\hline Trust $=2$ & $-0.012(0.017)$ & $0.020(0.016)$ & $0.024(0.039)$ & $0.085(0.056)$ & $0.076(0.062)$ \\
\hline Trust $=3$ & $-0.013(0.013)$ & $0.043(0.032)$ & $0.058(0.037)$ & $0.085(0.084)$ & $0.127(0.081)$ \\
\hline Trust $=4$ & $-0.031^{* * *}(0.010)$ & $0.022(0.025)$ & $0.037(0.024)$ & $0.072(0.053)$ & $0.057(0.075)$ \\
\hline Trust $=5$ & $-0.029^{* * *}(0.011)$ & $0.039(0.026)$ & $0.028(0.026)$ & $0.131^{* *}(0.058)$ & $0.102(0.096)$ \\
\hline Trust $=6$ & $-0.008(0.011)$ & $0.064^{* *}(0.030)$ & $0.100^{* *}(0.040)$ & $0.168(0.103)$ & $0.174^{* *}(0.078)$ \\
\hline Trust $=7$ & $-0.002(0.005)$ & $0.089^{* * *}(0.031)$ & $0.131^{* * *}(0.039)$ & $0.322^{* * *}(0.107)$ & $0.253^{* * *}(0.086)$ \\
\hline Trust $=8$ & $0.003(0.017)$ & $0.107^{* * *}(0.037)$ & $0.130^{* * *}(0.037)$ & $0.340^{* *}(0.136)$ & $0.306^{* * *}(0.112)$ \\
\hline Trust $=9$ & $0.008(0.021)$ & $0.077^{* *}(0.037)$ & $0.139^{* * *}(0.051)$ & $0.367^{* *}(0.162)$ & $0.356^{* * *}(0.105)$ \\
\hline Trust $=10$ & $-0.051^{* *}(0.020)$ & $0.044(0.028)$ & $0.094^{*}(0.054)$ & $0.349^{* * *}(0.086)$ & $0.259^{* * *}(0.062)$ \\
\hline Education (years) & $0.010^{* * *}(0.003)$ & $0.012^{* * *}(0.002)$ & $0.020^{* * *}(0.003)$ & $0.053^{* * *}(0.006)$ & $0.031^{* * *}(0.004)$ \\
\hline Age & $0.004^{* * *}(0.001)$ & $0.006^{* *}(0.002)$ & $0.008^{* * *}(0.003)$ & $0.026^{* * *}(0.007)$ & $-0.012^{* *}(0.005)$ \\
\hline $\mathrm{Age}^{2}$ & $-0.00003^{* *}(0.00001)$ & $-0.0001^{*}(0.00003)$ & $-0.0001^{*}(0.00003)$ & $-0.0002^{* * *}(0.0001)$ & $0.0001^{* *}(0.00004)$ \\
\hline $\ln (\mathrm{HH}$ inc. $)$ & $0.014^{* *}(0.006)$ & $0.020^{* * *}(0.003)$ & $0.051^{* * *}(0.011)$ & $0.110^{* * *}(0.025)$ & $0.132^{* * *}(0.017)$ \\
\hline Male & $-0.020^{* * *}(0.007)$ & $0.015^{* *}(0.006)$ & $-0.008(0.010)$ & $-0.003(0.064)$ & $-0.084^{* * *}(0.022)$ \\
\hline Married & $-0.018(0.014)$ & $0.021(0.013)$ & $-0.018(0.012)$ & $0.079^{*}(0.046)$ & $-0.098^{* * *}(0.035)$ \\
\hline Unemployed & $-0.016^{*}(0.009)$ & $-0.030^{* * *}(0.008)$ & $-0.095^{* * *}(0.028)$ & $-0.119^{* *}(0.049)$ & $0.074(0.058)$ \\
\hline Out of labor force & $0.012(0.009)$ & $0.021^{* *}(0.010)$ & $-0.019(0.015)$ & $0.125^{* * *}(0.039)$ & $0.064^{* * *}(0.018)$ \\
\hline Big city/suburb & $-0.017(0.015)$ & $-0.069^{* * *}(0.024)$ & $0.002(0.019)$ & $-0.215^{* * *}(0.062)$ & $0.224^{* * *}(0.032)$ \\
\hline Small city & $-0.023(0.017)$ & $-0.047^{* * *}(0.015)$ & $-0.004(0.022)$ & $-0.111^{* *}(0.047)$ & $0.094^{* * *}(0.013)$ \\
\hline$\underline{\text { Risk tolerance }}$ & $0.009^{* * *}(0.002)$ & $0.008^{* * *}(0.002)$ & $0.003(0.005)$ & $0.045^{* * *}(0.010)$ & $0.035^{* * *}(0.007)$ \\
\hline Country FE & Yes & Yes & Yes & Yes & Yes \\
\hline Year FE & - & - & - & Yes & - \\
\hline Range dep. var. & $0-2$ & $0-1$ & $0-1$ & $1-6$ & $1-5$ \\
\hline $\mathrm{p}($ Trust $9=$ Trust 5$)$ & 0.08 & 0.43 & 0.01 & 0.03 & 0.00 \\
\hline Observations & 20,865 & 20,865 & 20,865 & 60,272 & 30,208 \\
\hline Adjusted $\mathrm{R}^{2}$ & 0.050 & 0.085 & 0.125 & 0.123 & 0.093 \\
\hline
\end{tabular}

$(* * *, * *, *) \Leftrightarrow$ significant at the $1 \%, 5 \%$, and $10 \%$-level, respectively. Standard errors clustered at the country level in parentheses. "Envir. org. member" takes a value of 1 if the individual reports being member of an environmental/peace/animal organization, and 2 if the individual also actively participates in the environmental organization (rather than being a passive member only). "Voluntary work" is 1 if any voluntary work for either type of association (incl. sport, culture, union, professional, consumer, humanitarian, environmental, religious, political, science and other) is reported, and 0 otherwise. "Donated" is defined in a similar way, but focuses on having donated to such an organization. "Char. work" contains the reported frequency of being involved in work for voluntary/charitable organizations in the last 12 months, ranging from 1 (never) to 6 (at least once a week), and "Supports fuel tax" captures the support for a tax on fuels, ranging from 1 (strongly against) to 5 (strongly in favor). "p(Trust 9 = Trust 5 )" denotes the p-value of an F-test for equality of coefficients for Trust $=5$ (average trust in the ESS) and Trust $=9$ (largest point estimate in a regression of life satisfaction on trust). 
Table A.5: Regression estimates for pro-environmental outcomes II

\begin{tabular}{|c|c|c|c|c|c|}
\hline & $\begin{array}{c}\text { Supports energy subs. } \\
\text { (1) }\end{array}$ & $\begin{array}{c}\text { Envir. import. } \\
\text { (2) }\end{array}$ & $\begin{array}{c}\text { CC resp. } \\
(3)\end{array}$ & $\begin{array}{c}\text { I can red. CC } \\
(4)\end{array}$ & $\begin{array}{c}\text { Can save energy } \\
(5)\end{array}$ \\
\hline Trust $=1$ & $-0.199(0.152)$ & $-0.079^{* * *}(0.031)$ & $0.703(0.527)$ & $0.609(0.412)$ & $0.612^{* *}(0.282)$ \\
\hline Trust $=2$ & $-0.091(0.067)$ & $-0.075^{* * *}(0.025)$ & $0.403(0.297)$ & $0.324(0.274)$ & $0.466^{* *}(0.219)$ \\
\hline Trust $=3$ & $-0.046(0.077)$ & $-0.094^{* * *}(0.031)$ & $0.806^{* *}(0.384)$ & $0.739^{* *}(0.356)$ & $0.538^{* *}(0.243)$ \\
\hline Trust $=4$ & $-0.039(0.065)$ & $-0.123^{* *}(0.048)$ & $0.832^{* *}(0.372)$ & $0.797^{* * *}(0.249)$ & $0.709^{* *}(0.302)$ \\
\hline Trust $=5$ & $0.005(0.070)$ & $-0.066^{*}(0.036)$ & $0.938^{* *}(0.408)$ & $0.766^{* * *}(0.219)$ & $0.603^{* *}(0.238)$ \\
\hline Trust $=6$ & $-0.010(0.074)$ & $-0.092^{* *}(0.044)$ & $1.134^{* * *}(0.429)$ & $1.129^{* * *}(0.290)$ & $0.852^{* * *}(0.315)$ \\
\hline Trust $=7$ & $0.042(0.056)$ & $-0.021(0.042)$ & $1.234^{\text {*** }}(0.423)$ & $1.150^{* * *}(0.284)$ & $0.807^{* * *}(0.233)$ \\
\hline Trust $=8$ & $0.060(0.077)$ & $0.040(0.045)$ & $1.383^{* * *}(0.468)$ & $1.250^{* * *}(0.342)$ & $0.956^{* * *}(0.268)$ \\
\hline Trust $=9$ & $0.156^{* *}(0.063)$ & $0.089^{*}(0.046)$ & $1.722^{* * *}(0.530)$ & $1.545^{* * *}(0.407)$ & $1.118^{* * *}(0.386)$ \\
\hline Trust $=10$ & $-0.035(0.088)$ & $0.166^{* * *}(0.034)$ & $1.958^{\text {*** }}(0.667)$ & $1.485^{* * *}(0.420)$ & $0.939^{* * *}(0.219)$ \\
\hline Education (years) & $0.019^{* * *}(0.003)$ & $0.018^{* * *}(0.002)$ & $0.065^{* * *}(0.010)$ & $-0.006(0.014)$ & $0.038^{* *}(0.016)$ \\
\hline Age & $-0.004(0.007)$ & $0.026^{* * *}(0.004)$ & $0.060^{* * *}(0.013)$ & $0.022^{* *}(0.009)$ & $0.018^{* *}(0.008)$ \\
\hline $\mathrm{Age}^{2}$ & $0.00002(0.0001)$ & $-0.0002^{* * *}(0.00003)$ & $-0.001^{* * *}(0.0001)$ & $-0.0002^{* *}(0.0001)$ & $-0.0003^{* * *}(0.0001)$ \\
\hline $\ln (\mathrm{HH}$ inc. $)$ & $0.099^{* * *}(0.021)$ & $-0.018(0.015)$ & $0.133^{*}(0.076)$ & $-0.045(0.044)$ & $0.099(0.080)$ \\
\hline Male & $-0.025(0.022)$ & $-0.079^{* * *}(0.010)$ & $-0.229^{* * *}(0.045)$ & $-0.208^{* * *}(0.044)$ & $0.093^{*}(0.051)$ \\
\hline Married & $-0.047^{* * *}(0.016)$ & $0.021^{* * *}(0.007)$ & $0.092^{* *}(0.037)$ & $0.113(0.072)$ & $0.181^{* * *}(0.025)$ \\
\hline Unemployed & $0.058(0.038)$ & $0.009(0.020)$ & $-0.021(0.121)$ & $0.093(0.082)$ & $-0.163^{* * *}(0.038)$ \\
\hline Out of labor force & $0.013(0.040)$ & $0.021^{* *}(0.010)$ & $0.139^{* *}(0.061)$ & $0.055(0.040)$ & $0.099^{*}(0.053)$ \\
\hline Big city/suburb & $0.026(0.032)$ & $-0.032^{* *}(0.013)$ & $0.046(0.039)$ & $0.170 *(0.093)$ & $0.014(0.063)$ \\
\hline Small city & $-0.021(0.021)$ & $-0.034^{*}(0.019)$ & $0.006(0.073)$ & $0.189(0.117)$ & $0.101^{*}(0.054)$ \\
\hline$\underline{\text { Risk tolerance }}$ & $0.014^{* *}(0.006)$ & $0.050^{* * *}(0.013)$ & $0.129^{* * *}(0.015)$ & $0.151^{* * *}(0.011)$ & $0.084^{* * *}(0.014)$ \\
\hline Country FE & Yes & Yes & Yes & Yes & Yes \\
\hline Range dep. var. & $1-5$ & $1-6$ & $0-10$ & $0-10$ & $0-10$ \\
\hline $\mathrm{p}($ Trust $9=$ Trust 5$)$ & 0.00 & 0.00 & 0.00 & 0.00 & 0.00 \\
\hline Observations & 30,528 & 231,263 & 29,771 & 29,680 & 30,713 \\
\hline Adjusted $\mathrm{R}^{2}$ & 0.065 & 0.055 & 0.234 & 0.059 & 0.159 \\
\hline
\end{tabular}

$(* * *, * *, *) \Leftrightarrow$ significant at the $1 \%, 5 \%$, and $10 \%$-level, respectively. Standard errors clustered at the country level in parentheses. "Supports energy subs." measures the support for subsidies on renewable energy to reduce climate change - 1 (strongly against) to 5 (strongly in favor). "Envir. import." captures the reported importance given to the environment - 1 (not at all) to 6 (very much). "CC resp." is the degree to which reducing climate change is felt as a personal responsibility importance given to the environment - 1 (not at all) to 6 (very much). "CC resp." is the degree to which reducing climate change is felt as a personal responsibility use - 0 (not at all likely) to 10 (extremely likely). "Can save energy" denotes the degree to which the respondent is confident about her ability to reduce energy consumption - 0 (not at all) to 10 (completely confident). "p(Trust $9=$ Trust 5 )" denotes the p-value of an F-test for equality of coefficients for Trust $=5$ (average trust in the ESS) and Trust $=9$ (largest point estimate in a regression of life satisfaction on trust). 


\section{A.5 Robustness tests}

In what follows, we present the analyses showing the robustness of our findings on the trust-income and trust-well-being relationships to the inclusion of further controls accounting for other forms of trust, additional (mental) health indicators and perceived minority status (Figure A.1) as well as for a series of measures for affective well-being (Figure A.2).

Our findings are also robust to the use of non-linear models, as shown by Tables A.6 and A.7, which provide ordered probit and logit estimates for trust and life satisfaction. That is,the observed positive relationship does not depend on the imposed interval scale of the life satisfaction variable in our baseline regressions. As indicated in Tables A.6 and A.7, increasing trust by 1 point is projected to increase the probability of being in the highest life satisfaction category by about $1 \%$ on average.

Finally, we confirm that our findings are robust to a last specification change and show, in Figure A.3, that the use of sampling weights does not affect our estimates in a qualitatively or quantitatively meaningful way. 

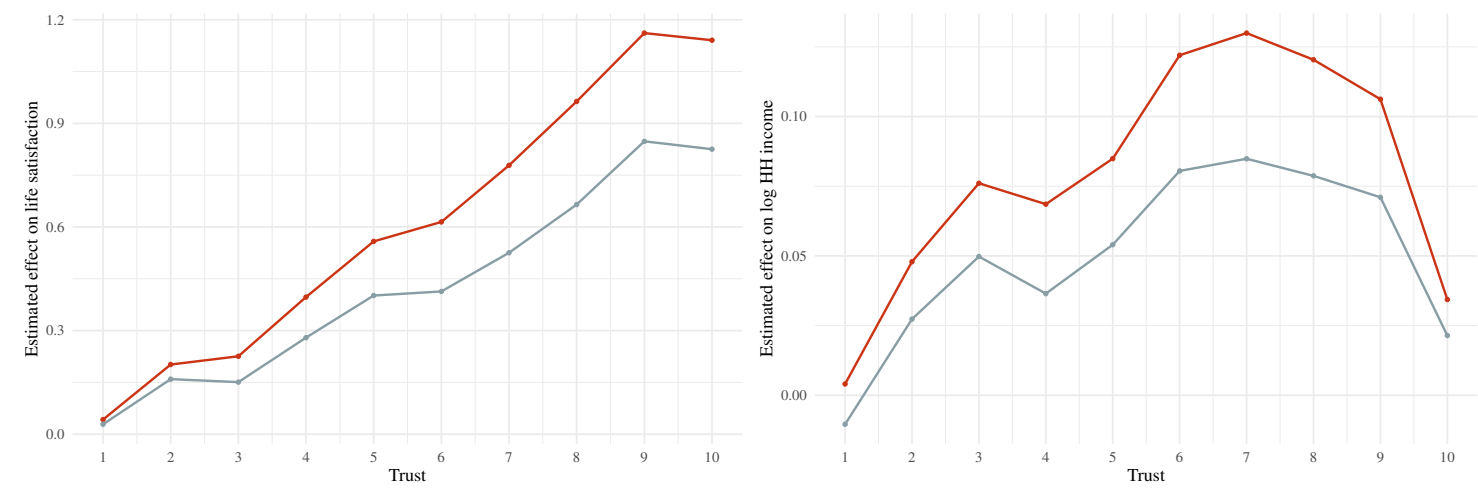

Figure A.1: Trust and life satisfaction (left) and log household income (right) in the ESS data with and without additional controls.

The top line is the baseline (red, based on a regression using the same variables as in Figure 1a) and the gray line below is based on additional controls for the level or trust in the police, parliament, politicians and the legal system (10 trust-level dummies in every case), being a member of an ethnic minority, being impaired by a disability, health or mental health condition, and whether the respondent has someone with whom to discuss intimate problems. Both regressions in each plot are based on the same observations and use sampling weights (post-stratification and population).
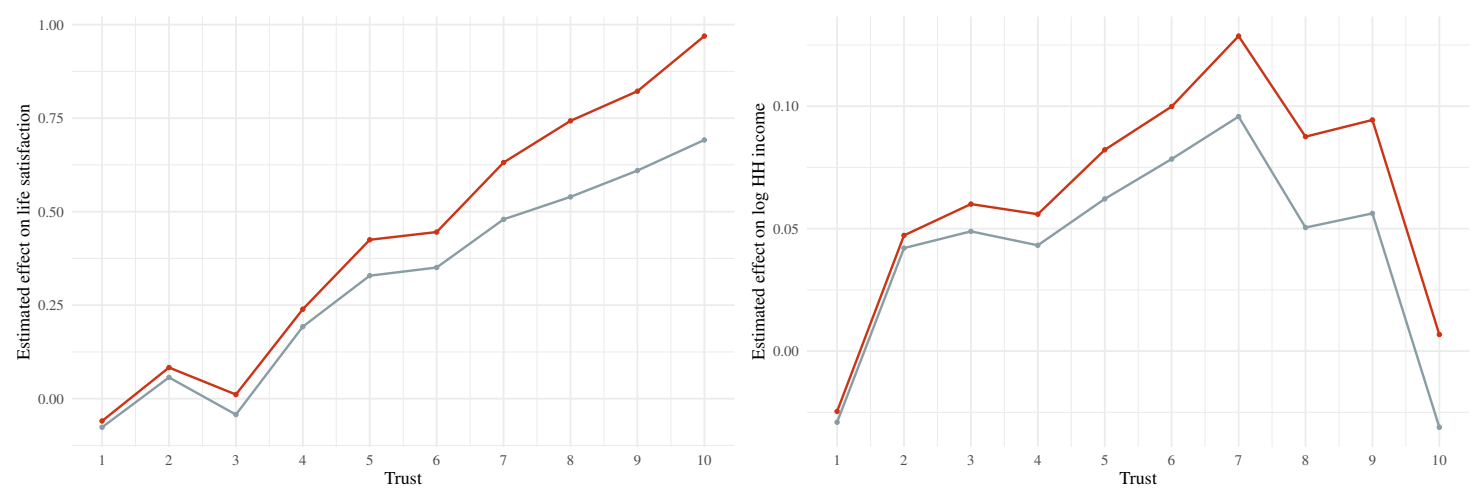

Figure A.2: Trust and life satisfaction (left) and log household income (right) in the ESS data with and without additional controls II.

The top line is the baseline (red, based on a regression using the same variables as in Figure 1a) and the gray line below is based on additional controls for affective well-being, namely how often the respondent felt (i) like having a lot of energy, (ii) calm, and (iii) anxious in the last week, and also (iv) the degree to which one feels positive about oneself, and (v) the agreement on the statement that it is hard to be hopeful for the state of this world. Both regressions in each plot are based on the same observations and use sampling weights (post-stratification and population). 
Table A.6: Ordered probit estimates for trust and life satisfaction in the ESS data

\begin{tabular}{|c|c|c|c|}
\hline & $\begin{array}{l}\text { Coef. } \\
(1)\end{array}$ & $\begin{array}{c}\text { ME on } \mathrm{p}(\mathrm{y}=10) \text { at mean } \\
(2)\end{array}$ & $\begin{array}{c}\text { Avg. ME on } \mathrm{p}(\mathrm{y}=10) \\
(3)\end{array}$ \\
\hline Trust & $0.0658^{* * *}(0.0010)$ & $0.0083^{* * *}(0.0001)$ & $0.0101^{* * *}(0.0002)$ \\
\hline Age & $-0.5060^{*}(0.2707)$ & $-0.0638^{*}(0.0341)$ & $-0.0775^{*}(0.0415)$ \\
\hline $\mathrm{Age}^{2}$ & $0.6561^{* * *}(0.0359)$ & $0.0827^{* * *}(0.0045)$ & $0.1005^{* * *}(0.0055)$ \\
\hline Male & $-0.0397^{* * *}(0.0048)$ & $-0.0050^{* * *}(0.0006)$ & $-0.0061^{* * *}(0.0007)$ \\
\hline $\ln (\mathrm{HH}$ income $)$ & $0.1996^{* * *}(0.0040)$ & $0.0251^{* * *}(0.0005)$ & $0.0306^{* * *}(0.0006)$ \\
\hline Unemployed & $-0.3676^{* * *}(0.0100)$ & $-0.0463^{* * *}(0.0013)$ & $-0.0563^{* * *}(0.0016)$ \\
\hline Out of labor force & $0.0613^{* * *}(0.0059)$ & $0.0077^{* * *}(0.0007)$ & $0.0094^{* * *}(0.0009)$ \\
\hline Married & $0.2238^{* * *}(0.0053)$ & $0.0282^{* * *}(0.0007)$ & $0.0343^{* * *}(0.0008)$ \\
\hline $\mathrm{HH}$ size & $-0.0122^{* * *}(0.0020)$ & $-0.0015^{* * *}(0.0002)$ & $-0.0019^{* * *}(0.0003)$ \\
\hline Immigrant & $-0.0697^{* * *}(0.0078)$ & $-0.0088^{* * *}(0.0010)$ & $-0.0107^{* * *}(0.0012)$ \\
\hline Big city/suburb & $-0.0729^{* * *}(0.0056)$ & $-0.0092^{* * *}(0.0007)$ & $-0.0112^{* * *}(0.0009)$ \\
\hline Small city & $-0.0571^{* * *}(0.0055)$ & $-0.0072^{* * *}(0.0007)$ & $-0.0087^{* * *}(0.0008)$ \\
\hline Social act. - abs. & $0.0571^{* * *}(0.0016)$ & $0.0072^{* * *}(0.0002)$ & $0.0088^{* * *}(0.0003)$ \\
\hline Social act. rel. & $0.0868^{* * *}(0.0026)$ & $0.0109^{* * *}(0.0003)$ & $0.0133^{* * *}(0.0004)$ \\
\hline Religiosity & $0.0302^{* * *}(0.0008)$ & $0.0038^{* * *}(0.0001)$ & $0.0046^{* * *}(0.0001)$ \\
\hline Crime victim & $-0.0738^{* * *}(0.0057)$ & $-0.0093^{* * *}(0.0007)$ & $-0.0113^{* * *}(0.0009)$ \\
\hline Risk tolerance & $-0.0061^{* * *}(0.0017)$ & $-0.0008^{* * *}(0.0002)$ & $-0.0009^{* * *}(0.0003)$ \\
\hline Father low educ. & $0.0186^{* * *}(0.0058)$ & $0.0023^{* * *}(0.0007)$ & $0.0029^{* * *}(0.0009)$ \\
\hline Pot. exp. & $-0.0751(0.2892)$ & $-0.0095(0.0364)$ & $-0.0115(0.0443)$ \\
\hline Pot. exp. ${ }^{2}$ & $-0.0261(0.0213)$ & $-0.0033(0.0027)$ & $-0.0040(0.0033)$ \\
\hline Health & $0.3131^{* * *}(0.0028)$ & $0.0395^{* * *}(0.0004)$ & $0.0480^{* * *}(0.0005)$ \\
\hline Education & $-0.0325(0.0586)$ & $-0.0041(0.0074)$ & $-0.0050(0.0090)$ \\
\hline Altruism & $0.0644^{* * *}(0.0025)$ & $0.0081^{* * *}(0.0003)$ & $0.0099^{* * *}(0.0004)$ \\
\hline Threshold 1 (SE) & -0.2744 & $(0.0257)$ & \\
\hline Threshold 2 (SE) & 0.005 & $(0.0254)$ & \\
\hline Threshold 3 (SE) & 0.3473 & $(0.0251)$ & \\
\hline Threshold 4 (SE) & 0.7268 & $(0.025)$ & \\
\hline Threshold 5 (SE) & 1.0116 & $(0.025)$ & \\
\hline Threshold 6 (SE) & 1.5275 & $(0.0251)$ & \\
\hline Threshold 7 (SE) & 1.8546 & $(0.0251)$ & \\
\hline Threshold 8 (SE) & 2.4007 & $(0.0252)$ & \\
\hline Threshold 9 (SE) & 3.2298 & $(0.0255)$ & \\
\hline Threshold 10 (SE) & 3.9123 & $(0.0257)$ & \\
\hline $\mathrm{N}$ & 226316 & & \\
\hline Country dummies & Yes & Yes & Yes \\
\hline Year dummies & Yes & Yes & Yes \\
\hline 8 Professional cat. dummies & Yes & Yes & Yes \\
\hline
\end{tabular}

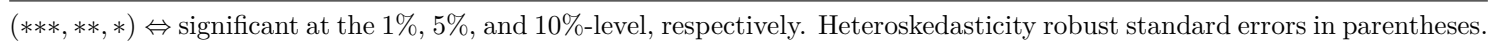
Age, age squared, household income, pot. experience, its square and education have been standardized (mean 0 and standard deviation of 1) before estimation. The professional category dummies are "professional", "technician", "clerk", "agricultural worker", "craft worker", "plant/machine worker", and "elementary occupation". The thresholds refer to the values of the latent variable at which the outcome changes according to the fitted model (10 thresholds separating 11 ordered response categories). 
Table A.7: Ordered logit estimates for trust and life satisfaction in the ESS data

\begin{tabular}{|c|c|c|c|}
\hline & $\begin{array}{l}\text { Coef. } \\
(1)\end{array}$ & $\begin{array}{c}\text { ME on } \mathrm{p}(\mathrm{y}=10) \text { at mean } \\
(2)\end{array}$ & $\begin{array}{c}\text { Avg. ME on } \mathrm{p}(\mathrm{y}=10) \\
(3)\end{array}$ \\
\hline Trust & $0.1213^{* * *}(0.0018)$ & $0.0071^{* * *}(0.0001)$ & $0.0097^{* * *}(0.0001)$ \\
\hline Age & $-0.9480^{* *}(0.4668)$ & $-0.0554^{* *}(0.0273)$ & $-0.0758^{* *}(0.0373)$ \\
\hline $\mathrm{Age}^{2}$ & $1.1312^{* * *}(0.0625)$ & $0.0661^{* * *}(0.0037)$ & $0.0905^{* * *}(0.0050)$ \\
\hline Male & $-0.0705^{* * *}(0.0082)$ & $-0.0041^{* * *}(0.0005)$ & $-0.0056^{* * *}(0.0007)$ \\
\hline $\ln (\mathrm{HH}$ income $)$ & $0.3632^{* * *}(0.0070)$ & $0.0212^{* * *}(0.0004)$ & $0.0290^{* * *}(0.0006)$ \\
\hline Unemployed & $-0.6652^{* * *}(0.0178)$ & $-0.0389^{* * *}(0.0011)$ & $-0.0532^{* * *}(0.0014)$ \\
\hline Out of labor force & $0.1053^{* * *}(0.0102)$ & $0.0062^{* * *}(0.0006)$ & $0.0084^{* * *}(0.0008)$ \\
\hline Married & $0.3936^{* * *}(0.0091)$ & $0.0230^{* * *}(0.0005)$ & $0.0315^{* * *}(0.0007)$ \\
\hline $\mathrm{HH}$ size & $-0.0242^{* * *}(0.0034)$ & $-0.0014^{* * *}(0.0002)$ & $-0.0019^{* * *}(0.0003)$ \\
\hline Immigrant & $-0.1337^{* * *}(0.0137)$ & $-0.0078^{* * *}(0.0008)$ & $-0.0107^{* * *}(0.0011)$ \\
\hline Big city/suburb & $-0.1300^{* * *}(0.0096)$ & $-0.0076^{* * *}(0.0006)$ & $-0.0104^{* * *}(0.0008)$ \\
\hline Small city & $-0.1014^{* * *}(0.0095)$ & $-0.0059^{* * *}(0.0006)$ & $-0.0081^{* * *}(0.0008)$ \\
\hline Social act. - abs. & $0.1020^{* * *}(0.0029)$ & $0.0060^{* * *}(0.0002)$ & $0.0082^{* * *}(0.0002)$ \\
\hline Social act. rel. & $0.1555^{* * *}(0.0045)$ & $0.0091^{* * *}(0.0003)$ & $0.0124^{* * *}(0.0004)$ \\
\hline Religiosity & $0.0529^{* * *}(0.0014)$ & $0.0031^{* * *}(0.0001)$ & $0.0042^{* * *}(0.0001)$ \\
\hline Crime victim & $-0.1236^{* * *}(0.0099)$ & $-0.0072^{* * *}(0.0006)$ & $-0.0099^{* * *}(0.0008)$ \\
\hline Risk tolerance & $-0.0113^{* * *}(0.0029)$ & $-0.0007^{* * *}(0.0002)$ & $-0.0009^{* * *}(0.0002)$ \\
\hline Father low educ. & $0.0330^{* * *}(0.0101)$ & $0.0019^{* * *}(0.0006)$ & $0.0026^{* * *}(0.0008)$ \\
\hline Pot. exp. & $-0.0599(0.4988)$ & $-0.0035(0.0291)$ & $-0.0048(0.0399)$ \\
\hline Pot. exp. ${ }^{2}$ & $-0.0299(0.0370)$ & $-0.0017(0.0022)$ & $-0.0024(0.0030)$ \\
\hline Health & $0.5616^{* * *}(0.0050)$ & $0.0328^{* * *}(0.0003)$ & $0.0449^{* * *}(0.0005)$ \\
\hline Education & $-0.0361(0.1010)$ & $-0.0021(0.0059)$ & $-0.0029(0.0081)$ \\
\hline Altruism & $0.1189^{* * *}(0.0044)$ & $0.0069^{* * *}(0.0003)$ & $0.0095^{* * *}(0.0004)$ \\
\hline Threshold 1 (SE) & -0.6321 & $(0.0463)$ & \\
\hline Threshold 2 (SE) & -0.0226 & $(0.045)$ & \\
\hline Threshold 3 (SE) & 0.6763 & $(0.0442)$ & \\
\hline Threshold 4 (SE) & 1.4072 & $(0.0439)$ & \\
\hline Threshold 5 (SE) & 1.9329 & $(0.0438)$ & \\
\hline Threshold 6 (SE) & 2.85 & $(0.044)$ & \\
\hline Threshold 7 (SE) & 3.4154 & $(0.0441)$ & \\
\hline Threshold 8 (SE) & 4.3434 & $(0.0444)$ & \\
\hline Threshold 9 (SE) & 5.7591 & $(0.045)$ & \\
\hline Threshold 10 (SE) & 7.0072 & $(0.0457)$ & \\
\hline $\mathrm{N}$ & 226316 & & \\
\hline Country dummies & Yes & Yes & Yes \\
\hline Year dummies & Yes & Yes & Yes \\
\hline 8 Professional cat. dummies & Yes & Yes & Yes \\
\hline
\end{tabular}

$(* * *, * *, *) \Leftrightarrow$ significant at the $1 \%, 5 \%$, and $10 \%$-level, respectively. Heteroskedasticity robust standard errors in parentheses. Age, age squared, household income, pot. experience, its square and education have been standardized (mean 0 and standard deviation of 1) before estimation. The professional category dummies are "professional", "technician", "clerk", "agricultural worker", "craft worker", "plant/machine worker", and "elementary occupation". The thresholds refer to the values of the latent variable at which the outcome changes according to the fitted model (10 thresholds separating 11 ordered response categories). 

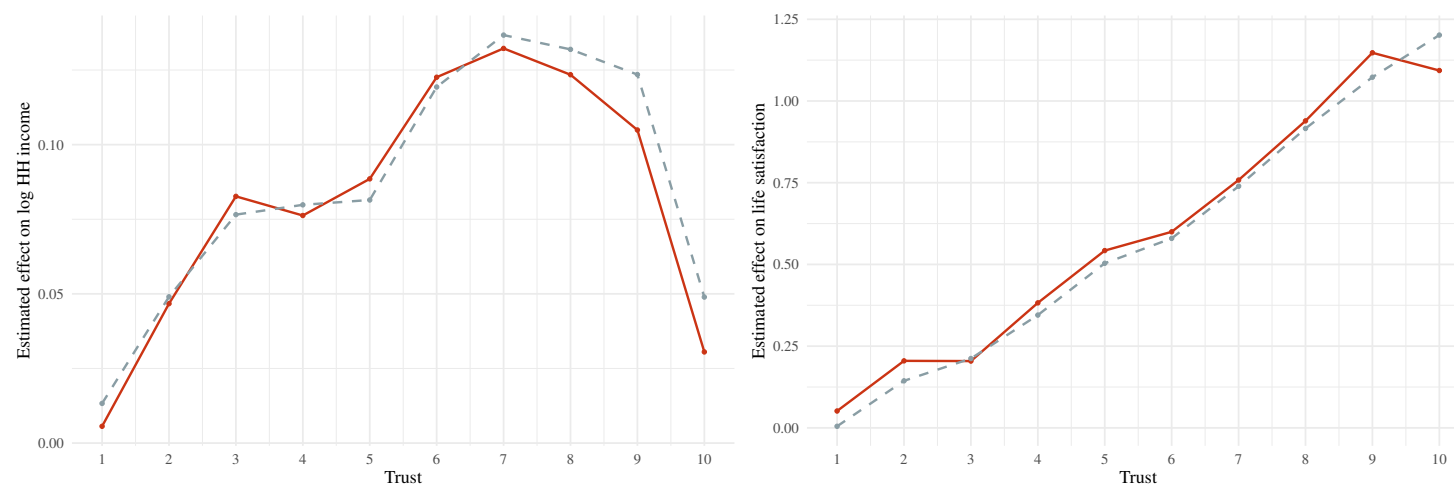

Figure A.3: Trust and income/life satisfaction with (solid) and without (dashed) sampling weights in the ESS data.

The right panel shows an analogous graph for the trust-life satisfaction relationship. Regression specifications are the same as in Figure 1a. 


\section{B Additional information and results for the SHP data}

\section{B.1 Variable description}

In what follows, we describe the SHP variables that we used for our analyses. Table B.2 provides descriptive statistics for all SHP variables. Average trust and life satis-

faction are around 6 and 8, respectively, which is above the corresponding values in the ESS data, but, as later shown in Appendix C.1, very similar to Sweden.

Table B.1: Description of SHP variables used

\begin{tabular}{|c|c|c|}
\hline & Description/Encoding & $\begin{array}{l}\text { Underlying } \\
\text { SHP Variable }\end{array}$ \\
\hline \multicolumn{3}{|l|}{ Main variables } \\
\hline Trust & $\begin{array}{l}\text { "You can't be too careful" (0) up to "most people can be } \\
\text { trusted" (10) }\end{array}$ & $\mathrm{pXXp} 45$ \\
\hline Life satisfaction & $\begin{array}{l}\text { How satisfied with life in general - from } 0 \text { (not at all satisfied) } \\
\text { to } 10 \text { (completely satisfied) }\end{array}$ & pXXc44 \\
\hline Log of net household income & $\begin{array}{l}\text { Log of annual net household income in CHF, with some } \\
\text { imputations for missing years (done by FORS, the data } \\
\text { provider) }\end{array}$ & ihtyni \\
\hline Log of net personal income & $\begin{array}{l}\text { Log of net personal income, with some imputations for missing } \\
\text { years (done by FORS, the data provider) }\end{array}$ & iptotni \\
\hline \multicolumn{3}{|l|}{ Pro-social/-env. variables } \\
\hline Envir. org. member & $\begin{array}{l}\text { Associational membership: protection of the environment - } 0 \\
\text { (no member), } 1 \text { (passive member), } 2 \text { (active member) }\end{array}$ & $\mathrm{pXXn44}$ \\
\hline Charity member & $\begin{array}{l}\text { Associational membership: charitable organization - } 0 \text { (no } \\
\text { member), } 1 \text { (passive member), } 2 \text { (active member) }\end{array}$ & $\mathrm{pXXn} 45$ \\
\hline Donated & $\begin{array}{l}\text { Whether or not made any donations to an organization or } \\
\text { person outside of kinship (I assume in past year, reference } \\
\text { frame not entirely clear from questionnaire) - } 1 \text { if yes, } 0 \text { if not }\end{array}$ & pXXn53 \\
\hline $\ln ($ Donation $)$ & Log of reported monetary donations & pXXn54 \\
\hline Voting frequency & $\begin{array}{l}\text { Suppose there are } 10 \text { federal polls in a year - how many do you } \\
\text { take part in? - from } 0 \text { ( } 0 \text { times voting) to } 10 \text { (10 times voting) }\end{array}$ & pXXp06 \\
\hline Environment $>$ growth & $\begin{array}{l}\text { Opinion on environmental protection - in favor of stronger } \\
\text { economic growth }(-1) \text {, neutral }(0) \text {, in favor of stronger } \\
\text { protection of the environment (1) }\end{array}$ & pXXp16 \\
\hline
\end{tabular}


More env. spending

Buy eco-friendly

Buy seasonal fruit/veg.

Voluntary work

Personal tragedy variables

Death of relative

Socioeconomic variables

Male

Age

Education (years)

Married

Divorced

Widowed

Number of children

Household size

Potential experience

Full time

In training

Unemployed

Out of labor force

Church freq.

Christian

Muslim

Catholic

Protestant

Atheist

Health

Health worsened
Public expenses: protection of the environment - spend less

$(-1)$, the same $(0)$ or more $(1)$

Protection of the environment: Buy eco-friendly/organic - never

(0) to 10 (always)

Protection of the environment: buy seasonal fruits and vegetables - never (0) to 10 (always)

Voluntary work - yes (1) or no (0)

Death of closely related person - 1 if yes, 0 if no

1 if male, 0 if not

Age in years

Years of education, deduced from ISCED class

1 if married, 0 if not (incl. registered partnerships)

1 if separated or divorced, 0 if not

1 if widow/-er, 0 if not

Number of children born to household

Number of persons in household

Potential experience, calculated as the maximum between Age years of education -6 and 0

Working full time (min $37 \mathrm{~h} /$ week) - 1 if yes, 0 if no

In school/training - 1 if yes 0 if no

1 if unemployed, 0 if not

1 if out of labor force, 0 if not

Participation in relig. services: frequency - never (1), only for

family ceremonies (2), only for religious celebrations (3),

religious celebrations and family events (4), a few times a year

(5), about once a month (6), every two weeks (7), once a week

(8), several times a week (9)

1 if yes, 0 otherwise - taken from the year before/after

(whichever is closest) in years where question was not asked

1 if yes, 0 otherwise - taken from the year before/after

(whichever is closest) in years where question was not asked

1 if yes, 0 otherwise - taken from the year before/after

(whichever is closest) in years where question was not asked

1 if yes, 0 otherwise - taken from the year before/after

(whichever is closest) in years where question was not asked

1 if yes, 0 otherwise - taken from the year before/after

(whichever is closest) in years where question was not asked

Health status - 1 (not well at all) to 5 (very well)

1 if health worsened in last 12 months, 0 otherwise
pXXp53

pXXp79

pXXp80

pXXn35

pXXl11

$\operatorname{sexXX}$

ageXX

edyearXX

civstaXX

civstaXX

civstaXX

ownkidXX

nbpersXX

occupaXX

occupaXX

wstatXX

wstatXX

pXXr04

pXXr01

pXXr01

pXXr01

pXXr01

pXXr01

pXXc01

pXXc03 
Canton

Region

Trust government

Big Five: reserved

Big Five: trusting

Big Five: thorough job

Big Five: relaxed

Big Five: imagination

Big Five: sociable

Big Five: fault

Big Five: lazy

Big Five: nervous

Big Five: artistic

$\underline{\text { Social origin variables }}$

Electoral status

Centr_eur
Canton of residence - 1 (AG), 2 (AI), 3 (AR), 4 (BE), 5 (BS), 6

(BL), 7 (FR), 8 (GE), 9 (GL), 10 (GR), 11 (JU), 12 (LU), 13

(NE), $14(\mathrm{NW}), 15$ (OW), 16 (SG), 17 (SH), 18 (SO), 19 (SZ),

20 (TG), 21 (TI), 22 (UR), 23 (VD), 24 (VS), 25 (ZG), 26 (ZH)

Region of residence - 1 Lake Geneva (VD, VS, GE); 2

Middleland (BE, FR, SO, NE, JU); 3 North-west Switzerland (BS, BL, AG); 4 Zurich; 5 Eastern Switzerland (GL, SH, AR, AI, SG, GR, TG); 6 Central Switzerland (LU, UR, SZ, OW, NW, ZG); 7 Ticino

Trust in the federal government - 0 (no confidence) to 10 (complete confidence)

Big Five 10: I see myself as someone who is reserved - 0 (completely disagree) to 10 (completely agree)

Big Five 10: I see myself as someone who is generally trusting 0 (completely disagree) to 10 (completely agree)

Big Five 10: I see myself as someone who does a thorough job 0 (completely disagree) to 10 (completely agree)

Big Five 10: I see myself as someone who is relaxed, handles stress well - 0 (completely disagree) to 10 (completely agree)

Big Five 10: I see myself as someone who has an active imagination - 0 (completely disagree) to 10 (completely agree)

Big Five 10: I see myself as someone who is outgoing, sociable 0 (completely disagree) to 10 (completely agree)

Big Five 10: I see myself as someone who tends to find fault with others- 0 (completely disagree) to 10 (completely agree)

Big Five 10: I see myself as someone who tends to be lazy - 0 (completely disagree) to 10 (completely agree)

Big Five 10: I see myself as someone who get nervous easily - 0 (completely disagree) to 10 (completely agree)

Big Five 10: I see myself as someone who has artistic interests 0 (completely disagree) to 10 (completely agree)

Electoral status: 1 if allowed to vote, 0 if not Region of origin: Central Europe - includes Austria, Belgium,

Denmark, Finland, France, Germany, Liechtenstein,

Netherlands, Sweden, UK
cantonXX

regionXX

pXXp04

pXXc60

pXXc61

pXXc62

pXXc63

pXXc64

pXXc65

pXXc66

pXXc67

pXXc68

pXXc69

pXXp05

pXXo20,

pXXo23,

pXXo37,

pXXo40, nat_1_XX, nat_2_XX, nat_3_XX 
Region of origin: Eastern Europe - includes Czech Republic, nat_3_XX

pXXo20,

Hungary, Poland, Romania, Russia, Slovakia, Turkey

pXXo23,

pXXo37,

pXXo40,

nat_1_XX,

nat_2_XX,

nat_3_XX

Ex_Yugo

Region of origin: Albania and Ex-Yugoslavia - includes Albania,

pXXo20,

Bosnia and Herzegovina, Croatia, Kosovo, Macedonia, Serbia,

pXXo23,

Slovenia, and Yugoslavia (nomenclature in accordance with

pXXo37, SHP codebook).

pXXo40,

nat_1_XX,

nat_2_XX,

Admin variables

idpers

idhous

year

weights_css

Personal identifier

Household identifier (to be used in conjunction with year)

Year of wave/interview period start

Individual-level cross-sectional sampling weights (keeping sample size)
nat_3_XX

idpers

idhousXX

weipXXts 
Table B.2: Summary statistics - SHP

\begin{tabular}{|c|c|c|c|c|c|}
\hline Statistic & $\mathrm{N}$ & Mean & St. Dev. & Min & Max \\
\hline Trust & 111,196 & 6.154 & 2.253 & 0 & 10 \\
\hline Life satisfaction & 111,196 & 8.040 & 1.398 & 0 & 10 \\
\hline Log of net personal income & 106,668 & 10.634 & 0.965 & 2.303 & 15.521 \\
\hline Log of net household income & 111,195 & 11.510 & 0.589 & 4.605 & 15.638 \\
\hline Age & 111,196 & 49.269 & 17.302 & 18 & 100 \\
\hline Male & 111,196 & 0.443 & 0.497 & 0 & 1 \\
\hline Unemployed & 111,196 & 0.016 & 0.127 & 0 & 1 \\
\hline Out of labor force & 111,196 & 0.294 & 0.456 & 0 & 1 \\
\hline Married & 111,196 & 0.594 & 0.491 & 0 & 1 \\
\hline Divorced & 111,196 & 0.101 & 0.301 & 0 & 1 \\
\hline Full time & 111,132 & 0.347 & 0.476 & 0 & 1 \\
\hline In training & 111,132 & 0.080 & 0.271 & 0 & 1 \\
\hline Household size & 111,196 & 2.771 & 1.322 & 1 & 12 \\
\hline Number of children & 109,875 & 1.559 & 1.319 & 0 & 14 \\
\hline Health & 111,196 & 4.029 & 0.655 & 1 & 5 \\
\hline Health worsened & 111,130 & 0.130 & 0.336 & 0 & 1 \\
\hline Education (years) & 111,196 & 13.464 & 3.065 & 8 & 21 \\
\hline Potential experience & 111,196 & 29.812 & 17.590 & 0 & 84 \\
\hline Death of relative & 111,142 & 1.772 & 0.420 & 1 & 2 \\
\hline Charity member & 71,963 & 0.337 & 0.596 & 0 & 2 \\
\hline Donated & 21,920 & 0.677 & 0.467 & 0 & 1 \\
\hline $\ln$ (Donation) & 14,166 & 5.889 & 1.316 & 0 & 12.429 \\
\hline Volunt. work & 86,400 & 0.472 & 0.499 & 0 & 1 \\
\hline Voting frequency & 61,709 & 7.720 & 3.054 & 0 & 10 \\
\hline Envir. org. member & 71,973 & 0.222 & 0.469 & 0 & 2 \\
\hline Buy eco-friendly & 21,792 & 5.786 & 2.544 & 0 & 10 \\
\hline Buy seasonal fruit/veg. & 21,863 & 7.514 & 2.221 & 0 & 10 \\
\hline More env. spending & 21,530 & 0.603 & 0.548 & -1 & 1 \\
\hline Environment $>$ growth & 65,648 & 0.345 & 0.742 & -1 & 1 \\
\hline Trust in government & 66,458 & 5.667 & 2.115 & 0 & 10 \\
\hline Muslim & 106,307 & 0.011 & 0.103 & 0 & 1 \\
\hline Catholic & 106,307 & 0.407 & 0.491 & 0 & 1 \\
\hline Protestant & 106,307 & 0.378 & 0.485 & 0 & 1 \\
\hline Atheist & 106,307 & 0.149 & 0.356 & 0 & 1 \\
\hline Church freq. & 106,401 & 3.982 & 2.148 & 1 & 9 \\
\hline Big Five: artistic & 71,843 & 5.693 & 2.738 & 0 & 10 \\
\hline Big Five: fault & 71,766 & 3.515 & 2.096 & 0 & 10 \\
\hline Big Five: imagination & 71,795 & 6.892 & 1.950 & 0 & 10 \\
\hline Big Five: lazy & 71,755 & 3.326 & 2.350 & 0 & 10 \\
\hline Big Five: nervous & 71,805 & 3.993 & 2.367 & 0 & 10 \\
\hline Big Five: reserved & 71,775 & 4.243 & 2.786 & 0 & 10 \\
\hline Big Five: trusting & 71,766 & 7.193 & 1.672 & 0 & 10 \\
\hline Big Five: relaxed & 71,830 & 6.973 & 1.748 & 0 & 10 \\
\hline Big Five: sociable & 71,837 & 7.409 & 1.708 & 0 & 10 \\
\hline Big Five: thorough job & 71,737 & 8.254 & 1.300 & 0 & 10 \\
\hline
\end{tabular}




\section{B.2 Empirical approach}

For the SHP we have the estimation equation

$$
y_{i t}=\beta_{0}+\sum_{k=1}^{10} \beta_{k} \mathbb{1}\left(\text { Trust }_{i t}=k\right)+\delta X_{i t}+\eta_{t}+\eta_{c}+\epsilon_{i t},
$$

where $y_{i t}$ is the outcome of interest for individual $i$ at time $t, \eta_{c}$ are canton fixed effects, $\eta_{t}$ are year fixed effects, and $X_{i t}$ is a vector of individual controls. Cantons are the Swiss equivalent of states in the United States, with both countries sharing a federalist system.

As an additional identification strategy aimed at the trust-well-being relationship, we run a matched difference-in-differences regression on trust and well-being leveraging exogenous happiness shocks. This approach largely mirrors the method used by Liberini et al. (2017) and focuses on a comparison between couples where one spouse died and similar couples who were spared that fate in the period under observation. Based on information in the SHP, we select individuals who are observable for at least three years prior and three years after the death of the spouse (i.e. a total of 6 years) and match those individuals with control individuals. When doing so, we make sure to select control individuals who are observable for the entire time frame for which we have well-being data (2003-2017) to avoid missing control observations around the time of the death of the spouse of the matched treated individual. To this end, we employ nearest neighbor matching (with replacement) based on age, age squared, reported health, a labor force participation indicator and an indicator denoting whether or not the respondent's health has worsened in the past year. Propensity scores were generated in a logit model using data from 2005, which is before the first treatment couples incurred a fatality. With this matched dataset, we run a difference-in-differences regression based on two years before the death of 
the spouse (excluding the year immediately before the death to prevent anticipation effects) and one or two survey waves after the event, which we consider the "treatment periods". In Appendix B.3.2 below we provide a set of standard balancing tests comparing treatment and control individuals based on observables (Tables B.4 and B.5), the table with the main estimates (Table B.6), and graphical evidence on the parallel trend assumption (Figures B.1 and B.2). Treatment and control groups have virtually identical pre-treatment values, and two-sample t-tests cannot reject balance in all the covariates considered at all conventional significance levels.

For our IV approach, we take a subsample of individuals who (i) have at least one parent who is a citizen of a different country (discarding cases where parents are from two different non-Swiss countries), (ii) were living with at least one of the foreign parents at the age of 15, and (iii) were either born in Switzerland or lived there for at least 15 years at the time they are first recorded in the survey. The last restriction is intended to counteract the possibility that effects on behavioral outcomes are primarily driven by individuals self-selecting to migrate based on factors relevant to the dependent variables under examination in the present study. Ensuring that the time of migration is reasonably far in the past (or in case of second generation immigrants, that the decision was not even up to the individual) precludes any short to medium term links between the act of migration and the reported attitudes and behaviors.

For this subsample, inherited trust is estimated based on cohort-specific country

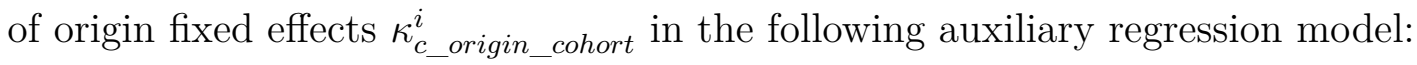

$$
\text { Trust }_{j t}=\sum_{k=1}^{3} \mathbb{1}\left(\text { cohort }_{j}=k\right) \kappa_{c \_ \text {origin_cohort_k }}^{i}+\delta X_{j t}+u_{j t}, j \neq i
$$

The $i$ superscript reflects the fact that we exclude observations of individual $i$, 
as well as those of other household members of $i$, in the estimation of the inherited trust component to prevent any mechanical correlation between $i$ 's trust and the instrument. The vector of covariates $X_{j t}$ includes age, age squared, years of education, log household income, labor force participation and religion (Christian, Muslim, Atheist or other). In Appendix B.5.2, we also use instruments based on an auxiliary regression where $X_{j t}$ is limited to age and age squared, which produces very similar results. Cohorts are determined by the age of the individual in 2000, with cohort 1 encompassing those aged 34 or younger, cohort 2 those aged between 35 and 54, and cohort 3 those aged 55 or older in that year. These cohorts have been chosen such that they are approximately one generation apart and roughly equal in size in terms of the number of observations per cohort.

The cohort-specific country of origin fixed effect thus represents an estimate of the prevailing level of trust at a given time period (see Table B.14 for those estimates).

With these instrument values, the first stage takes the form

$$
\text { Trust }_{i t}=\alpha_{0}+\alpha_{1} \underbrace{\sum_{k=1}^{3} \mathbb{1}\left(\text { cohort }_{i}=k\right) \kappa_{\text {c_origin_cohort_k }}^{i}}_{=\text {inherited trust }}+\gamma X_{i t}+\rho_{\text {reg_CH }}+\rho_{t}+\rho_{\text {reg_orig }}+v_{i t},
$$

where $X_{i t}$ is a vector of controls, $\rho_{\text {reg_CH }}, \rho_{t}, \rho_{\text {reg_orig }}$ are region of residence, time and region of origin fixed effects, respectively. The latter account for any timeinvariant region-specific factors such as culture and customs that may be transmitted from parents to their offspring along with a given level of trust. ${ }^{2}$ The second stage of the IV estimation is

\footnotetext{
${ }^{2}$ Regions of origin are grouped into Albania and ex-Yugoslavia, Central Europe, Eastern Europe, and Southern Europe. There are few individuals from other regions of the world (the base category) in the sample, as for conservative purposes every country of origin with less than 60 observations was dropped from the estimation.
} 


$$
y_{i t}=\delta_{0}+\beta \text { Trust }_{i t}+\delta X_{i t}+\eta_{\text {reg_CH}}+\eta_{t}+\eta_{\text {reg_orig }}+\epsilon_{i t},
$$

i.e. trust enters the model linearly as opposed to the dummy variables used in the baseline OLS specification. 


\section{B.3 Trust and income/life satisfaction}

In this section, we provide a variety of additional evidence in support of a humpshaped relationship between trust and income, and a positive effect of trust on reported life satisfaction. In Table B.3, we first present the full regression table which underlies our trust-income/life satisfaction relationship as shown in Figure 1b. Subsequently, we show that the death of a spouse does not affect reported trust despite the large impact on reported well-being in our matched difference-in-differences estimation. Tables B.4 and B.5 provide the standard balance of covariates, B.6 the main effects, and Figures B.1 and B.2 evidence on parallel trends). Lastly, we use our inherited trust instruments in a series of regressions of life satisfaction on trust, with Table B.7 showing strong positive effects consistent with our evidence based on our other data sources and approaches.

\section{B.3.1 Full table of estimates displayed in the main part}

Table B.3 provides the full regression table corresponding to our estimates for the relationship between trust and log household income/life satisfaction in the SHP as displayed in Figure 1b. An F-test rejects equality of coefficients for Trust $=9$ and Trust $=10$ for log household income, log personal income and life satisfaction at the 10\%-level or higher, which supports our observation that income maximizing level of trust is located somewhere between 7 and 9 in the Swiss data, while the well-being optimum appears to be at the maximum of the trust scale. 
Table B.3: Regression estimates for trust and income/life satisfaction in the SHP data corresponding to Figure $1 \mathrm{~b}$

\begin{tabular}{|c|c|c|c|}
\hline & $\begin{array}{c}\ln (\mathrm{HH} \text { inc. }) \\
(1)\end{array}$ & $\begin{array}{c}\ln (\text { pers inc.) } \\
(2) \\
\end{array}$ & $\begin{array}{l}\text { Life satisf. } \\
\qquad(3)\end{array}$ \\
\hline Trust $=1$ & $0.018(0.029)$ & $0.059(0.040)$ & $-0.054(0.133)$ \\
\hline Trust $=2$ & $0.066^{* * *}(0.021)$ & $0.076^{* * *}(0.028)$ & $0.086(0.083)$ \\
\hline Trust $=3$ & $0.066^{* * *}(0.020)$ & $0.085^{* * *}(0.028)$ & $0.023(0.075)$ \\
\hline Trust $=4$ & $0.097^{* * *}(0.020)$ & $0.063^{* *}(0.027)$ & $-0.068(0.079)$ \\
\hline Trust $=5$ & $0.096^{* * *}(0.018)$ & $0.088^{* * *}(0.024)$ & $0.234^{* * *}(0.068)$ \\
\hline Trust $=6$ & $0.145^{* * *}(0.019)$ & $0.134^{* * *}(0.026)$ & $0.170^{* *}(0.070)$ \\
\hline Trust $=7$ & $0.152^{* * *}(0.019)$ & $0.158^{* * *}(0.025)$ & $0.303^{* * *}(0.069)$ \\
\hline Trust $=8$ & $0.148^{* * *}(0.019)$ & $0.158^{* * *}(0.026)$ & $0.509^{* * *}(0.069)$ \\
\hline Trust $=9$ & $0.159^{* * *}(0.022)$ & $0.161^{* * *}(0.029)$ & $0.708^{* * *}(0.074)$ \\
\hline Trust $=10$ & $0.123^{* * *}(0.023)$ & $0.116^{* * *}(0.031)$ & $0.807^{* * *}(0.080)$ \\
\hline Age & $0.119^{*}(0.062)$ & $0.300^{* * *}(0.072)$ & $-0.271^{* * *}(0.097)$ \\
\hline $\mathrm{Age}^{2}$ & $0.0001^{* * *}(0.0001)$ & $-0.00003(0.0001)$ & $0.001^{* * *}(0.0001)$ \\
\hline Education (years) & $-0.083(0.061)$ & $-0.223^{* * *}(0.071)$ & $0.212^{* *}(0.095)$ \\
\hline Male & $-0.014(0.011)$ & $0.401^{* * *}(0.013)$ & $-0.182^{* * *}(0.031)$ \\
\hline Unemployed & $-0.271^{* * *}(0.032)$ & $-0.383^{* * *}(0.045)$ & $-0.955^{* * *}(0.107)$ \\
\hline Out of labor force & $-0.162^{* * *}(0.014)$ & $-0.335^{* * *}(0.021)$ & $-0.020(0.035)$ \\
\hline Health & $0.055^{* * *}(0.005)$ & $0.040^{* * *}(0.007)$ & $0.704^{* * *}(0.019)$ \\
\hline Full time & $0.151^{* * *}(0.011)$ & $0.472^{* * *}(0.014)$ & $0.032(0.031)$ \\
\hline In training & $-0.112^{* * *}(0.036)$ & $-0.533^{* * *}(0.052)$ & $0.086(0.076)$ \\
\hline Married & $0.177^{* * *}(0.013)$ & $-0.210^{* * *}(0.016)$ & $0.297^{* * *}(0.038)$ \\
\hline Divorced & $-0.028^{*}(0.016)$ & $0.059^{* * *}(0.018)$ & $-0.154^{* * *}(0.048)$ \\
\hline No. HH. members & $0.166^{* * *}(0.005)$ & $-0.017^{* * *}(0.007)$ & $-0.046^{* * *}(0.014)$ \\
\hline No. children & $-0.052^{* * *}(0.004)$ & $-0.011^{* *}(0.005)$ & $0.015(0.013)$ \\
\hline Potential experience & $-0.108^{*}(0.061)$ & $-0.280^{* * *}(0.071)$ & $0.222^{* *}(0.096)$ \\
\hline Potential experience ${ }^{2}$ & $-0.0003^{* * *}(0.00005)$ & $-0.0001(0.0001)$ & $-0.0001(0.0001)$ \\
\hline Electoral status & & & $0.114(0.072)$ \\
\hline Recent death of relative & & & $-0.009(0.020)$ \\
\hline Canton FE & Yes & Yes & Yes \\
\hline Year FE & Yes & Yes & Yes \\
\hline $\mathrm{p}($ Trust $9=$ Trust 10$)$ & 0.05 & 0.04 & 0.05 \\
\hline Observations & 69,707 & 66,642 & 39,978 \\
\hline Adjusted $\mathrm{R}^{2}$ & 0.389 & 0.409 & 0.203 \\
\hline
\end{tabular}

$(* * *, * *, *) \Leftrightarrow$ significant at the $1 \%, 5 \%$, and $10 \%$-level, respectively. Standard errors clustered at the individual level in parentheses. "p(Trust $9=$ Trust 10)" denotes the p-value of an F-test for equality of coefficients for Trust $=9$ and Trust $=10$. The pattern also translates to household income, which is not on display in the main part of the paper. Estimates are generated using cross-sectional sampling weights. 


\section{B.3.2 Spousal deaths as exogenous well-being shocks}

As highlighted in Table B.4, individuals losing their spouse tend to be older, unhealthier, and more likely female when we compare them to potential control individuals. As shown in Table B.5, our matching approach removes these imbalances for all the matching variables considered. We find, as shown in Table B.6, that the death of a spouse causes a large decrease in reported well-being in the two subsequent years, but see no effects on trust.

Finally, Figures B.1 and B.2 show that treatment and control groups have virtually identical pre-treatment values. In other words, we not only have parallel trends, but also a pronounced similarity in levels, which further enhances our confidence in the comparability of our matched treatment and control individuals. 
Table B.4: Covariate balance before matching

\begin{tabular}{lcccc}
\hline \hline Variable & Mean treated & Mean controls & Difference & $\mathrm{p}($ Diff. $=0)$ \\
\hline Age & 63.61 & 36.82 & 26.8 & 0 \\
Age $^{2}$ 1000 & 4.2 & 1.67 & 2.53 & 0 \\
$\ln (\mathrm{HH}$ inc. $)$ & 11.27 & 11.45 & -0.18 & 0.03 \\
Male & 0.16 & 0.39 & -0.23 & 0 \\
Health & 3.9 & 4.1 & -0.2 & 0.01 \\
Health worsened & 0.1 & 0.12 & -0.03 & 0.18 \\
Out of labor force & 0.65 & 0.3 & 0.35 & 0 \\
N treated & 88 & & & \\
N controls & 344 & & & \\
\hline \hline
\end{tabular}

Table B.5: Covariate balance after matching (nearest neighbor, with replacement)

\begin{tabular}{lcccc}
\hline \hline Variable & Mean treated & Mean controls & Difference & $\mathrm{p}($ Diff. $=0)$ \\
\hline Age & 63.61 & 62.03 & 1.58 & 0.5 \\
Age $^{2} / 1000$ & 4.2 & 4.02 & 0.18 & 0.5 \\
$\ln (\mathrm{HH}$ inc. & 11.27 & 11.39 & -0.12 & 0.26 \\
Male & 0.16 & 0.16 & 0 & 1 \\
Health & 3.9 & 3.98 & -0.08 & 0.5 \\
Health worsened & 0.1 & 0.11 & -0.02 & 0.77 \\
Out of labor force & 0.65 & 0.69 & -0.05 & 0.57 \\
N treated & 62 & & & \\
N controls & 62 & & & \\
\hline \hline
\end{tabular}


Table B.6: Impact of spousal death on happiness and trust

\begin{tabular}{|c|c|c|c|c|}
\hline & $\begin{array}{c}\text { Lf. satisf. } \\
(1)\end{array}$ & $\begin{array}{c}\text { Trust } \\
(2)\end{array}$ & $\begin{array}{c}\text { Lf. satisf. } \\
(3)\end{array}$ & $\begin{array}{c}\text { Trust } \\
(4) \\
\end{array}$ \\
\hline Death period & $\begin{array}{c}0.005 \\
(0.243)\end{array}$ & $\begin{array}{l}0.508^{*} \\
(0.279)\end{array}$ & & \\
\hline Death period ${ }_{2}$ & & & $\begin{array}{l}-0.168 \\
(0.239)\end{array}$ & $\begin{array}{c}0.366 \\
(0.248)\end{array}$ \\
\hline Treatment $=1$ & $\begin{array}{l}-0.217 \\
(0.250)\end{array}$ & $\begin{array}{l}-0.167 \\
(0.381)\end{array}$ & $\begin{array}{l}-0.205 \\
(0.247)\end{array}$ & $\begin{array}{l}-0.164 \\
(0.380)\end{array}$ \\
\hline Age & $\begin{array}{l}-0.064 \\
(0.050)\end{array}$ & $\begin{array}{c}0.016 \\
(0.055)\end{array}$ & $\begin{array}{l}-0.052 \\
(0.051)\end{array}$ & $\begin{array}{c}0.015 \\
(0.059)\end{array}$ \\
\hline $\mathrm{Age}^{2} / 1000$ & $\begin{array}{l}0.693^{*} \\
(0.417)\end{array}$ & $\begin{array}{l}-0.004 \\
(0.428)\end{array}$ & $\begin{array}{c}0.567 \\
(0.419)\end{array}$ & $\begin{array}{l}-0.025 \\
(0.455)\end{array}$ \\
\hline Male & $\begin{array}{c}0.352 \\
(0.264)\end{array}$ & $\begin{array}{c}0.188 \\
(0.485)\end{array}$ & $\begin{array}{c}0.085 \\
(0.250)\end{array}$ & $\begin{array}{c}0.057 \\
(0.459)\end{array}$ \\
\hline $\ln (\mathrm{HH}$ inc.) & $\begin{array}{l}-0.032 \\
(0.251)\end{array}$ & $\begin{array}{c}0.258 \\
(0.271)\end{array}$ & $\begin{array}{c}0.028 \\
(0.207)\end{array}$ & $\begin{array}{c}0.230 \\
(0.264)\end{array}$ \\
\hline Health & $\begin{array}{c}0.668^{* * *} \\
(0.166)\end{array}$ & & $\begin{array}{c}0.717^{* * *} \\
(0.145)\end{array}$ & \\
\hline Death period $*$ treatment & $\begin{array}{c}-1.192^{* * *} \\
(0.354)\end{array}$ & $\begin{array}{l}-0.118 \\
(0.343)\end{array}$ & & \\
\hline Death period ${ }_{2} *$ treatment & & & $\begin{array}{c}-0.652^{* *} \\
(0.314)\end{array}$ & $\begin{array}{l}-0.121 \\
(0.266)\end{array}$ \\
\hline Year FE & Yes & Yes & Yes & Yes \\
\hline Observations & 372 & 372 & 496 & 496 \\
\hline Adjusted $\mathrm{R}^{2}$ & 0.184 & 0.027 & 0.151 & 0.040 \\
\hline
\end{tabular}

$(* * *, * *, *) \Leftrightarrow$ significant at the $1 \%, 5 \%$, and $10 \%$-level, respectively. Standard errors clustered at the individual level in parentheses. "Death period" denotes the year when the death of the spouse was first recorded in the data. "Death period 2 " adds the year after "Death period" as well, such that the treatment effect is averaged over those two years. Both types of regressions include two pretreatment years, excluding the year just before the death was recorded to remove potential anticipation effects. 


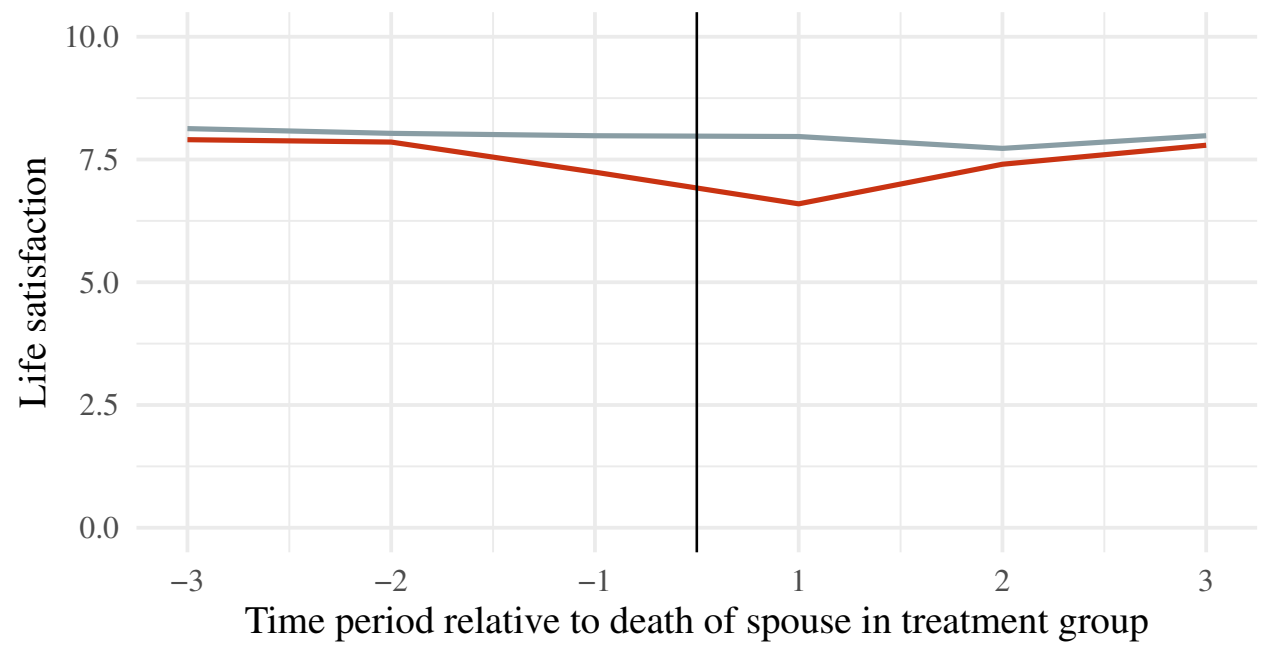

Treatment status $-0-1$

Figure B.1: Difference-in-differences plot of spousal death and life satisfaction.

We exclude period -1 to remove potential anticipation effects, and we cannot reject equality of life satisfaction across treatment status in the two other pre-treatment years, supporting the parallel trends assumption.

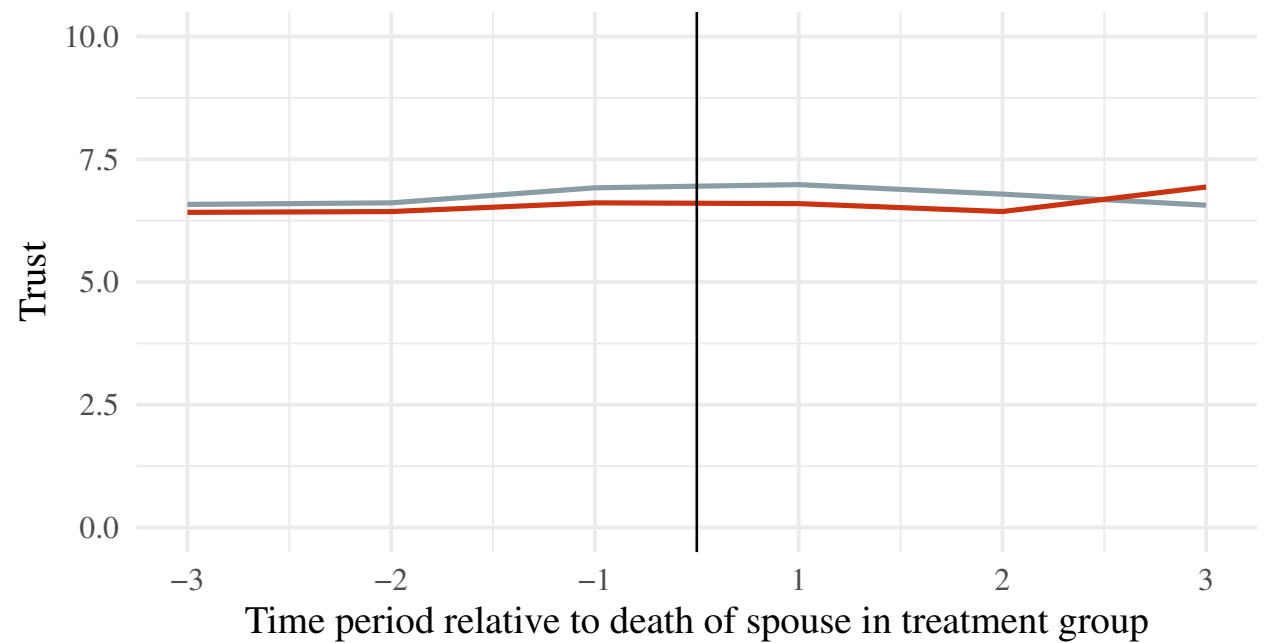

Treatment status $-0-1$

Figure B.2: Difference-in-differences plot of spousal death and trust.

We exclude period -1 to remove potential anticipation effects, and we cannot reject equality of trust across treatment status in the two other pre-treatment years, supporting the parallel trends assumption. 


\section{B.3.3 Instrumental variable estimates for trust and well-being}

In this section, we examine the relationship between trust and life satisfaction using our inherited trust instrument. Table B.7 provides the main estimates. This approach confirms our main results presented in Section 3. That is, we find sizable positive effects across various specifications, particularly once we focus on a series of binary specifications where we compare low/medium trust individuals with hightrust respondents. Given that the standard deviation of trust is slightly above 2 in our sample, the binary specifications, which tend to compare people with trust levels of 6 or lower to respondents with trust levels of 9 and 10, cover more than two standard deviations in trust on average. 


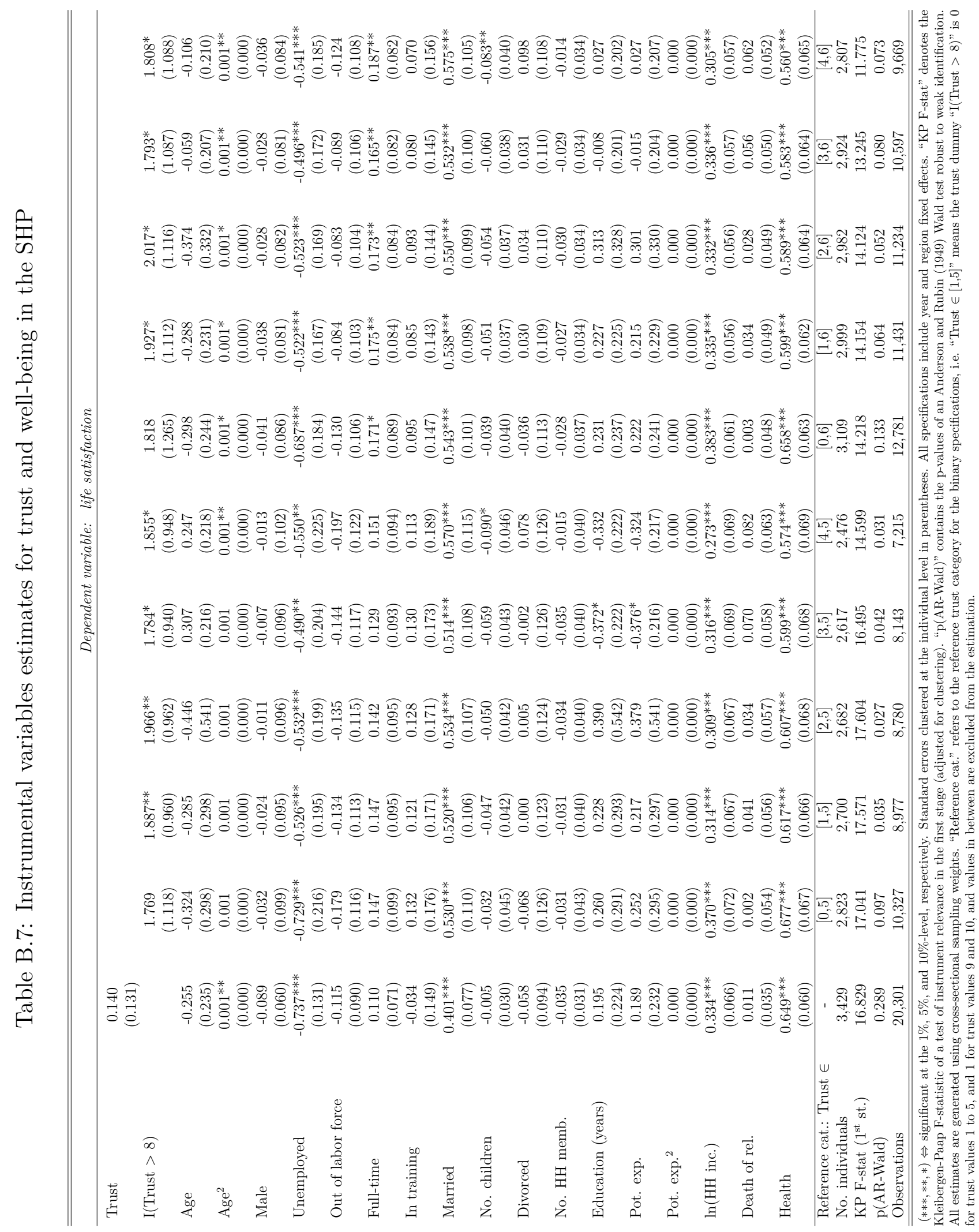




\section{B.4 Trust and cooperative outcomes}

In this section, we start by providing two additional plots of the observed (descriptive) relationship between trust, pro-social behavior, and well-being for outcomes where we have a larger set of possible responses, which renders the variables closer to a continuous measure than most of the other (mainly binary) indicators at our disposal. Consistent with the presented evidence on voting and donation amounts, we find that individuals who purchase eco-friendly products as well as seasonal produce with greater frequency exhibit a higher life satisfaction on average, with the highest well-being located at a point where both trust and the degree of reported pro-social behavior is high.

Next, we provide a more systematic analysis of the pro-social/pro-environmental outcomes under consideration. As a first set of cooperative outcomes, we consider membership in a charitable organization, both the intensive and extensive margins of donations, as well as reported engagement in voluntary work. In light of the frequent votes and elections taking place in Switzerland, where being called to the ballots four times a year on a variety of local, regional and national issues is quite common, we also focus on the reported voting frequency as a further indicator of engagement. Voting frequency takes values from 0 to 10 and denotes how often an individual would go and vote in a hypothetical scenario of 10 (unspecified) votes. Tables B.8, B.12, B.9, and B.13 provide the main results. We start with Table B.8. Similar to the ESS results, in Table B. 8 we observe increasing coefficients as we move up the trust scale, indicating a higher degree of reported cooperation for high trust individuals. Table B.8 also indicates that the estimates for trust $=10$ are significantly larger (at 10\%-level or lower) than the Swiss median level of 7 for all outcomes, with only one exception (the extensive margin of donations). We replicate these findings by applying our IV ap- 
proach, the estimates for which are displayed in Table B.12. These estimates provide additional evidence on the positive relationship between trust and these outcomes, with all trust coefficients being significant at the 10\%-level or lower (see Table B.12). Then, we extend our analyses to a broad range of outcomes related to environmental attitudes and behaviors, namely membership in an environmental organization, reported frequency of buying eco-friendly/organic and seasonal products, support for more government spending on environmental issues, reported position in a hypothetical trade-off between economic growth and the environment. Table B.9 provides the main results. Again, we see a persistent pattern: high-trust individuals consistently report both more favorable attitudes towards environmental issues as well as a higher frequency of green behaviors as captured by the purchase of eco-friendly products and seasonal fruit and vegetables. As before, we replicate these findings by applying our IV approach, the estimates for which are displayed in Table B.12. Table B.12 confirms our previous findings.

Finally, Tables B.10 and B.11 provide first-stage estimates for all the estimations using an IV approach (as reported in Tables B.12 and B.13). In all estimations the (Kleibergen-Paap) F-statistics comfortably pass the conventional thresholds. Further, in Table B.14 we also display the estimated averages of the inherited trust instrument values by cohort and country of origin. 


\section{B.4.1 Additional descriptive plots for trust, cooperative outcomes, and well-being}
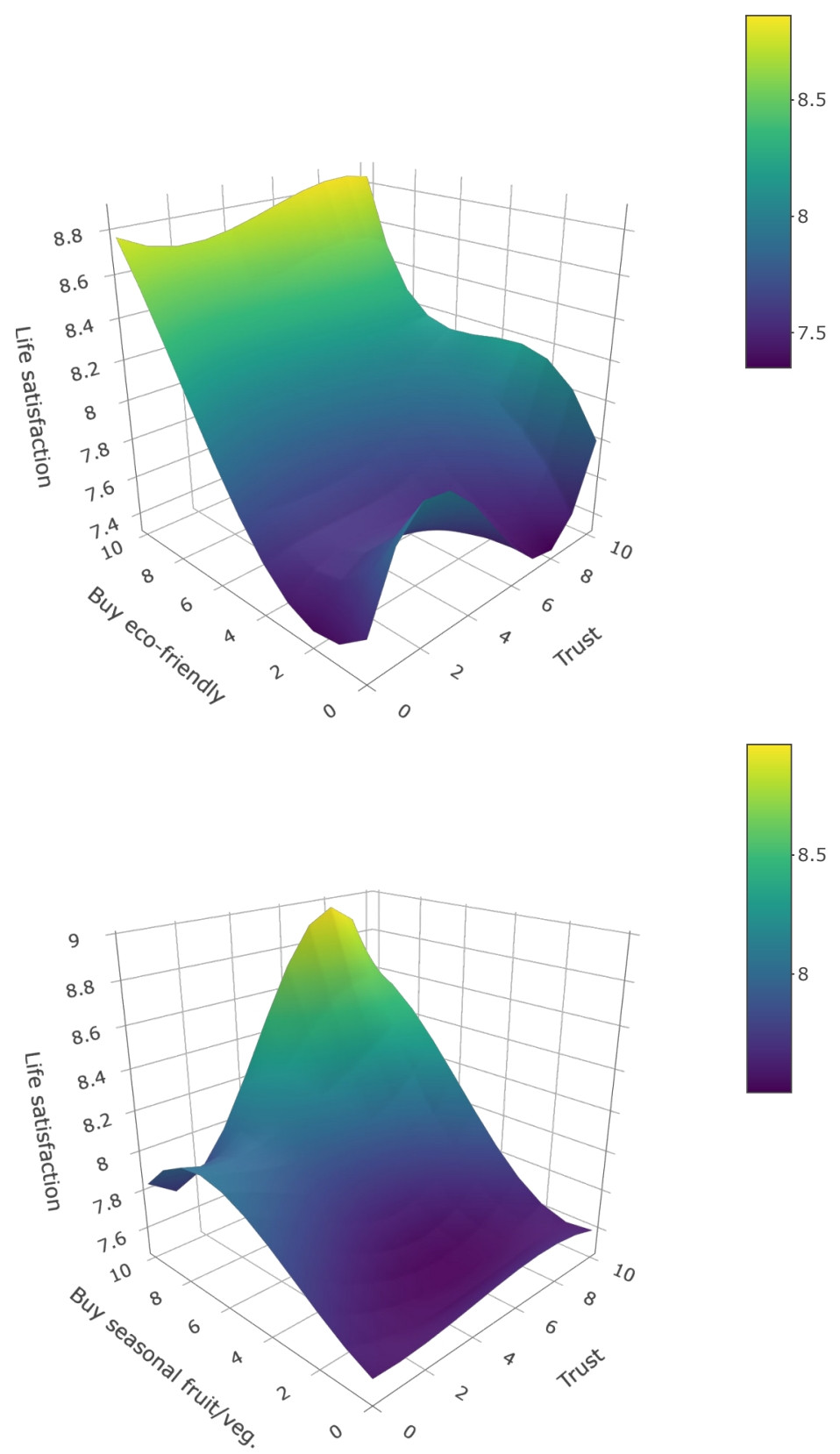

Figure B.3: Pro-social behavior, trust and life satisfaction in the SHP data.

The top panel shows the descriptive relationship between trust, the reported frequency of buying eco-friendly products (higher value equals higher frequency), and reported life satisfaction. The bottom panel indicates the corresponding relationship between trust, the reported frequency of buying seasonal fruits and vegetables, and life satisfaction. The graphs are constructed using smoothed means of life satisfaction across the trust/pro-social behavior grid, based on a third order polynomial (and corresponding two-way interaction terms) of trust and the respective pro-social behavior. 


\section{B.4.2 Baseline regressions}

Table B.8: OLS estimates for trust and cooperative/pro-social behavior in the SHP data in Table 2

\begin{tabular}{|c|c|c|c|c|c|}
\hline & $\begin{array}{c}\text { Charity member } \\
\text { (1) }\end{array}$ & $\begin{array}{c}\text { Donated } \\
(2)\end{array}$ & $\begin{array}{c}\ln (\text { Donation }) \\
(3)\end{array}$ & $\begin{array}{c}\text { Voluntary work } \\
(4)\end{array}$ & $\begin{array}{c}\text { Voting frequency } \\
(5)\end{array}$ \\
\hline Trust $=1$ & $0.030(0.024)$ & $-0.014(0.048)$ & $-0.150(0.199)$ & $0.017(0.024)$ & $0.221(0.212)$ \\
\hline Trust $=2$ & $0.048^{* * *}(0.015)$ & $0.040(0.030)$ & $0.281^{* *}(0.120)$ & $0.032^{* *}(0.014)$ & $0.381^{* * *}(0.133)$ \\
\hline Trust $=3$ & $0.034^{* *}(0.014)$ & $0.080^{* * *}(0.026)$ & $0.233^{* *}(0.101)$ & $0.047^{* * *}(0.013)$ & $0.589^{* * *}(0.119)$ \\
\hline Trust $=4$ & $0.052^{\text {*** }}(0.013)$ & $0.083^{* * *}(0.024)$ & $0.100(0.096)$ & $0.065^{* * *}(0.013)$ & $0.892^{* * *}(0.116)$ \\
\hline Trust $=5$ & $0.062^{* * *}(0.011)$ & $0.117^{* * *}(0.021)$ & $0.157^{*}(0.087)$ & $0.083^{* * *}(0.011)$ & $0.891^{* * *}(0.107)$ \\
\hline Trust $=6$ & $0.104^{* * *}(0.012)$ & $0.158^{* * *}(0.022)$ & $0.343^{* * *}(0.088)$ & $0.117^{* * *}(0.012)$ & $1.210^{* * *}(0.112)$ \\
\hline Trust $=7$ & $0.118^{* * *}(0.012)$ & $0.194^{* * *}(0.021)$ & $0.383^{* * *}(0.086)$ & $0.150^{* * *}(0.011)$ & $1.360^{* * *}(0.110)$ \\
\hline Trust $=8$ & $0.147^{* * *}(0.012)$ & $0.222^{* * *}(0.021)$ & $0.479^{* * *}(0.087)$ & $0.160^{* * *}(0.011)$ & $1.444^{* * *}(0.112)$ \\
\hline Trust $=9$ & $0.210^{* * *}(0.017)$ & $0.210^{* * *}(0.023)$ & $0.610^{* * *}(0.094)$ & $0.203^{* * *}(0.014)$ & $1.566^{* * *}(0.123)$ \\
\hline Trust $=10$ & $0.174^{* * *}(0.017)$ & $0.202^{* * *}(0.025)$ & $0.604^{* * *}(0.098)$ & $0.177^{* * *}(0.015)$ & $1.495^{* * *}(0.127)$ \\
\hline Age & $0.013^{* * *}(0.001)$ & $0.021^{* * *}(0.001)$ & $0.031^{* * *}(0.006)$ & $0.012^{* * *}(0.001)$ & $0.029^{* * *}(0.010)$ \\
\hline $\mathrm{Age}^{2}$ & $-0.0001^{* * *}(0.00001)$ & $-0.0001^{* * *}(0.00001)$ & $-0.0001(0.0001)$ & $-0.0001^{* * *}(0.00001)$ & $0.0001(0.0001)$ \\
\hline $\ln (\mathrm{HH}$ inc. $)$ & $0.085^{* * *}(0.007)$ & $0.063^{* * *}(0.007)$ & $0.522^{* * *}(0.028)$ & $0.003(0.006)$ & $0.557^{* * *}(0.043)$ \\
\hline Education (years) & $0.018^{* * *}(0.001)$ & $0.016^{* * *}(0.001)$ & $0.067^{* * *}(0.005)$ & $0.007^{* * *}(0.001)$ & $0.136^{* * *}(0.008)$ \\
\hline Male & $-0.042^{* * *}(0.008)$ & $-0.046^{* * *}(0.008)$ & $0.162^{* * *}(0.030)$ & $0.077^{* * *}(0.007)$ & $0.521^{* * *}(0.055)$ \\
\hline Married & $-0.039^{* * *}(0.011)$ & $0.003(0.011)$ & $0.039(0.039)$ & $0.027^{* * *}(0.010)$ & $0.403^{* * *}(0.078)$ \\
\hline Divorced & $-0.071^{* * *}(0.015)$ & $-0.041^{* * *}(0.015)$ & $-0.151^{* * *}(0.051)$ & $-0.035^{* * *}(0.013)$ & $-0.413^{* * *}(0.118)$ \\
\hline Unemployed & $-0.040^{* * *}(0.016)$ & $-0.100^{* * *}(0.027)$ & $-0.379^{* * *}(0.104)$ & $-0.038^{* *}(0.015)$ & $-0.242^{*}(0.132)$ \\
\hline Out of labor force & $-0.014(0.010)$ & $-0.032^{* * *}(0.010)$ & $-0.028(0.037)$ & $-0.018^{* *}(0.008)$ & $0.258^{* * *}(0.057)$ \\
\hline Full time & $-0.054^{* * *}(0.009)$ & $-0.021^{* *}(0.009)$ & $0.030(0.033)$ & $-0.055^{* * *}(0.008)$ & $-0.424^{* * *}(0.057)$ \\
\hline HH size & $-0.007^{*}(0.004)$ & $-0.015^{* * *}(0.004)$ & $-0.115^{* * *}(0.016)$ & $0.015^{* * *}(0.003)$ & $0.001(0.023)$ \\
\hline No. children & $0.017^{* * *}(0.004)$ & $0.001(0.004)$ & $0.056^{* * *}(0.015)$ & $0.017^{* * *}(0.003)$ & $-0.080^{* * *}(0.024)$ \\
\hline Canton FE & Yes & Yes & Yes & Yes & Yes \\
\hline Year FE & Yes & Yes & Yes & Yes & Yes \\
\hline Range dep. var. & $0-2$ & $0-1$ & $0+$ & $0-1$ & $0-10$ \\
\hline $\mathrm{p}($ Trust $10=$ Trust 7$)$ & 0.00 & 0.61 & 0.00 & 0.03 & 0.08 \\
\hline Observations & 71,492 & 21,489 & 14,041 & 85,044 & 61,320 \\
\hline Adjusted $\mathrm{R}^{2}$ & 0.058 & 0.147 & 0.208 & 0.130 & 0.128 \\
\hline
\end{tabular}

$(* * *, * *, *) \Leftrightarrow$ significant at the $1 \%, 5 \%$, and $10 \%$-level, respectively. Standard errors clustered at the individual level in parentheses. "Charity member" denotes membership in a charitable organization - 1 (passive member, i.e. no participation in organization activities) and 2 (active member), and 0 otherwise. "Donated" is a dummy equal to 1 if respondent reports any donations (cash or in-kind) in the past year. "ln(Donation)" denotes the log of monetary donations. "Voluntary work" = 1 if respondent reports having performed voluntary work (and 0 otherwise). "Voting frequency" denotes the reported frequency of participating in federal votes - 0 (never) to 10 (always). "p(Trust $10=$ Trust 7 )" denotes the p-value of an F-test for equality of coefficients for Trust $=10$ and Trust $=7$. 
Table B.9: Regression estimates for trust and cooperative/pro-social behavior in the SHP data in Table 2 - II

\begin{tabular}{|c|c|c|c|c|c|}
\hline & $\begin{array}{l}\text { Envir. org. member } \\
\text { (1) }\end{array}$ & $\begin{array}{l}\text { Buy eco-friendly } \\
\text { (2) }\end{array}$ & $\begin{array}{l}\text { Buy seasonal fruit/veg. } \\
\text { (3) }\end{array}$ & $\begin{array}{l}\text { More envir. spending } \\
\text { (4) }\end{array}$ & $\begin{array}{c}\text { Environment }>\text { growth } \\
(5)\end{array}$ \\
\hline Trust $=1$ & $0.035^{*}(0.021)$ & $0.105(0.291)$ & $-0.054(0.290)$ & $0.102^{*}(0.061)$ & $0.021(0.041)$ \\
\hline Trust $=2$ & $0.023^{*}(0.013)$ & $0.518^{* * *}(0.185)$ & $0.291^{*}(0.176)$ & $0.055(0.040)$ & $0.009(0.027)$ \\
\hline Trust $=3$ & $0.025^{* *}(0.011)$ & $0.487^{* * *}(0.168)$ & $0.119(0.160)$ & $0.080^{* *}(0.035)$ & $0.028(0.024)$ \\
\hline Trust $=4$ & $0.023^{* *}(0.010)$ & $0.814^{* * *}(0.153)$ & $0.243(0.149)$ & $0.085^{* *}(0.033)$ & $0.069^{* * *}(0.023)$ \\
\hline Trust $=5$ & $0.042^{* * *}(0.009)$ & $0.798^{* * *}(0.140)$ & $0.300^{* *}(0.136)$ & $0.101^{* * *}(0.029)$ & $0.075^{* * *}(0.020)$ \\
\hline Trust $=6$ & $0.070^{* * *}(0.010)$ & $1.064^{* * *}(0.142)$ & $0.433^{* * *}(0.137)$ & $0.139^{* * *}(0.030)$ & $0.104^{* * *}(0.021)$ \\
\hline Trust $=7$ & $0.094^{* * *}(0.009)$ & $1.247^{* * *}(0.139)$ & $0.528^{* * *}(0.134)$ & $0.185^{* * *}(0.029)$ & $0.136^{* * *}(0.021)$ \\
\hline Trust $=8$ & $0.124^{* * *}(0.010)$ & $1.451^{* * *}(0.140)$ & $0.693^{* * *}(0.135)$ & $0.208^{* * *}(0.029)$ & $0.173^{* * *}(0.021)$ \\
\hline Trust $=9$ & $0.169^{* * *}(0.015)$ & $1.623^{* * *}(0.154)$ & $0.913^{* * *}(0.144)$ & $0.231^{* * *}(0.032)$ & $0.220^{* * *}(0.024)$ \\
\hline Trust $=10$ & $0.157^{* * *}(0.016)$ & $1.747^{* * *}(0.165)$ & $1.016^{* * *}(0.152)$ & $0.226^{* * *}(0.034)$ & $0.208^{* * *}(0.025)$ \\
\hline Age & $0.009^{* * *}(0.001)$ & $0.059^{* * *}(0.009)$ & $0.065^{* * *}(0.007)$ & $0.006^{* * *}(0.002)$ & $-0.002(0.002)$ \\
\hline $\mathrm{Age}^{2}$ & $-0.0001^{* * *}(0.00001)$ & $-0.001^{* * *}(0.0001)$ & $-0.0004^{* * *}(0.0001)$ & $-0.0001^{* * *}(0.00002)$ & $-0.00001(0.00002)$ \\
\hline $\ln (\mathrm{HH}$ inc.) & $0.027^{* * *}(0.007)$ & $0.427^{* * *}(0.043)$ & $-0.086^{* *}(0.036)$ & $0.010(0.009)$ & $-0.082^{* * *}(0.009)$ \\
\hline Education (years) & $0.020^{* * *}(0.001)$ & $0.121^{* * *}(0.008)$ & $0.039^{* * *}(0.006)$ & $0.016^{* * *}(0.002)$ & $0.010^{* * *}(0.002)$ \\
\hline Male & $0.010(0.008)$ & $-0.483^{* * *}(0.048)$ & $-0.715^{* * *}(0.042)$ & $-0.050^{* * *}(0.010)$ & $-0.113^{* * *}(0.012)$ \\
\hline Married & $-0.053^{* * *}(0.010)$ & $-0.172^{* * *}(0.064)$ & $0.184^{* * *}(0.053)$ & $-0.068^{* * *}(0.013)$ & $-0.054^{* * *}(0.015)$ \\
\hline Divorced & $-0.042^{* * *}(0.013)$ & $-0.249^{* * *}(0.088)$ & $-0.047(0.071)$ & $-0.025(0.018)$ & $-0.024(0.020)$ \\
\hline Unemployed & $-0.038^{* *}(0.016)$ & $-0.224(0.156)$ & $-0.330^{* *}(0.148)$ & $-0.030(0.031)$ & $-0.046^{*}(0.025)$ \\
\hline Out of labor force & $-0.039^{* * *}(0.008)$ & $-0.096(0.059)$ & $-0.105^{* *}(0.049)$ & $0.0002(0.013)$ & $-0.042^{* * *}(0.013)$ \\
\hline Full time & $-0.076^{* * *}(0.008)$ & $-0.176^{* * *}(0.052)$ & $-0.181^{* * *}(0.046)$ & $-0.076^{* * *}(0.011)$ & $-0.066^{* * *}(0.012)$ \\
\hline $\mathrm{HH}$ size & $0.005(0.003)$ & $-0.099^{* * *}(0.025)$ & $0.006(0.021)$ & $-0.007(0.005)$ & $0.008(0.005)$ \\
\hline No. children & $-0.002(0.003)$ & $-0.053^{* *}(0.024)$ & $0.023(0.019)$ & $-0.013^{* * *}(0.005)$ & $0.015^{* * *}(0.005)$ \\
\hline Canton FE & Yes & Yes & Yes & Yes & Yes \\
\hline Year FE & Yes & Yes & Yes & Yes & Yes \\
\hline Range dep. var. & $0-2$ & $0-10$ & $0-10$ & {$[-1,1]$} & {$[-1,1]$} \\
\hline $\mathrm{p}($ Trust $10=$ Trust 7$)$ & 0.00 & 0.00 & 0.00 & 0.05 & 0.00 \\
\hline Observations & 71,502 & 21,368 & 21,437 & 21,103 & 65,205 \\
\hline Adjusted $\mathrm{R}^{2}$ & 0.047 & 0.108 & 0.105 & 0.049 & 0.047 \\
\hline
\end{tabular}

$(* * *, * *, *) \Leftrightarrow$ significant at the $1 \%, 5 \%$, and $10 \%$-level, respectively. Standard errors clustered at the individual level in parentheses. "Envir. org. member" $=1$ if respondent reports being a passive member of an environmental organization, and 2 for being an active member, and 0 otherwise. "Buy eco-friendly" and "Buy seasonal fruit/veg." denote the reported frequency of buying eco-friendly/organic and seasonal products, respectively - 0 (never) to 10 (always). "More envir. spending" is the reported preference for more (1), the same (0) or less (-1) public spending on the environment. "Environment > growth" is the reported preference for environment (1) or economic growth (-1), with 0 being indifference. "p(Trust $10=$ Trust 7 )" denotes the p-value of an F-test for equality of coefficients for Trust $=10$ and Trust $=7$. 


\section{B.4.3 IV estimates}

Table B.10: Instrumental variable first stage estimates for trust and cooperative/prosocial behavior in the SHP data

\begin{tabular}{|c|c|c|c|c|c|}
\hline & $(1)$ & (2) & $(3)$ & (4) & $(5)$ \\
\hline & Charity member & Donated & $\ln ($ Donation $)$ & Voluntary work & Voting frequency \\
\hline \multirow[t]{2}{*}{ Inherited trust } & $0.367^{* * *}$ & $0.445^{* * *}$ & $0.552^{* * *}$ & $0.368^{* * *}$ & $0.386^{* * *}$ \\
\hline & $(0.075)$ & $(0.088)$ & $(0.104)$ & $(0.072)$ & $(0.088)$ \\
\hline \multirow[t]{2}{*}{ Age } & -0.009 & -0.008 & -0.007 & -0.019 & -0.006 \\
\hline & $(0.016)$ & $(0.020)$ & $(0.023)$ & $(0.015)$ & $(0.019)$ \\
\hline \multirow[t]{2}{*}{$\mathrm{Age}^{2}$} & 0.000 & 0.000 & 0.000 & $0.000^{*}$ & 0.000 \\
\hline & $(0.000)$ & $(0.000)$ & $(0.000)$ & $(0.000)$ & $(0.000)$ \\
\hline \multirow[t]{2}{*}{ Male } & -0.140 & -0.166 & $-0.240^{* *}$ & $-0.215^{* *}$ & -0.145 \\
\hline & $(0.090)$ & $(0.105)$ & $(0.122)$ & $(0.088)$ & $(0.106)$ \\
\hline \multirow[t]{2}{*}{ Unemployed } & $-0.448^{* *}$ & -0.348 & -0.487 & $-0.559 * * *$ & $-0.403^{*}$ \\
\hline & $(0.181)$ & $(0.310)$ & $(0.460)$ & $(0.184)$ & $(0.225)$ \\
\hline \multirow[t]{2}{*}{ Out of labor force } & $-0.405^{* * *}$ & $-0.255^{* *}$ & $-0.288^{* *}$ & $-0.412^{* * *}$ & $-0.375^{* * *}$ \\
\hline & $(0.102)$ & $(0.124)$ & $(0.145)$ & $(0.097)$ & $(0.119)$ \\
\hline \multirow[t]{2}{*}{ Full time } & $-0.344^{* * *}$ & $-0.245^{* *}$ & -0.123 & $-0.375^{* * *}$ & $-0.399 * * *$ \\
\hline & $(0.097)$ & $(0.119)$ & $(0.136)$ & $(0.098)$ & $(0.113)$ \\
\hline \multirow[t]{2}{*}{ Married } & 0.047 & 0.074 & 0.115 & 0.084 & 0.097 \\
\hline & $(0.119)$ & $(0.145)$ & $(0.164)$ & $(0.119)$ & $(0.143)$ \\
\hline \multirow[t]{2}{*}{ No. children } & $0.114^{* * *}$ & $0.109^{*}$ & $0.123^{* *}$ & $0.124^{* * *}$ & $0.140^{* * *}$ \\
\hline & $(0.042)$ & $(0.056)$ & $(0.059)$ & $(0.044)$ & $(0.047)$ \\
\hline \multirow[t]{2}{*}{ Divorced } & -0.051 & -0.001 & -0.041 & 0.002 & -0.168 \\
\hline & $(0.158)$ & $(0.187)$ & $(0.210)$ & $(0.156)$ & $(0.193)$ \\
\hline \multirow[t]{2}{*}{$\mathrm{HH}$ size } & $-0.124^{* * *}$ & $-0.139 * *$ & $-0.128^{*}$ & $-0.149 * * *$ & $-0.165^{* * *}$ \\
\hline & $(0.041)$ & $(0.059)$ & $(0.071)$ & $(0.045)$ & $(0.046)$ \\
\hline \multirow[t]{2}{*}{ Education (years) } & $0.123^{* * *}$ & $0.109^{* * *}$ & $0.093^{* * *}$ & $0.122^{* * *}$ & $0.115^{* * *}$ \\
\hline & $(0.013)$ & $(0.015)$ & $(0.017)$ & $(0.013)$ & $(0.016)$ \\
\hline \multirow[t]{2}{*}{$\ln (\mathrm{HH}$ inc. $)$} & $0.449^{* * *}$ & $0.496^{* * *}$ & $0.323^{* * *}$ & $0.415^{* * *}$ & $0.422^{* * *}$ \\
\hline & $(0.075)$ & $(0.098)$ & $(0.111)$ & $(0.074)$ & $(0.087)$ \\
\hline No. individuals & 3340.000 & 2099.000 & 1466.000 & 2938.000 & 2320.000 \\
\hline KP F-stat (1 ${ }^{\text {st }}$ st. $)$ & 23.794 & 25.846 & 28.334 & 25.931 & 19.024 \\
\hline $\mathrm{R}^{2}$ & 0.100 & 0.110 & 0.085 & 0.105 & 0.084 \\
\hline Observations & 13,204 & 3,944 & 2,479 & 15,126 & 9,419 \\
\hline Region FE & Yes & Yes & Yes & Yes & Yes \\
\hline Reg. orig. FE & Yes & Yes & Yes & Yes & Yes \\
\hline Year FE & Yes & Yes & Yes & Yes & Yes \\
\hline
\end{tabular}

$(* * *, * *, *) \Leftrightarrow$ significant at the $1 \%, 5 \%$, and $10 \%$-level, respectively. Standard errors clustered at the individual level in parentheses. "KP F-stat" denotes the Kleibergen-Paap F-statistic of a test of instrument relevance in the first stage (adjusted for clustering). 
Table B.11: Instrumental variable first stage estimates for trust and cooperative/prosocial behavior in the SHP data II

\begin{tabular}{|c|c|c|c|c|c|}
\hline & (1) & (2) & (3) & (4) & (5) \\
\hline & Envir. org. member & Buy eco-friendly & Buy seasonal fruit/veg. & More envir. spending & Environment $>$ growth \\
\hline \multirow[t]{2}{*}{ Inherited trust } & $0.367^{* * *}$ & $0.434^{* * *}$ & $0.455^{* * *}$ & $0.451^{* * *}$ & $0.369^{* * *}$ \\
\hline & $(0.075)$ & $(0.089)$ & $(0.087)$ & $(0.088)$ & $(0.080)$ \\
\hline \multirow[t]{2}{*}{ Age } & -0.009 & -0.003 & -0.004 & -0.001 & -0.002 \\
\hline & $(0.016)$ & $(0.020)$ & $(0.020)$ & $(0.020)$ & $(0.017)$ \\
\hline \multirow[t]{2}{*}{$\mathrm{Age}^{2}$} & 0.000 & 0.000 & 0.000 & 0.000 & 0.000 \\
\hline & $(0.000)$ & $(0.000)$ & $(0.000)$ & $(0.000)$ & $(0.000)$ \\
\hline \multirow[t]{2}{*}{ Male } & -0.139 & $-0.176^{*}$ & -0.163 & -0.169 & $-0.159^{*}$ \\
\hline & $(0.090)$ & $(0.106)$ & $(0.105)$ & $(0.106)$ & $(0.094)$ \\
\hline \multirow{2}{*}{ Unemployed } & $-0.448^{* *}$ & -0.273 & -0.288 & -0.343 & $-0.385^{* *}$ \\
\hline & $(0.181)$ & $(0.305)$ & $(0.302)$ & $(0.308)$ & $(0.193)$ \\
\hline \multirow[t]{2}{*}{ Out of labor force } & $-0.405^{* * *}$ & $-0.241^{*}$ & $-0.237^{*}$ & $-0.243^{*}$ & $-0.386^{* * *}$ \\
\hline & $(0.102)$ & $(0.124)$ & $(0.124)$ & $(0.125)$ & $(0.108)$ \\
\hline \multirow[t]{2}{*}{ Full time } & $-0.343^{* * *}$ & $-0.261^{* *}$ & $-0.249^{* *}$ & $-0.268^{* *}$ & $-0.330^{* * *}$ \\
\hline & $(0.097)$ & $(0.120)$ & $(0.119)$ & $(0.120)$ & $(0.102)$ \\
\hline \multirow[t]{2}{*}{ Married } & 0.047 & 0.083 & 0.086 & 0.093 & 0.037 \\
\hline & $(0.119)$ & $(0.144)$ & $(0.145)$ & $(0.146)$ & $(0.125)$ \\
\hline \multirow[t]{2}{*}{ No. children } & $0.115^{* * *}$ & $0.098^{*}$ & $0.113^{* *}$ & $0.112^{* *}$ & $0.122^{* * *}$ \\
\hline & $(0.042)$ & $(0.057)$ & $(0.056)$ & $(0.056)$ & $(0.044)$ \\
\hline \multirow[t]{2}{*}{ Divorced } & -0.051 & 0.038 & 0.001 & 0.021 & -0.081 \\
\hline & $(0.158)$ & $(0.185)$ & $(0.187)$ & $(0.190)$ & $(0.168)$ \\
\hline \multirow[t]{2}{*}{ HH size } & $-0.124^{* * *}$ & $-0.139 * *$ & $-0.144^{* *}$ & $-0.151^{* *}$ & $-0.132^{* * * *}$ \\
\hline & $(0.041)$ & $(0.060)$ & $(0.060)$ & $(0.060)$ & $(0.043)$ \\
\hline \multirow[t]{2}{*}{ Education (years) } & $0.123^{* * *}$ & $0.111^{* * *}$ & $0.110^{* * *}$ & $0.104^{* * *}$ & $0.119^{* * *}$ \\
\hline & $(0.013)$ & $(0.015)$ & $(0.015)$ & $(0.015)$ & $(0.014)$ \\
\hline \multirow[t]{2}{*}{$\ln (\mathrm{HH}$ inc. $)$} & $0.449^{* * *}$ & $0.490^{* * *}$ & $0.507^{* * *}$ & $0.472^{* * *}$ & $0.454^{* * *}$ \\
\hline & $(0.075)$ & $(0.098)$ & $(0.097)$ & $(0.100)$ & $(0.080)$ \\
\hline No. individuals & 3,339 & 2,095 & 2,093 & 2,065 & 2,978 \\
\hline KP F-stat (1 $1^{\text {st }}$ st. $)$ & 23.936 & 23.933 & 27.174 & 26.235 & 21.398 \\
\hline $\mathrm{R}^{2}$ & 0.100 & 0.109 & 0.112 & 0.107 & 0.099 \\
\hline Observations & 13,202 & 3,923 & 3,935 & 3,845 & 12,007 \\
\hline Region FE & Yes & Yes & Yes & Yes & Yes \\
\hline Reg. orig. FE & Yes & Yes & Yes & Yes & Yes \\
\hline Year FE & Yes & Yes & Yes & Yes & Yes \\
\hline
\end{tabular}

$(* * *, * *, *) \Leftrightarrow$ significant at the $1 \%, 5 \%$, and $10 \%$-level, respectively. Standard errors clustered at the individual level in parentheses. "KP F-stat" denotes the Kleibergen-Paap F-statistic of a test of instrument relevance in the first stage (adjusted for clustering). 
Table B.12: Full table of instrumental variable estimates for trust and cooperative/pro-social behavior in the SHP data in Table 2

\begin{tabular}{|c|c|c|c|c|c|}
\hline & $\begin{array}{c}(1) \\
\text { Charity member }\end{array}$ & $\begin{array}{c}(2) \\
\text { Donated }\end{array}$ & $\begin{array}{c}(3) \\
\ln (\text { Donation })\end{array}$ & $\begin{array}{c}(4) \\
\text { Voluntary work }\end{array}$ & $\begin{array}{c}(5) \\
\text { Voting frequency }\end{array}$ \\
\hline \multirow[t]{2}{*}{ Trust } & $0.121^{* *}$ & $0.065^{*}$ & $0.454^{* * *}$ & $0.097^{* *}$ & $0.726^{* *}$ \\
\hline & $(0.052)$ & $(0.038)$ & $(0.145)$ & $(0.041)$ & $(0.361)$ \\
\hline \multirow[t]{2}{*}{ Age } & $0.015^{* * *}$ & $0.016^{* * *}$ & 0.018 & $0.010^{* * *}$ & $0.058^{* *}$ \\
\hline & $(0.004)$ & $(0.004)$ & $(0.018)$ & $(0.003)$ & $(0.027)$ \\
\hline \multirow[t]{2}{*}{$\mathrm{Age}^{2}$} & $-0.000^{* * *}$ & $-0.000 * * *$ & 0.000 & $-0.000 * * *$ & -0.000 \\
\hline & $(0.000)$ & $(0.000)$ & $(0.000)$ & $(0.000)$ & $(0.000)$ \\
\hline \multirow[t]{2}{*}{ Male } & -0.020 & $-0.052^{* * *}$ & $0.230 * * *$ & $0.069^{* * *}$ & $0.584^{* * *}$ \\
\hline & $(0.022)$ & $(0.020)$ & $(0.088)$ & $(0.020)$ & $(0.162)$ \\
\hline \multirow[t]{2}{*}{ Unemployed } & -0.015 & $-0.134^{* *}$ & -0.163 & 0.055 & 0.173 \\
\hline & $(0.045)$ & $(0.058)$ & $(0.241)$ & $(0.041)$ & $(0.299)$ \\
\hline \multirow{2}{*}{ Out of labor force } & 0.033 & $-0.057^{* *}$ & -0.068 & 0.014 & $0.468^{* *}$ \\
\hline & $(0.035)$ & $(0.026)$ & $(0.106)$ & $(0.026)$ & $(0.230)$ \\
\hline \multirow{2}{*}{ Full time } & -0.029 & -0.015 & 0.123 & -0.036 & -0.139 \\
\hline & $(0.029)$ & $(0.024)$ & $(0.095)$ & $(0.024)$ & $(0.220)$ \\
\hline \multirow[t]{2}{*}{ Married } & $-0.067^{* *}$ & -0.007 & 0.034 & 0.038 & 0.296 \\
\hline & $(0.028)$ & $(0.026)$ & $(0.115)$ & $(0.024)$ & $(0.205)$ \\
\hline \multirow[t]{2}{*}{ No. children } & 0.005 & -0.015 & -0.065 & $0.016^{*}$ & -0.128 \\
\hline & $(0.012)$ & $(0.010)$ & $(0.042)$ & $(0.010)$ & $(0.082)$ \\
\hline \multirow[t]{2}{*}{ Divorced } & $-0.103^{* * *}$ & -0.040 & 0.001 & $-0.058^{*}$ & $-0.826 * * *$ \\
\hline & $(0.036)$ & $(0.033)$ & $(0.133)$ & $(0.030)$ & $(0.304)$ \\
\hline \multirow[t]{2}{*}{ HH size } & 0.003 & -0.000 & -0.019 & $0.018^{*}$ & 0.114 \\
\hline & $(0.012)$ & $(0.012)$ & $(0.049)$ & $(0.010)$ & $(0.089)$ \\
\hline \multirow[t]{2}{*}{ Education (years) } & 0.006 & $0.017^{* * *}$ & 0.019 & 0.002 & $0.114^{* *}$ \\
\hline & $(0.008)$ & $(0.005)$ & $(0.018)$ & $(0.006)$ & $(0.047)$ \\
\hline \multirow[t]{2}{*}{$\ln (\mathrm{HH}$ inc. $)$} & 0.029 & 0.040 & $0.450^{* * *}$ & -0.025 & 0.139 \\
\hline & $(0.031)$ & $(0.026)$ & $(0.093)$ & $(0.022)$ & $(0.189)$ \\
\hline No. individuals & 3,340 & 2,099 & 1,466 & 2,938 & 2,320 \\
\hline KP F-stat (1 ${ }^{\text {st }}$ st.) & 23.794 & 25.846 & 28.334 & 25.931 & 19.024 \\
\hline p(AR-Wald) & 0.014 & 0.096 & 0.000 & 0.013 & 0.039 \\
\hline Observations & 13,204 & 3,944 & 2,479 & 15,126 & 9,419 \\
\hline Region FE & Yes & Yes & Yes & Yes & Yes \\
\hline Reg. orig. FE & Yes & Yes & Yes & Yes & Yes \\
\hline Year FE & Yes & Yes & Yes & Yes & Yes \\
\hline
\end{tabular}

$(* * *, * *, *) \Leftrightarrow$ significant at the $1 \%, 5 \%$, and $10 \%$-level, respectively. Standard errors clustered at the individual level in parentheses. "KP F-stat" denotes the Kleibergen-Paap F-statistic of a test of instrument relevance in the first stage (adjusted for clustering). " $p$ (AR-Wald)" contains the p-values of an Anderson and Rubin (1949) Wald test robust to weak identification. 
Table B.13: Full table of instrumental variable estimates for trust and cooperative/pro-social behavior in the SHP data in Table 2 - II

\begin{tabular}{|c|c|c|c|c|c|}
\hline & (1) & (2) & (3) & (4) & (5) \\
\hline & Envir. org. member & Buy eco-friendly & Buy seasonal fruit/veg. & More envir. spending & Environment $>$ growth \\
\hline \multirow[t]{2}{*}{ Trust } & $0.144^{* * *}$ & $0.501^{* *}$ & 0.299 & $0.095^{* *}$ & 0.088 \\
\hline & $(0.043)$ & $(0.236)$ & $(0.199)$ & $(0.044)$ & $(0.065)$ \\
\hline \multirow[t]{2}{*}{ Age } & 0.003 & $0.058 * *$ & $0.074^{* * *}$ & 0.000 & $-0.013^{* * *}$ \\
\hline & $(0.003)$ & $(0.023)$ & $(0.021)$ & $(0.005)$ & $(0.005)$ \\
\hline \multirow[t]{2}{*}{$\mathrm{Age}^{2}$} & -0.000 & $-0.001^{* * *}$ & $-0.000^{* * *}$ & -0.000 & $0.000^{*}$ \\
\hline & $(0.000)$ & $(0.000)$ & $(0.000)$ & $(0.000)$ & $(0.000)$ \\
\hline \multirow[t]{2}{*}{ Male } & 0.014 & $-0.321^{* *}$ & $-0.541^{* * *}$ & -0.037 & $-0.098^{* * *}$ \\
\hline & $(0.021)$ & $(0.128)$ & $(0.109)$ & $(0.026)$ & $(0.030)$ \\
\hline \multirow[t]{2}{*}{ Unemployed } & 0.029 & -0.407 & -0.056 & -0.022 & $-0.125^{*}$ \\
\hline & $(0.043)$ & $(0.316)$ & $(0.348)$ & $(0.074)$ & $(0.065)$ \\
\hline \multirow[t]{2}{*}{ Out of labor force } & 0.005 & -0.063 & -0.071 & 0.039 & 0.011 \\
\hline & $(0.030)$ & $(0.161)$ & $(0.138)$ & $(0.033)$ & $(0.041)$ \\
\hline \multirow{2}{*}{ Full time } & -0.023 & -0.169 & $-0.246^{*}$ & -0.039 & -0.041 \\
\hline & $(0.028)$ & $(0.146)$ & $(0.126)$ & $(0.031)$ & $(0.036)$ \\
\hline \multirow[t]{2}{*}{ Married } & -0.041 & -0.127 & 0.193 & $-0.066^{* *}$ & 0.012 \\
\hline & $(0.026)$ & $(0.170)$ & $(0.139)$ & $(0.032)$ & $(0.035)$ \\
\hline \multirow[t]{2}{*}{ No. children } & -0.015 & -0.074 & 0.004 & $-0.022^{*}$ & 0.020 \\
\hline & $(0.011)$ & $(0.063)$ & $(0.050)$ & $(0.013)$ & $(0.015)$ \\
\hline \multirow[t]{2}{*}{ Divorced } & -0.037 & -0.299 & $-0.288^{*}$ & -0.041 & 0.012 \\
\hline & $(0.035)$ & $(0.203)$ & $(0.171)$ & $(0.041)$ & $(0.046)$ \\
\hline \multirow[t]{2}{*}{ HH size } & $0.019^{*}$ & -0.083 & -0.005 & 0.011 & 0.006 \\
\hline & $(0.011)$ & $(0.073)$ & $(0.060)$ & $(0.015)$ & $(0.016)$ \\
\hline \multirow{2}{*}{ Education (years) } & -0.003 & $0.100^{* * *}$ & 0.034 & $0.015^{* *}$ & 0.007 \\
\hline & $(0.006)$ & $(0.033)$ & $(0.028)$ & $(0.006)$ & $(0.009)$ \\
\hline \multirow[t]{2}{*}{$\ln (\mathrm{HH}$ inc. $)$} & $-0.051^{*}$ & $0.267^{*}$ & $-0.249^{*}$ & -0.005 & $-0.107^{* * *}$ \\
\hline & $(0.027)$ & $(0.161)$ & $(0.139)$ & $(0.032)$ & $(0.037)$ \\
\hline No. individuals & 3,339 & 2,095 & 2,093 & 2,065 & 2,978 \\
\hline KP F-stat (1 ${ }^{\text {st }}$ st.) & 23.936 & 23.933 & 27.174 & 26.235 & 21.398 \\
\hline p(AR-Wald) & 0.000 & 0.041 & 0.130 & 0.029 & 0.167 \\
\hline Observations & 13,202 & 3,923 & 3,935 & 3,845 & 12,007 \\
\hline Region FE & Yes & Yes & Yes & Yes & Yes \\
\hline Reg. orig. FE & Yes & Yes & Yes & Yes & Yes \\
\hline Year FE & Yes & Yes & Yes & Yes & Yes \\
\hline
\end{tabular}


Table B.14: Inherited trust estimates by country of origin and age cohort

\begin{tabular}{|c|c|c|c|c|}
\hline & Country of origin & Cohort 1 (18-34) & Cohort $2(35-54)$ & Cohort $3(55+)$ \\
\hline 1 & Afghanistan & 5.119 & 4.430 & 5.936 \\
\hline 2 & Albania & 4.044 & 5.869 & 4.001 \\
\hline 3 & Algeria & 4.605 & 6.373 & 4.020 \\
\hline 4 & Argentina & 5.662 & 6.509 & \\
\hline 5 & Austria & 5.094 & 5.248 & 4.663 \\
\hline 6 & Belgium & 4.448 & 4.580 & 3.438 \\
\hline 7 & Bosnia-Herzegovina & 5.252 & 4.826 & \\
\hline 8 & Brazil & 3.081 & 3.596 & \\
\hline 9 & Canada & 4.573 & 4.781 & 4.556 \\
\hline 10 & China & 4.337 & 4.783 & \\
\hline 11 & Colombia & 4.658 & 2.902 & \\
\hline 12 & Croatia & 4.553 & 3.817 & 4.562 \\
\hline 13 & Czech Republic & 5.161 & 3.491 & 5.005 \\
\hline 14 & Denmark and territories & 5.692 & 5.855 & 5.672 \\
\hline 15 & Egypt & 4.001 & 5.506 & 5.141 \\
\hline 16 & Finland & 5.673 & 4.788 & 5.639 \\
\hline 17 & France and territories & 4.283 & 4.401 & 4.744 \\
\hline 18 & Germany & 5.365 & 5.167 & 4.681 \\
\hline 19 & Greece & 3.360 & 5.268 & 4.537 \\
\hline 20 & Hungary & 4.607 & 4.774 & 5.504 \\
\hline 21 & India & 5.173 & 5.179 & \\
\hline 22 & Italy & 4.139 & 4.630 & 4.068 \\
\hline 23 & Japan & 4.610 & 5.457 & \\
\hline 24 & Kosovo & 4.051 & 6.471 & \\
\hline 25 & Lebanon & 3.641 & 6.243 & \\
\hline 26 & Liechtenstein & 4.958 & 5.558 & 5.171 \\
\hline 27 & Macedonia (Ex-Republic of Yugoslavia) & 4.119 & 5.176 & \\
\hline 28 & Malaysia & 7.002 & 7.786 & \\
\hline 29 & Morocco & 5.789 & 2.976 & \\
\hline 30 & Mexico & 4.511 & 4.266 & 4.266 \\
\hline 31 & Netherlands and territories & 6.366 & 5.615 & 5.612 \\
\hline 32 & Peru & 4.848 & & \\
\hline 33 & Philippines & 2.148 & 5.124 & 3.232 \\
\hline 34 & Poland & 4.358 & 5.488 & 5.277 \\
\hline 35 & Portugal & 3.388 & 3.350 & \\
\hline 36 & Romania & 3.931 & 4.991 & 5.358 \\
\hline 37 & Russia & 4.430 & 4.751 & 1.174 \\
\hline 38 & Serbia & 3.800 & 4.762 & 3.804 \\
\hline 39 & Slovakia & 4.498 & 4.505 & 4.647 \\
\hline 40 & Slovenia & 5.996 & 5.908 & 5.883 \\
\hline 41 & Spain and territories & 3.879 & 4.894 & 4.391 \\
\hline 42 & Sri Lanka & 4.646 & 3.960 & \\
\hline 43 & Sweden & 4.633 & 4.488 & 6.637 \\
\hline 44 & Thailand & 5.503 & & \\
\hline 45 & Tunisia & 4.600 & 4.610 & \\
\hline 46 & Turkey & 4.510 & 4.752 & 5.658 \\
\hline 47 & United Kingdom and territories & 4.729 & 5.624 & 4.050 \\
\hline 48 & United States and territories & 4.883 & 5.819 & 4.836 \\
\hline 49 & Yugoslavia & 5.203 & 4.330 & \\
\hline
\end{tabular}

Age in year 2000 in parentheses. All cells represent averages across individual estimates. Empty cells denote missing values due to insufficient observations for estimation purposes. 


\section{B.5 Robustness tests}

In this section, we present the battery of robustness tests applied to the SHP data. The corresponding estimates are presented in Figures B.4 and B.5 and Tables B.15, B.16, B.21, and B.22.

As per standard procedure, we start by presenting the analyses testing the robustness of our findings on the trust-income and trust-well-being relationships to the inclusion of additional controls, in particular related to other forms of trust and religious attitudes as well as the big five personality attributes. Figures B.4 and B.5 provide the corresponding estimates, which confirm our previous findings. Next, we turn to the relationship between trust and cooperative attitudes/behaviors. Tables B.15 and B.16 show that also our results are robust to the inclusion of the abovementioned additional variables, despite the smaller sample size that some covariates engender (which we partly correct by taking the reported value by the same individual in the wave closest to the year in question when a value is absent for variables such as religion and personality questions). The use of additional controls in the IV approach also does not affect our results. Tables B.17, B.18, B.19, and B.20 provide the corresponding estimates.

As for the ESS data, our findings are also robust to the use of non-linear models, as shown by Tables B.21 and B.22, which provide ordered probit and logit estimates for trust and life satisfaction. That is, also in the case of the SHP data, the observed positive relationship does not depend on the imposed interval scale of the life satisfaction variable in our baseline regressions.

Based on the SHP data, and very much like in the case of the ESS data, increasing trust by 1 point is projected to increase the probability of being in the highest life satisfaction category by about $1.2-1.3 \%$ on average. 
Finally, we confirm once more that our findings are robust to a last specification change and show, in Figure B.6 and Table B.23, that the use of sampling weights does not affect our estimates in a qualitatively or quantitatively meaningful way.

\section{B.5.1 Additional control variables}
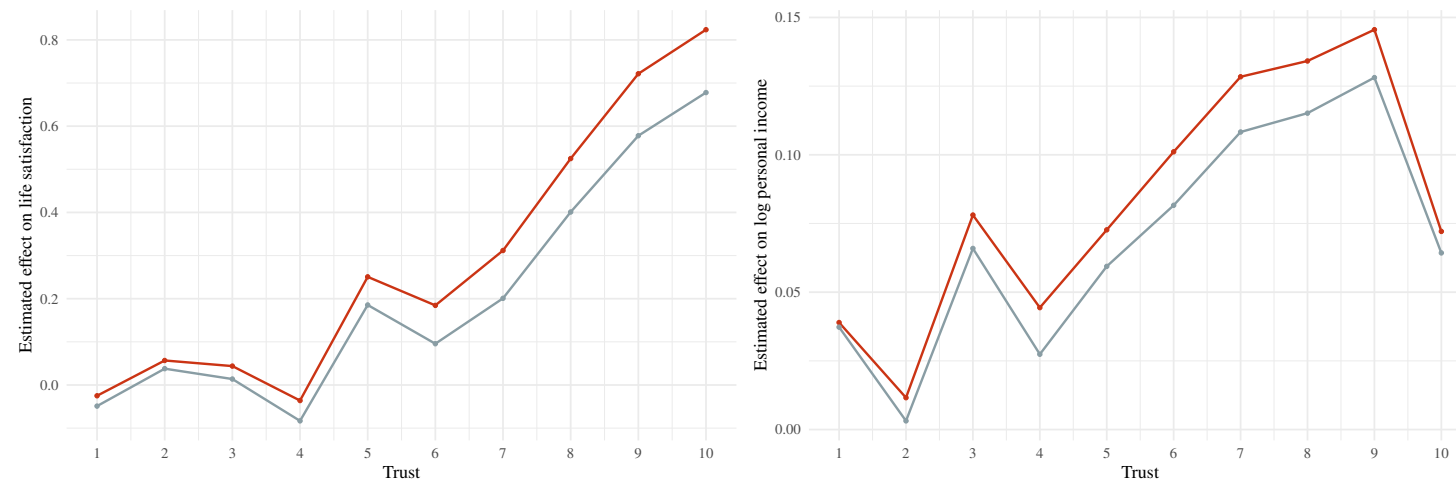

Figure B.4: Trust and life satisfaction (left) and log personal income (right) in the SHP data.

The top line is the baseline (red, based on a regression using the same variables as in Figure 1b) and the gray line below is based on additional controls for the level or trust in the government (10 trust-level dummies), religion (Catholic, Protestant, Muslim, Atheist or other), and the frequency of church attendance. Both regressions in each plot are based on the same observations and use cross-sectional sampling weights.
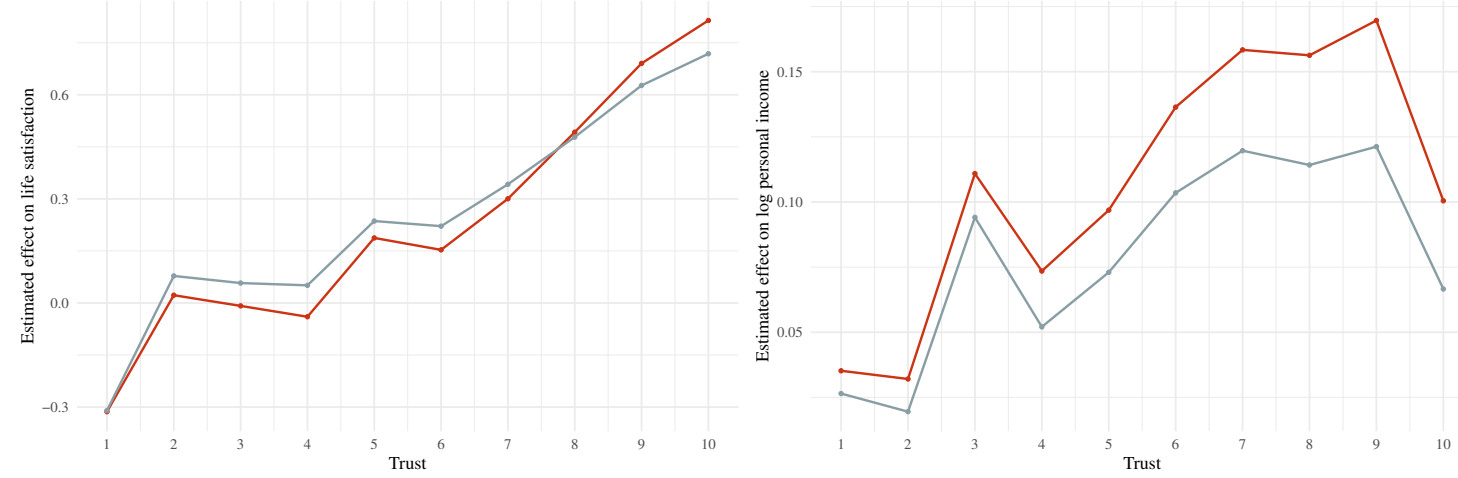

Figure B.5: Trust and life satisfaction (left) and log personal income (right) in the SHP data.

The red line is the baseline (based on a regression using the same variables as in Figure 1b) and the gray line is based on additional controls for 10 items covering the big five personality dimensions (openness, neuroticism, agreeableness, extraversion, conscientiousness). Both regressions in each plot are based on the same observations and use crosssectional sampling weights. 


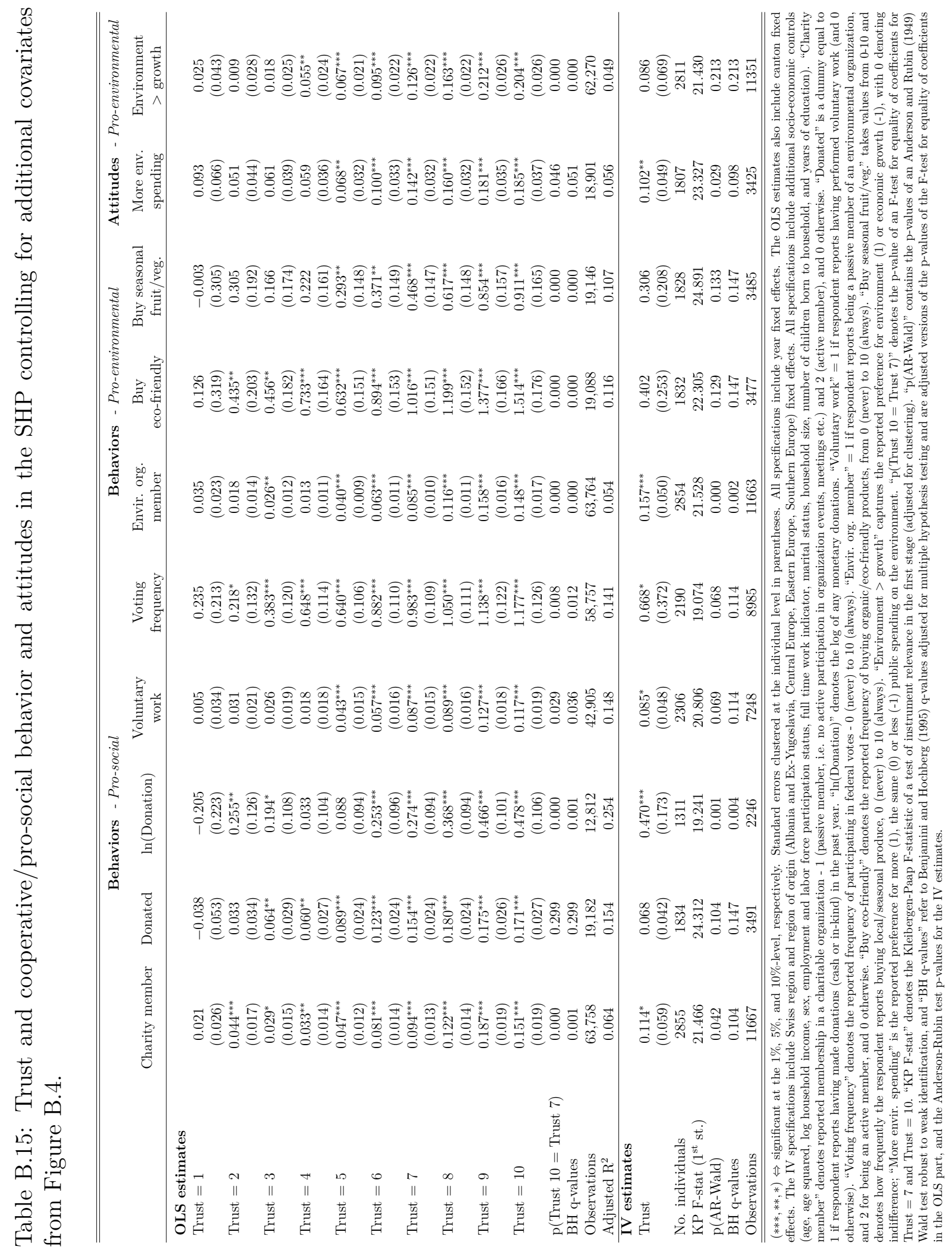




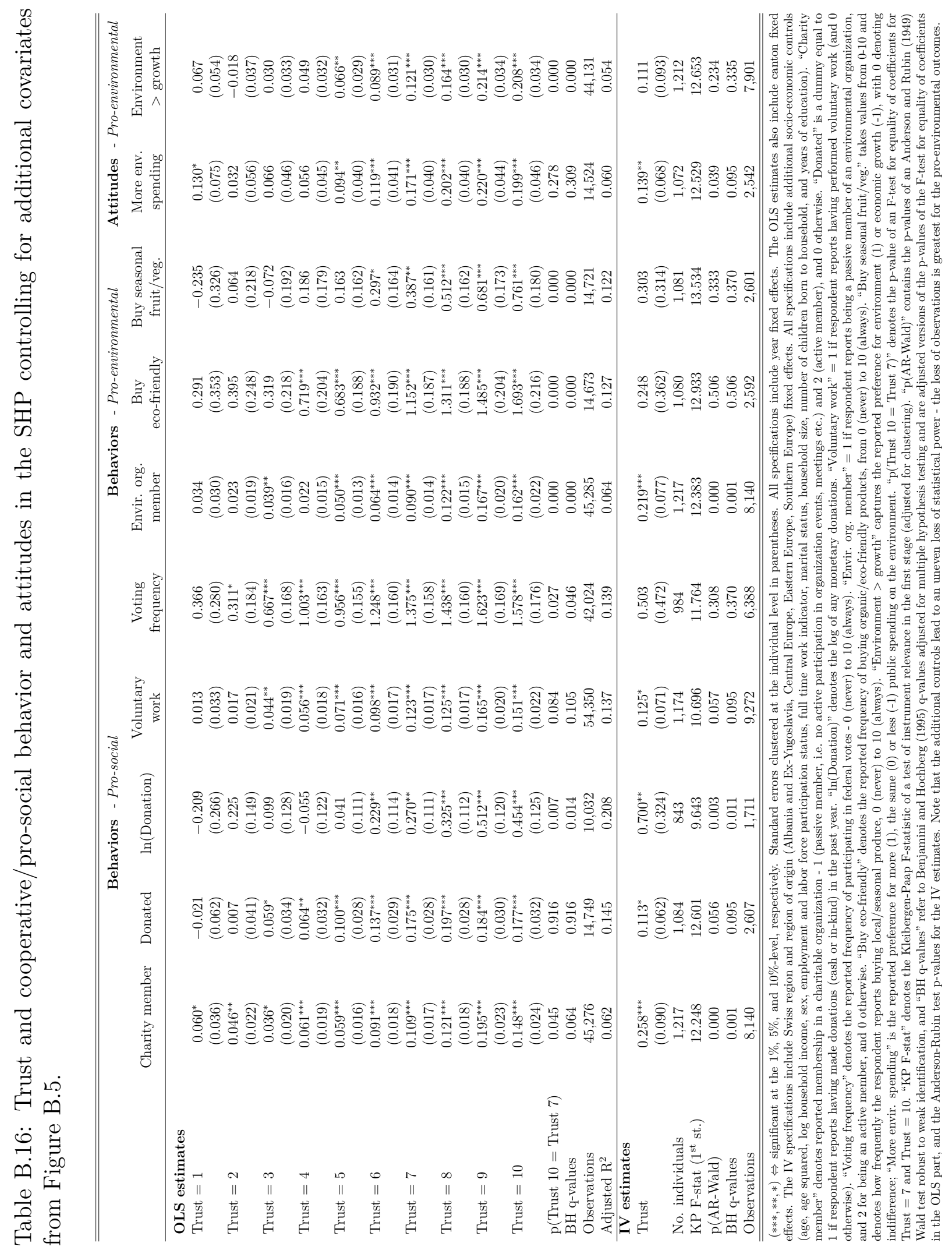




\section{B.5.2 Alternative specification for inherited trust instrument}

The instrument specifications used in this section follow the basic layout of the auxiliary regression detailed in equation 3 of Appendix B.2. However, the vector of covariates $X_{j t}$ has been limited to age, and age squared, while our main instrument is estimated including also education, log household income, labor force participation and religion (Christian, Muslim, Atheist or other) as additional controls. 
Table B.17: Instrumental variable first stage estimates for trust and cooperative/prosocial behavior in the SHP data using alternative inherited trust estimates

\begin{tabular}{|c|c|c|c|c|c|}
\hline & $\begin{array}{c}(1) \\
\text { Charity member }\end{array}$ & $\begin{array}{c}(2) \\
\text { Donated }\end{array}$ & $\begin{array}{c}(3) \\
\ln (\text { Donation })\end{array}$ & $\begin{array}{c}(4) \\
\text { Voluntary work }\end{array}$ & $\begin{array}{c}(5) \\
\text { Voting frequency }\end{array}$ \\
\hline Inherited trust & $\begin{array}{c}0.329^{* * *} \\
(0.076)\end{array}$ & $\begin{array}{c}0.366^{* * *} \\
(0.095)\end{array}$ & $\begin{array}{c}0.545^{* * *} \\
(0.099)\end{array}$ & $\begin{array}{c}0.328^{* * *} \\
(0.072)\end{array}$ & $\begin{array}{c}0.315^{* * *} \\
(0.093)\end{array}$ \\
\hline Age & $\begin{array}{l}-0.008 \\
(0.016)\end{array}$ & $\begin{array}{l}-0.007 \\
(0.020)\end{array}$ & $\begin{array}{l}-0.009 \\
(0.023)\end{array}$ & $\begin{array}{l}-0.019 \\
(0.015)\end{array}$ & $\begin{array}{l}-0.004 \\
(0.019)\end{array}$ \\
\hline $\mathrm{Age}^{2}$ & $\begin{array}{c}0.000 \\
(0.000)\end{array}$ & $\begin{array}{c}0.000 \\
(0.000)\end{array}$ & $\begin{array}{c}0.000 \\
(0.000)\end{array}$ & $\begin{array}{l}0.000^{*} \\
(0.000)\end{array}$ & $\begin{array}{c}0.000 \\
(0.000)\end{array}$ \\
\hline Male & $\begin{array}{l}-0.125 \\
(0.090)\end{array}$ & $\begin{array}{l}-0.148 \\
(0.106)\end{array}$ & $\begin{array}{l}-0.233^{*} \\
(0.122)\end{array}$ & $\begin{array}{c}-0.203^{* *} \\
(0.088)\end{array}$ & $\begin{array}{l}-0.128 \\
(0.106)\end{array}$ \\
\hline Unemployed & $\begin{array}{c}-0.457^{* *} \\
(0.181)\end{array}$ & $\begin{array}{l}-0.349 \\
(0.309)\end{array}$ & $\begin{array}{l}-0.503 \\
(0.458)\end{array}$ & $\begin{array}{c}-0.566^{* * *} \\
(0.184)\end{array}$ & $\begin{array}{l}-0.421^{*} \\
(0.225)\end{array}$ \\
\hline Out of labor force & $\begin{array}{c}-0.412^{* * *} \\
(0.102)\end{array}$ & $\begin{array}{c}-0.264^{* *} \\
(0.124)\end{array}$ & $\begin{array}{c}-0.293^{* *} \\
(0.145)\end{array}$ & $\begin{array}{c}-0.419^{* * *} \\
(0.097)\end{array}$ & $\begin{array}{c}-0.387^{* * * *} \\
(0.120)\end{array}$ \\
\hline Full time & $\begin{array}{c}-0.352^{* * *} \\
(0.097)\end{array}$ & $\begin{array}{c}-0.252^{* *} \\
(0.120)\end{array}$ & $\begin{array}{l}-0.121 \\
(0.136)\end{array}$ & $\begin{array}{c}-0.379^{* * *} \\
(0.098)\end{array}$ & $\begin{array}{c}-0.410^{* * *} \\
(0.113)\end{array}$ \\
\hline Married & $\begin{array}{c}0.051 \\
(0.118)\end{array}$ & $\begin{array}{l}0.075 \\
(0.145)\end{array}$ & $\begin{array}{l}0.112 \\
(0.163)\end{array}$ & $\begin{array}{c}0.083 \\
(0.119)\end{array}$ & $\begin{array}{c}0.101 \\
(0.143)\end{array}$ \\
\hline No. children & $\begin{array}{c}0.111^{* * *} \\
(0.042)\end{array}$ & $\begin{array}{l}0.104^{*} \\
(0.056)\end{array}$ & $\begin{array}{l}0.123^{* *} \\
(0.059)\end{array}$ & $\begin{array}{c}0.120^{* * *} \\
(0.044)\end{array}$ & $\begin{array}{c}0.134^{* * *} \\
(0.047)\end{array}$ \\
\hline Divorced & $\begin{array}{l}-0.046 \\
(0.158)\end{array}$ & $\begin{array}{l}-0.007 \\
(0.187)\end{array}$ & $\begin{array}{l}-0.049 \\
(0.210)\end{array}$ & $\begin{array}{c}0.001 \\
(0.156)\end{array}$ & $\begin{array}{l}-0.163 \\
(0.193)\end{array}$ \\
\hline HH size & $\begin{array}{c}-0.120^{* * *} \\
(0.041)\end{array}$ & $\begin{array}{c}-0.137^{* *} \\
(0.059)\end{array}$ & $\begin{array}{l}-0.125^{*} \\
(0.070)\end{array}$ & $\begin{array}{c}-0.144^{* * *} \\
(0.045)\end{array}$ & $\begin{array}{c}-0.161^{* * *} \\
(0.046)\end{array}$ \\
\hline Education (years) & $\begin{array}{c}0.120^{* * *} \\
(0.013)\end{array}$ & $\begin{array}{c}0.107^{* * *} \\
(0.015)\end{array}$ & $\begin{array}{c}0.090^{* * *} * \\
(0.017)\end{array}$ & $\begin{array}{c}0.120^{* * *} \\
(0.013)\end{array}$ & $\begin{array}{c}0.114^{* * *} \\
(0.016)\end{array}$ \\
\hline $\ln (\mathrm{HH}$ inc.) & $\begin{array}{c}0.445^{* * *} \\
(0.075)\end{array}$ & $\begin{array}{c}0.498^{* * *} \\
(0.098)\end{array}$ & $\begin{array}{c}0.314^{* * *} \\
(0.111)\end{array}$ & $\begin{array}{c}0.412^{* * *} \\
(0.074)\end{array}$ & $\begin{array}{c}0.420^{* * *} \\
(0.087)\end{array}$ \\
\hline No. individuals & 3,343 & 2,101 & 1,467 & 2,941 & 2,321 \\
\hline KP F-stat (1 ${ }^{\text {st }}$ st.) & 18.578 & 14.975 & 30.086 & 20.893 & 11.509 \\
\hline $\mathrm{R}^{2}$ & 0.100 & 0.108 & 0.086 & 0.104 & 0.083 \\
\hline Observations & 13,218 & 3,948 & 2,480 & 15,139 & 9,428 \\
\hline Region FE & Yes & Yes & Yes & Yes & Yes \\
\hline Reg. orig. FE & Yes & Yes & Yes & Yes & Yes \\
\hline Year FE & Yes & Yes & Yes & Yes & Yes \\
\hline
\end{tabular}

$(* * *, * *, *) \Leftrightarrow$ significant at the $1 \%, 5 \%$, and $10 \%$-level, respectively. Standard errors clustered at the individual level in parentheses. "KP F-stat" denotes the Kleibergen-Paap F-statistic of a test of instrument relevance in the first stage (adjusted for clustering). 
Table B.18: Instrumental variable first stage estimates for trust and cooperative/prosocial behavior in the SHP data using alternative inherited trust estimates II

\begin{tabular}{|c|c|c|c|c|c|}
\hline & $\begin{array}{l}\text { (1) } \\
\text { Envir. org. member }\end{array}$ & $\begin{array}{c}(2) \\
\text { Buy eco-friendly }\end{array}$ & $\begin{array}{c}\text { (3) } \\
\text { Buy seasonal fruit/veg. }\end{array}$ & $\begin{array}{c}\text { (4) } \\
\text { More envir. spending }\end{array}$ & $\begin{array}{l}(5) \\
\text { Env. protect. }\end{array}$ \\
\hline Inherited trust & $0.330^{* * *}$ & $0.348^{* * *}$ & $0.370^{* * *}$ & $0.360^{* * *}$ & $0.319^{* * *}$ \\
\hline & $(0.076)$ & $(0.095)$ & $(0.095)$ & $(0.096)$ & $(0.081)$ \\
\hline Age & $\begin{array}{l}-0.008 \\
(0.016)\end{array}$ & $\begin{array}{l}-0.002 \\
(0.020)\end{array}$ & $\begin{array}{l}-0.003 \\
(0.020)\end{array}$ & $\begin{array}{l}-0.001 \\
(0.020)\end{array}$ & $\begin{array}{l}-0.000 \\
(0.017)\end{array}$ \\
\hline $\mathrm{Age}^{2}$ & $\begin{array}{c}0.000 \\
(0.000)\end{array}$ & $\begin{array}{l}0.000 \\
(0.000)\end{array}$ & $\begin{array}{c}0.000 \\
(0.000)\end{array}$ & $\begin{array}{l}0.000 \\
(0.000)\end{array}$ & $\begin{array}{l}0.000 \\
(0.000)\end{array}$ \\
\hline Male & $\begin{array}{l}-0.124 \\
(0.090)\end{array}$ & $\begin{array}{l}-0.159 \\
(0.106)\end{array}$ & $\begin{array}{l}-0.145 \\
(0.105)\end{array}$ & $\begin{array}{l}-0.152 \\
(0.106)\end{array}$ & $\begin{array}{l}-0.144 \\
(0.094)\end{array}$ \\
\hline Unemployed & $\begin{array}{c}-0.457^{* *} \\
(0.181)\end{array}$ & $\begin{array}{l}-0.278 \\
(0.303)\end{array}$ & $\begin{array}{l}-0.292 \\
(0.302)\end{array}$ & $\begin{array}{l}-0.346 \\
(0.307)\end{array}$ & $\begin{array}{c}-0.397^{* *} \\
(0.193)\end{array}$ \\
\hline Out of labor force & $\begin{array}{c}-0.413^{* * *} \\
(0.102)\end{array}$ & $\begin{array}{c}-0.250^{* *} \\
(0.124)\end{array}$ & $\begin{array}{c}-0.246^{* *} \\
(0.124)\end{array}$ & $\begin{array}{c}-0.252^{* *} \\
(0.125)\end{array}$ & $\begin{array}{c}-0.396^{* * *} \\
(0.108)\end{array}$ \\
\hline Full time & $\begin{array}{c}-0.351^{* * *} \\
(0.097)\end{array}$ & $\begin{array}{c}-0.270^{* *} \\
(0.120)\end{array}$ & $\begin{array}{c}-0.257^{* *} \\
(0.120)\end{array}$ & $\begin{array}{c}-0.275^{* *} \\
(0.120)\end{array}$ & $\begin{array}{c}-0.338^{* * *} \\
(0.102)\end{array}$ \\
\hline Married & $\begin{array}{c}0.052 \\
(0.118)\end{array}$ & $\begin{array}{l}0.084 \\
(0.144)\end{array}$ & $\begin{array}{c}0.087 \\
(0.144)\end{array}$ & $\begin{array}{c}0.094 \\
(0.146)\end{array}$ & $\begin{array}{c}0.041 \\
(0.124)\end{array}$ \\
\hline No. children & $\begin{array}{c}0.111^{* * *} \\
(0.042)\end{array}$ & $\begin{array}{l}0.093^{*} \\
(0.056)\end{array}$ & $\begin{array}{l}0.108^{*} \\
(0.056)\end{array}$ & $\begin{array}{l}0.107^{*} \\
(0.056)\end{array}$ & $\begin{array}{c}0.117^{* * *} \\
(0.043)\end{array}$ \\
\hline Divorced & $\begin{array}{l}-0.046 \\
(0.158)\end{array}$ & $\begin{array}{c}0.032 \\
(0.185)\end{array}$ & $\begin{array}{l}-0.006 \\
(0.187)\end{array}$ & $\begin{array}{l}0.016 \\
(0.190)\end{array}$ & $\begin{array}{l}-0.076 \\
(0.168)\end{array}$ \\
\hline HH size & $\begin{array}{c}-0.120^{* * *} \\
(0.041)\end{array}$ & $\begin{array}{c}-0.138^{* *} \\
(0.060)\end{array}$ & $\begin{array}{c}-0.142^{* *} \\
(0.060)\end{array}$ & $\begin{array}{c}-0.150^{* *} \\
(0.060)\end{array}$ & $\begin{array}{c}-0.128^{* * *} \\
(0.043)\end{array}$ \\
\hline Education (years) & $\begin{array}{c}0.120^{* * *} \\
(0.013)\end{array}$ & $\begin{array}{c}0.108^{* * *} \\
(0.015)\end{array}$ & $\begin{array}{c}0.107^{* * *} \\
(0.015)\end{array}$ & $\begin{array}{c}0.102^{* * *} \\
(0.015)\end{array}$ & $\begin{array}{c}0.117^{* * *} \\
(0.014)\end{array}$ \\
\hline $\ln$ (HH inc.) & $\begin{array}{c}0.445^{* * *} \\
(0.075)\end{array}$ & $\begin{array}{c}0.493^{* * *} \\
(0.098)\end{array}$ & $\begin{array}{c}0.509 * * * \\
(0.097)\end{array}$ & $\begin{array}{c}0.474^{* * *} \\
(0.100)\end{array}$ & $\begin{array}{c}0.452^{* * *} \\
(0.079)\end{array}$ \\
\hline No. individuals & 3,342 & 2,097 & 2,095 & 2,067 & 2,981 \\
\hline KP F-stat (1 ${ }^{\text {st }}$ st.) & 18.693 & 13.438 & 15.225 & 14.081 & 15.478 \\
\hline $\mathrm{R}^{2}$ & 0.100 & 0.107 & 0.110 & 0.104 & 0.099 \\
\hline Observations & 13,216 & 3,927 & 3,939 & 3,849 & 12,019 \\
\hline Region FE & Yes & Yes & Yes & Yes & Yes \\
\hline Reg. orig. FE & Yes & Yes & Yes & Yes & Yes \\
\hline Year FE & Yes & Yes & Yes & Yes & Yes \\
\hline
\end{tabular}

$(* * *, * *, *) \Leftrightarrow$ significant at the $1 \%, 5 \%$, and $10 \%$-level, respectively. Standard errors clustered at the individual level in parentheses. "KP F-stat" denotes the Kleibergen-Paap F-statistic of a test of instrument relevance in the first stage (adjusted for clustering). 
Table B.19: Table of instrumental variable estimates for trust and cooperative/prosocial behavior in the SHP data using alternative inherited trust estimates

\begin{tabular}{|c|c|c|c|c|c|}
\hline & (1) & $(2)$ & $(3)$ & $\begin{array}{l}\text { (4) } \\
\text { Voluntarv work }\end{array}$ & $\begin{array}{c}(5) \\
\text { Votino freguncy }\end{array}$ \\
\hline \multirow[t]{2}{*}{ Trust } & $0.146^{* * *}$ & $0.083^{*}$ & $0.442^{* * *}$ & $0.097^{* *}$ & $0.798^{*}$ \\
\hline & $(0.056)$ & $(0.049)$ & $(0.136)$ & $(0.042)$ & $(0.412)$ \\
\hline \multirow[t]{2}{*}{ Age } & $0.015^{* * *}$ & $0.017^{* * *}$ & 0.018 & $0.010 * * *$ & $0.058^{* *}$ \\
\hline & $(0.004)$ & $(0.004)$ & $(0.018)$ & $(0.003)$ & $(0.028)$ \\
\hline \multirow{2}{*}{$\operatorname{Age}^{2}$} & $-0.000^{* * *}$ & $-0.000 * * *$ & 0.000 & $-0.000^{* * *}$ & -0.000 \\
\hline & $(0.000)$ & $(0.000)$ & $(0.000)$ & $(0.000)$ & $(0.000)$ \\
\hline \multirow[t]{2}{*}{ Male } & -0.018 & $-0.050^{* *}$ & $0.227^{* * *}$ & $0.069^{* * *}$ & $0.585^{* * *}$ \\
\hline & $(0.023)$ & $(0.020)$ & $(0.087)$ & $(0.020)$ & $(0.166)$ \\
\hline \multirow[t]{2}{*}{ Unemployed } & -0.002 & $-0.127^{* *}$ & -0.168 & 0.056 & 0.213 \\
\hline & $(0.048)$ & $(0.061)$ & $(0.236)$ & $(0.042)$ & $(0.317)$ \\
\hline \multirow[t]{2}{*}{ Out of labor force } & 0.045 & $-0.053^{*}$ & -0.071 & 0.014 & $0.508^{* *}$ \\
\hline & $(0.037)$ & $(0.028)$ & $(0.103)$ & $(0.026)$ & $(0.249)$ \\
\hline \multirow[t]{2}{*}{ Full time } & -0.018 & -0.010 & 0.122 & -0.035 & -0.102 \\
\hline & $(0.031)$ & $(0.026)$ & $(0.094)$ & $(0.025)$ & $(0.238)$ \\
\hline \multirow[t]{2}{*}{ Married } & $-0.069^{* *}$ & -0.011 & 0.038 & 0.038 & 0.284 \\
\hline & $(0.029)$ & $(0.026)$ & $(0.114)$ & $(0.024)$ & $(0.209)$ \\
\hline \multirow[t]{2}{*}{ No. children } & 0.003 & -0.017 & -0.063 & $0.016^{*}$ & -0.135 \\
\hline & $(0.012)$ & $(0.010)$ & $(0.041)$ & $(0.010)$ & $(0.088)$ \\
\hline \multirow[t]{2}{*}{ Divorced } & $-0.102^{* * *}$ & -0.041 & 0.003 & $-0.058^{*}$ & $-0.815^{* * *}$ \\
\hline & $(0.038)$ & $(0.033)$ & $(0.132)$ & $(0.030)$ & $(0.310)$ \\
\hline \multirow[t]{2}{*}{ HH size } & 0.006 & 0.003 & -0.022 & $0.018^{*}$ & 0.126 \\
\hline & $(0.012)$ & $(0.013)$ & $(0.048)$ & $(0.010)$ & $(0.096)$ \\
\hline \multirow[t]{2}{*}{ Education (years) } & 0.003 & $0.015^{* *}$ & 0.020 & 0.002 & $0.106^{* *}$ \\
\hline & $(0.008)$ & $(0.006)$ & $(0.018)$ & $(0.006)$ & $(0.053)$ \\
\hline \multirow[t]{2}{*}{$\ln (\mathrm{HH}$ inc. $)$} & 0.017 & 0.029 & $0.455^{* * *}$ & -0.025 & 0.108 \\
\hline & $(0.033)$ & $(0.031)$ & $(0.090)$ & $(0.023)$ & $(0.209)$ \\
\hline No. individuals & 3,343 & 2,101 & 1,467 & 2,941 & 2,321 \\
\hline KP F-stat (1 ${ }^{\text {st }}$ st.) & 18.578 & 14.975 & 30.086 & 20.893 & 11.509 \\
\hline $\mathrm{p}(\mathrm{AR}-$ Wald $)$ & 0.002 & 0.056 & 0.000 & 0.014 & 0.042 \\
\hline Observations & 13,218 & 3,948 & 2,480 & 15,139 & 9,428 \\
\hline Region FE & Yes & Yes & Yes & Yes & Yes \\
\hline Reg. orig. FE & Yes & Yes & Yes & Yes & Yes \\
\hline Year FE & Yes & Yes & Yes & Yes & Yes \\
\hline
\end{tabular}

$(* * *, * *, *) \Leftrightarrow$ significant at the $1 \%, 5 \%$, and $10 \%$-level, respectively. Standard errors clustered at the individual level in parentheses. "KP F-stat" denotes the Kleibergen-Paap F-statistic of a test of instrument relevance in the first stage (adjusted for clustering). " $p$ (AR-Wald)" contains the p-values of an Anderson and Rubin (1949) Wald test robust to weak identification. 
Table B.20: Instrumental variable estimates for trust and cooperative/pro-social behavior in the SHP data using alternative inherited trust estimates - II

\begin{tabular}{|c|c|c|c|c|c|}
\hline & $\begin{array}{c}\text { (1) } \\
\text { Envir. org. member }\end{array}$ & $\begin{array}{c}(2) \\
\text { Buy eco-friendly }\end{array}$ & $\begin{array}{c}(3) \\
\text { Buy seasonal fruit/veg. }\end{array}$ & $\begin{array}{l}\text { (4) } \\
\text { More envir. spending }\end{array}$ & $\begin{array}{l}(5) \\
\text { Env. protect. }\end{array}$ \\
\hline \multirow[t]{2}{*}{ Trust } & $0.156^{* * *}$ & $0.509^{* *}$ & 0.363 & $0.101^{* *}$ & 0.080 \\
\hline & $(0.045)$ & $(0.256)$ & $(0.257)$ & $(0.050)$ & $(0.066)$ \\
\hline \multirow[t]{2}{*}{ Age } & 0.003 & $0.058^{* *}$ & $0.074^{* * *}$ & -0.000 & $-0.013^{* * *}$ \\
\hline & $(0.004)$ & $(0.023)$ & $(0.021)$ & $(0.005)$ & $(0.005)$ \\
\hline \multirow[t]{2}{*}{$\mathrm{Age}^{2}$} & -0.000 & $-0.001^{* * *}$ & $-0.001^{* * *}$ & -0.000 & $0.000^{*}$ \\
\hline & $(0.000)$ & $(0.000)$ & $(0.000)$ & $(0.000)$ & $(0.000)$ \\
\hline \multirow[t]{2}{*}{ Male } & 0.014 & $-0.321^{* *}$ & $-0.539 * * *$ & -0.036 & $-0.099 * * *$ \\
\hline & $(0.022)$ & $(0.128)$ & $(0.112)$ & $(0.026)$ & $(0.030)$ \\
\hline \multirow[t]{2}{*}{ Unemployed } & 0.035 & -0.403 & -0.031 & -0.019 & $-0.128^{*}$ \\
\hline & $(0.045)$ & $(0.316)$ & $(0.356)$ & $(0.075)$ & $(0.066)$ \\
\hline \multirow[t]{2}{*}{ Out of labor force } & 0.011 & -0.061 & -0.054 & 0.041 & 0.007 \\
\hline & $(0.031)$ & $(0.164)$ & $(0.147)$ & $(0.034)$ & $(0.041)$ \\
\hline \multirow[t]{2}{*}{ Full time } & -0.018 & -0.166 & $-0.224^{*}$ & -0.037 & -0.044 \\
\hline & $(0.029)$ & $(0.149)$ & $(0.136)$ & $(0.032)$ & $(0.036)$ \\
\hline \multirow[t]{2}{*}{ Married } & -0.043 & -0.127 & 0.180 & $-0.064^{* *}$ & 0.012 \\
\hline & $(0.027)$ & $(0.171)$ & $(0.143)$ & $(0.032)$ & $(0.035)$ \\
\hline \multirow[t]{2}{*}{ No. children } & -0.016 & -0.075 & 0.000 & $-0.023^{*}$ & 0.020 \\
\hline & $(0.011)$ & $(0.064)$ & $(0.053)$ & $(0.013)$ & $(0.015)$ \\
\hline \multirow[t]{2}{*}{ Divorced } & -0.036 & -0.298 & $-0.291^{*}$ & -0.040 & 0.011 \\
\hline & $(0.036)$ & $(0.204)$ & $(0.174)$ & $(0.042)$ & $(0.046)$ \\
\hline \multirow[t]{2}{*}{ HH size } & $0.020^{*}$ & -0.082 & 0.006 & 0.012 & 0.005 \\
\hline & $(0.011)$ & $(0.075)$ & $(0.066)$ & $(0.016)$ & $(0.016)$ \\
\hline \multirow[t]{2}{*}{ Education (years) } & -0.004 & $0.100^{* * *}$ & 0.028 & $0.014^{* *}$ & 0.008 \\
\hline & $(0.006)$ & $(0.034)$ & $(0.033)$ & $(0.006)$ & $(0.009)$ \\
\hline \multirow[t]{2}{*}{$\ln (\mathrm{HH}$ inc. $)$} & $-0.056^{* *}$ & 0.263 & $-0.287^{*}$ & -0.007 & $-0.103^{* * *}$ \\
\hline & $(0.029)$ & $(0.170)$ & $(0.167)$ & $(0.034)$ & $(0.037)$ \\
\hline No. individuals & 3,342 & 2,097 & 2,095 & 2,067 & 2,981 \\
\hline KP F-stat (1 ${ }^{\text {st }}$ st.) & 18.693 & 13.438 & 15.225 & 14.081 & 15.478 \\
\hline $\mathrm{p}(\mathrm{AR}-$ Wald $)$ & 0.000 & 0.065 & 0.108 & 0.075 & 0.236 \\
\hline Observations & 13,216 & 3,927 & 3,939 & 3,849 & 12,019 \\
\hline Region FE & Yes & Yes & Yes & Yes & Yes \\
\hline Reg. orig. FE & Yes & Yes & Yes & Yes & Yes \\
\hline Year FE & Yes & Yes & Yes & Yes & Yes \\
\hline
\end{tabular}




\section{B.5.3 Ordered probit/logit}

Table B.21: Ordered probit estimates for trust and life satisfaction in the SHP data

\begin{tabular}{|c|c|c|c|}
\hline & $\begin{array}{l}\text { Coef. } \\
(1)\end{array}$ & $\begin{array}{c}\text { ME on } \mathrm{p}(\mathrm{y}=10) \text { at mean } \\
(2)\end{array}$ & $\begin{array}{c}\text { Avg. ME on } \mathrm{p}(\mathrm{y}=10) \\
(3)\end{array}$ \\
\hline Trust & $0.0585^{* * *}(0.0015)$ & $0.0121^{* * *}(0.0003)$ & $0.0124^{* * *}(0.0003)$ \\
\hline Education & $0.6433^{* * *}(0.1641)$ & $0.1327^{* * *}(0.0339)$ & $0.1364^{* * *}(0.0348)$ \\
\hline Age & $-3.8417^{* * *}(0.7540)$ & $-0.7924^{* * *}(0.1556)$ & $-0.8145^{* * *}(0.1599)$ \\
\hline $\mathrm{Age}^{2}$ & $0.6986^{* * *}(0.0644)$ & $0.1441^{* * *}(0.0133)$ & $0.1481^{* * *}(0.0137)$ \\
\hline Male & $-0.1007^{* * *}(0.0075)$ & $-0.0208^{* * *}(0.0016)$ & $-0.0214^{* * *}(0.0016)$ \\
\hline Married & $0.2402^{* * *}(0.0101)$ & $0.0496^{* * *}(0.0021)$ & $0.0509^{* * *}(0.0021)$ \\
\hline Divorced & $-0.0800^{* * *}(0.0132)$ & $-0.0165^{* * *}(0.0027)$ & $-0.0170^{* * *}(0.0028)$ \\
\hline Unemployed & $-0.4735^{* * *}(0.0253)$ & $-0.0977^{* * *}(0.0052)$ & $-0.1004^{* * *}(0.0054)$ \\
\hline Married & $0.5209^{* * *}(0.0051)$ & $0.1075^{* * *}(0.0012)$ & $0.1104^{* * *}(0.0012)$ \\
\hline $\ln (\mathrm{HH}$ inc.) & $0.1298^{* * *}(0.0038)$ & $0.0268^{* * *}(0.0008)$ & $0.0275^{* * *}(0.0008)$ \\
\hline Out of labor force & $0.0445^{* * *}(0.0097)$ & $0.0092^{* * *}(0.0020)$ & $0.0094^{* * *}(0.0020)$ \\
\hline Full time & $0.0119(0.0090)$ & $0.0024(0.0019)$ & $0.0025(0.0019)$ \\
\hline In training & $0.0128(0.0176)$ & $0.0026(0.0036)$ & $0.0027(0.0037)$ \\
\hline HH size & $-0.0320^{* * *}(0.0037)$ & $-0.0066^{* * *}(0.0008)$ & $-0.0068^{* * *}(0.0008)$ \\
\hline No. children & $0.0164^{* * *}(0.0033)$ & $0.0034^{* * *}(0.0007)$ & $0.0035^{* * *}(0.0007)$ \\
\hline Pot. exp. & $2.7207^{* * *}(0.6568)$ & $0.5612^{* * *}(0.1355)$ & $0.5768^{* * *}(0.1393)$ \\
\hline Pot. exp. ${ }^{2}$ & $0.0366(0.0364)$ & $0.0076(0.0075)$ & $0.0078(0.0077)$ \\
\hline$\underline{\text { Recent death of relative }}$ & $-0.0069(0.0076)$ & $-0.0014(0.0016)$ & $-0.0015(0.0016)$ \\
\hline Threshold 1 (SE) & -0.9384 & $(0.0412)$ & \\
\hline Threshold 2 (SE) & -0.8393 & $(0.0399)$ & \\
\hline Threshold 3 (SE) & -0.6117 & $(0.0377)$ & \\
\hline Threshold 4 (SE) & -0.3295 & $(0.0362)$ & \\
\hline Threshold 5 (SE) & -0.0191 & $(0.0354)$ & \\
\hline Threshold 6 (SE) & 0.6151 & $(0.0349)$ & \\
\hline Threshold 7 (SE) & 0.9593 & $(0.0348)$ & \\
\hline Threshold 8 (SE) & 1.6692 & $(0.035)$ & \\
\hline Threshold 9 (SE) & 2.8188 & $(0.0354)$ & \\
\hline Threshold 10 (SE) & 3.5192 & $(0.0356)$ & \\
\hline$\underline{\mathrm{N}}$ & 109754 & & \\
\hline Canton dummies & Yes & Yes & Yes \\
\hline Year dummies & Yes & Yes & Yes \\
\hline
\end{tabular}

$(* * *, * *, *) \Leftrightarrow$ significant at the $1 \%, 5 \%$, and $10 \%$-level, respectively. Heteroskedasticity robust standard errors in parentheses. Age, age squared, household income, pot. experience, its square and education have been standardized (mean 0 and standard deviation of 1 ) before estimation. The thresholds refer to the values of the latent variable at which the outcome changes according to the fitted model (10 thresholds separating 11 ordered response categories). 
Table B.22: Ordered logit estimates for trust and life satisfaction in the SHP data

\begin{tabular}{|c|c|c|c|}
\hline & $\begin{array}{l}\text { Coef. } \\
(1)\end{array}$ & $\begin{array}{c}\text { ME on } \mathrm{p}(\mathrm{y}=10) \text { at mean } \\
(2)\end{array}$ & $\begin{array}{l}\text { Avg. ME on } \mathrm{p}(\mathrm{y}=10) \\
(3)\end{array}$ \\
\hline Trust & $0.1087^{* * *}(0.0027)$ & $0.0116^{* * *}(0.0003)$ & $0.0126^{* * *}(0.0003)$ \\
\hline Education & $1.1152^{* * *}(0.2742)$ & $0.1185^{* * *}(0.0291)$ & $0.1292^{* * *}(0.0318)$ \\
\hline Age & $-6.6627^{* * *}(1.2612)$ & $-0.7079^{* * *}(0.1340)$ & $-0.7721^{* * *}(0.1462)$ \\
\hline $\mathrm{Age}^{2}$ & $1.2417^{* * *}(0.1125)$ & $0.1319^{* * *}(0.0120)$ & $0.1439^{* * *}(0.0130)$ \\
\hline Male & $-0.1735^{* * *}(0.0131)$ & $-0.0184^{* * *}(0.0014)$ & $-0.0201^{* * *}(0.0015)$ \\
\hline Married & $0.4208^{* * *}(0.0177)$ & $0.0447^{* * *}(0.0019)$ & $0.0488^{* * *}(0.0021)$ \\
\hline Divorced & $-0.1432^{* * *}(0.0233)$ & $-0.0152^{* * *}(0.0025)$ & $-0.0166^{* * *}(0.0027)$ \\
\hline Unemployed & $-0.8741^{* * *}(0.0457)$ & $-0.0929^{* * *}(0.0049)$ & $-0.1013^{* * *}(0.0053)$ \\
\hline Married & $0.9338^{* * *}(0.0093)$ & $0.0992^{* * *}(0.0011)$ & $0.1082^{* * *}(0.0012)$ \\
\hline $\ln$ (HH inc.) & $0.2324^{* * *}(0.0068)$ & $0.0247^{* * *}(0.0007)$ & $0.0269^{* * *}(0.0008)$ \\
\hline Out of labor force & $0.0850^{* * *}(0.0169)$ & $0.0090^{* * *}(0.0018)$ & $0.0099^{* * *}(0.0020)$ \\
\hline Full time & $0.0242(0.0156)$ & $0.0026(0.0017)$ & $0.0028(0.0018)$ \\
\hline In training & $0.0241(0.0302)$ & $0.0026(0.0032)$ & $0.0028(0.0035)$ \\
\hline $\mathrm{HH}$ size & $-0.0585^{* * *}(0.0064)$ & $-0.0062^{* * *}(0.0007)$ & $-0.0068^{* * *}(0.0007)$ \\
\hline No. children & $0.0343^{* * *}(0.0059)$ & $0.0036^{* * *}(0.0006)$ & $0.0040^{* * *}(0.0007)$ \\
\hline Pot. exp. & $4.6680^{* * *}(1.0982)$ & $0.4959^{* * *}(0.1167)$ & $0.5409^{* * *}(0.1273)$ \\
\hline Pot. exp. ${ }^{2}$ & $0.0844(0.0637)$ & $0.0090(0.0068)$ & 0.0098 \\
\hline$\underline{\text { Recent death of relative }}$ & $-0.0117(0.0132)$ & $-0.0012(0.0014)$ & $-0.0014(0.0015)$ \\
\hline Threshold 1 (SE) & -2.3567 & $(0.0891)$ & \\
\hline Threshold 2 (SE) & -2.091 & $(0.0832)$ & \\
\hline Threshold 3 (SE) & -1.5086 & $(0.0739)$ & \\
\hline Threshold 4 (SE) & -0.8296 & $(0.0674)$ & \\
\hline Threshold 5 (SE) & -0.1252 & $(0.0638)$ & \\
\hline Threshold 6 (SE) & 1.2003 & $(0.0614)$ & \\
\hline Threshold 7 (SE) & 1.863 & $(0.0612)$ & \\
\hline Threshold 8 (SE) & 3.1266 & $(0.0615)$ & \\
\hline Threshold 9 (SE) & 5.0405 & $(0.0626)$ & \\
\hline Threshold 10 (SE) & 6.2604 & $(0.0633)$ & \\
\hline $\mathrm{N}$ & 109754 & & \\
\hline Canton dummies & Yes & Yes & Yes \\
\hline Year dummies & Yes & Yes & Yes \\
\hline
\end{tabular}

$\overline{(* * *, * *, *) \Leftrightarrow \text { significant at the } 1 \%, 5 \% \text {, and } 10 \% \text {-level, respectively. Heteroskedasticity robust standard errors in }}$ parentheses. Age, age squared, household income, pot. experience, its square and education have been standardized (mean 0 and standard deviation of 1 ) before estimation. The thresholds refer to the values of the latent variable at which the outcome changes according to the fitted model (10 thresholds separating 11 ordered response categories). 


\section{B.5.4 Sensitivity to sampling weights}
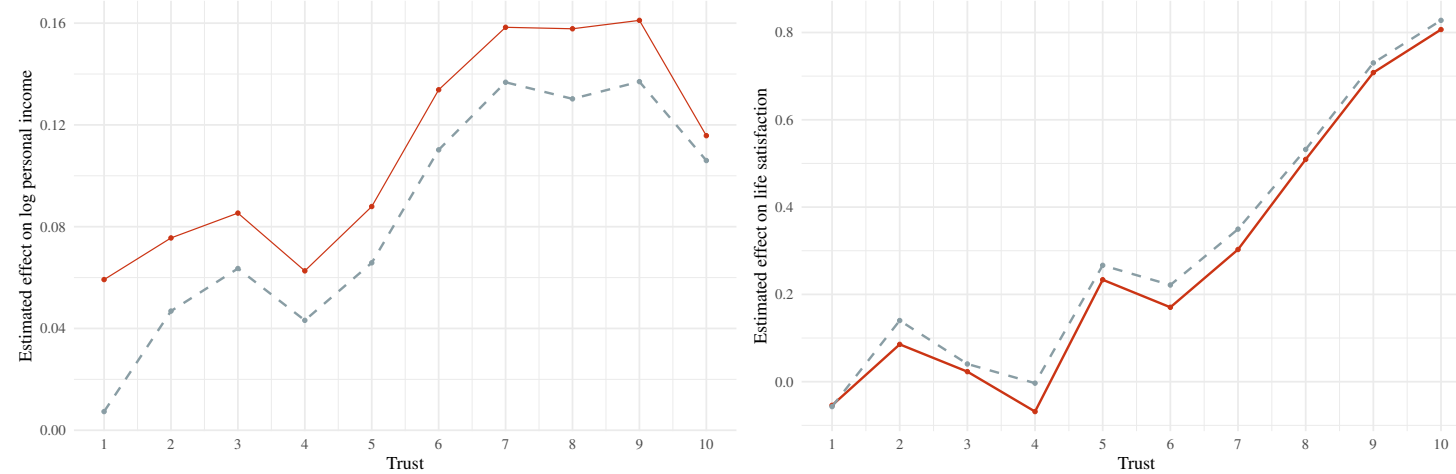

Figure B.6: Trust and income/life satisfaction with (solid) and without (dashed) cross-sectional sampling weights in the SHP data.

The left panel displays the estimated effects of trust on the log of personal income. The right panel shows an analogous graph for the trust-life satisfaction relationship. Regression specifications are the same as in Figure 1b. 


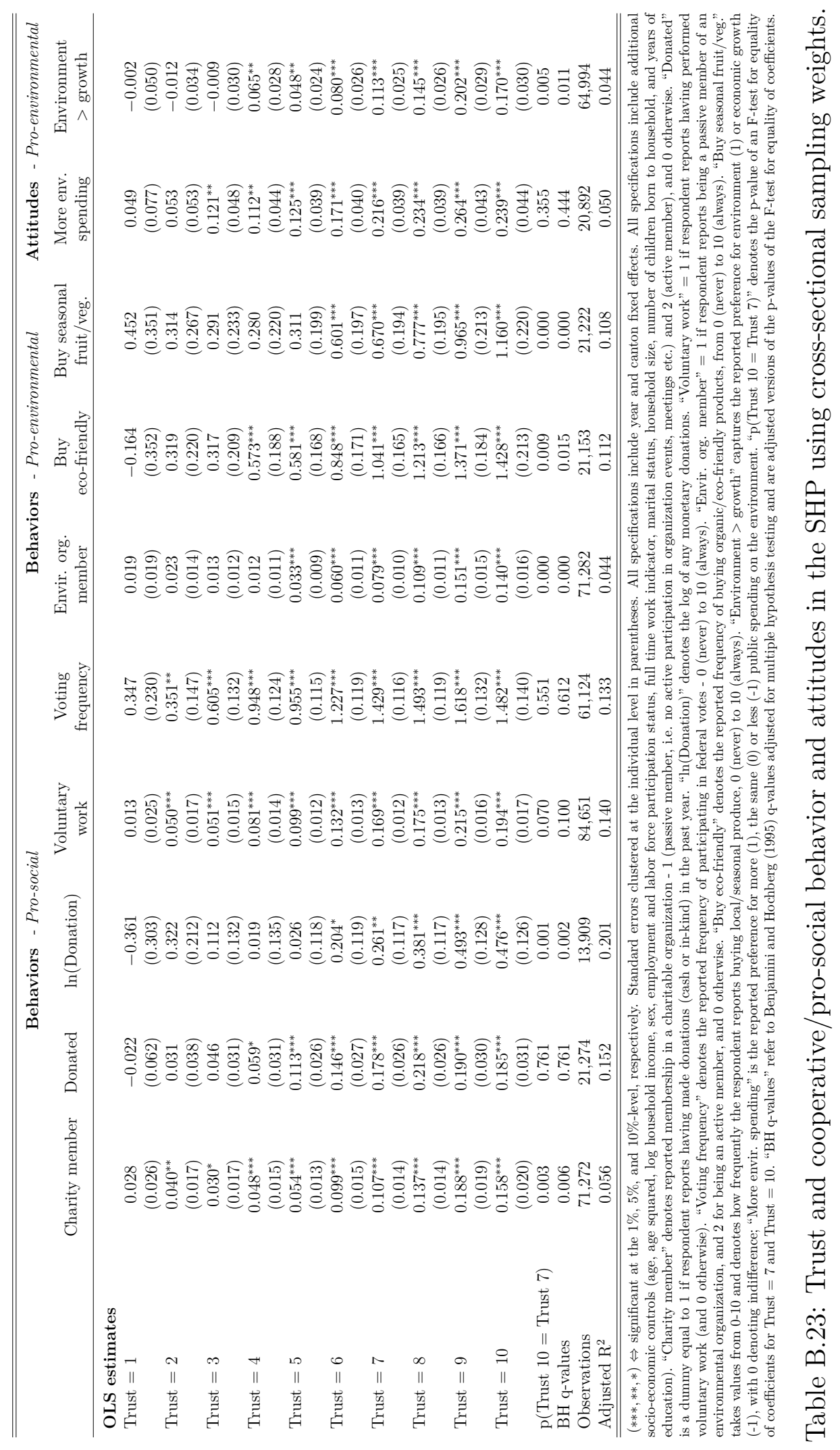




\section{Additional information and results from the SOM data}

\section{C.1 Variable description}

In what follows, we describe the SOM variables that we used for our analyses. Incomes are bracketed in the SOM, and bracket means are used to assign the values of the income variables. More details are provided in the variable description below. Table C.2 provides descriptive statistics for all SOM variables. Average trust is around 6.5 and average life satisfaction is about 3.2 on a 1-4 scale, which translates into 7.5 when responses are scaled up to the 0-10 scale used in the SHP and ESS. Mean trust and life satisfaction are very similar to the Swiss data, and above the ESS averages.

Table C.1: Description of SOM variables used

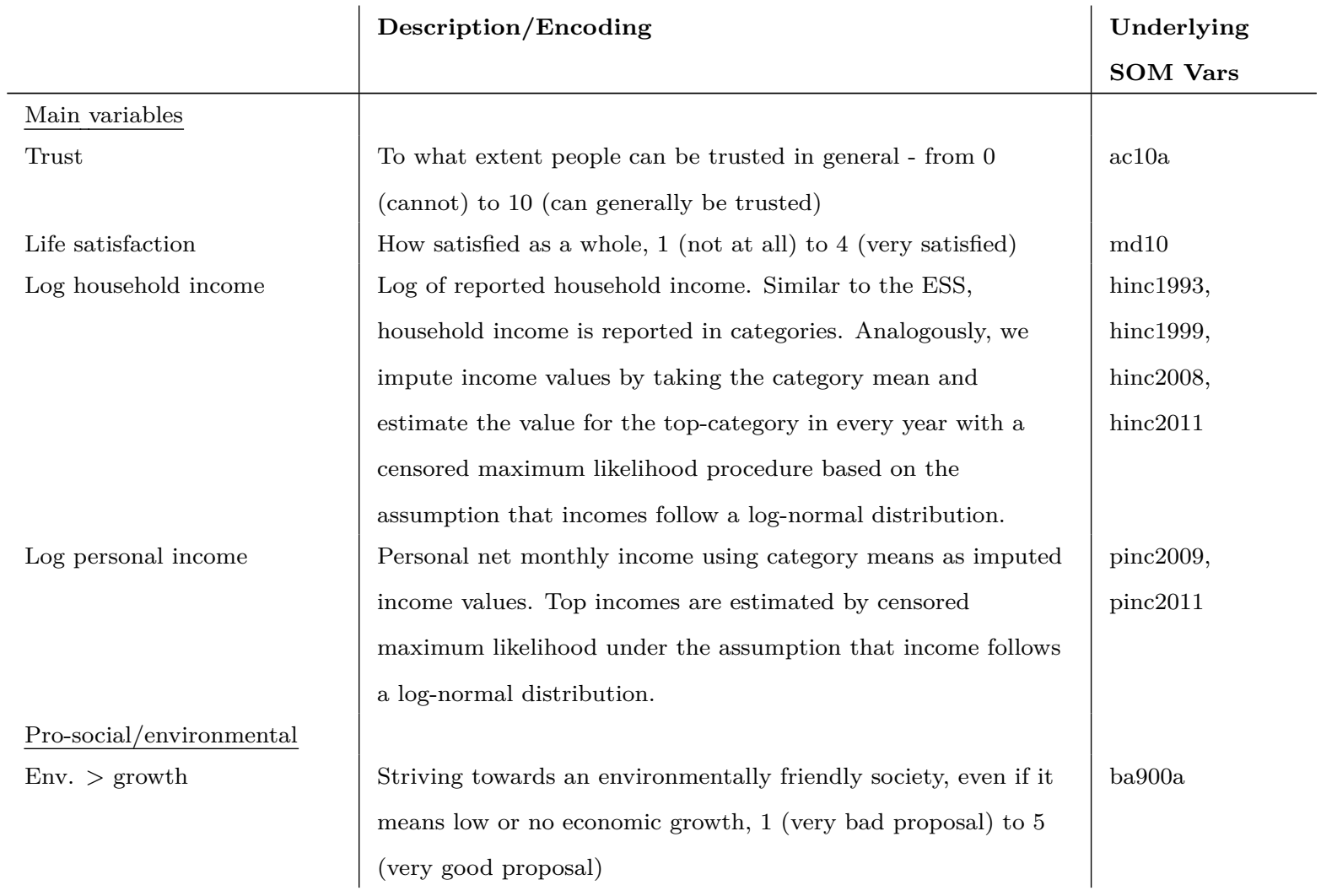


Env. soc. good

Choose alt. transp.

Sort waste

Fav. carb. tax incr.

Limit HH energy

Eng. aidorg.

Donate aidorg.

Envir. org. member

Hum. aid. member

Demographics

Age

Male

Married

Health

Educ. medium

Educ. high

Foreigner

Single HH

HH with kids

Prayed

How often: socialize (friends)

How often: gone out
Striving towards an environmentally friendly society - 1 (very

bad proposal) to 5 (very good proposal)

Do for environmental reasons: chose to walk/bike/use PT instead of driving

How often for environmental reasons: sort household waste - 1 (never) to 5 (always)

Opinion towards proposal to increase $\mathrm{CO}_{2}$ tax on petrol - 1

(very bad proposal) to 5 (very good proposal)

How important is it to limit emission sources: Household energy consumption - 1 (not at all important) to 4 (very important)

Over the last 12 months: donated money or helped an aid organization in any other way 1 (never) to 6 (at least once a week)

Over the last 12 months: donated money to an aid organization 1 (never) to 6 (at least once a week)

Membership/active in: Environmental organization - 1 if member, 0 otherwise

Membership/active in: Humanitarian aid organization - 1 if member, 0 otherwise

Age in years, based on register data

1 if male, 0 if female (those who stated unspecific third option are coded as "NA")

1 if married, 0 otherwise

from 0 (very bad/worst possible state) to 10 (very good/best

possible state) - note that the wording changed in 2002, leading us to include an interaction term allowing for differential health coefficients before and after the wording changed Dummy for having degree up to high school (1 if yes, 0 if no)

beyond comprehensive school grades 1-9

Dummy for having university degree or higher ( 1 if yes 0 if no)

1 if not a Swedish citizen, 0 otherwise

Living by myself - 1 if yes, 0 otherwise

1 if yes, 0 otherwise

Last 12 months: prayed to god -1 (never) to 7 (several times a week)

Past 12 months: socialized with friends - 1 (never) to 7 (several times a week)

Past 12 months: gone to a restaurant/pub/bar at night - 1 (never) to 7 (several times a week) ba900b

ha101b3

ha101c

ha900m

ha800e

ma190a

ma190b

mb99b

mb99g

agereg

sex

constr. from ind. data (civilstand)

mf10, mf30

edu3

edu3

citizen

hhtypela

hhtypec

bc20

ma10a

ma50c 
Anxiety: pension

Anxiety: unemployment

Anxiety: illness

Anxiety: crime

Dual citizen

Subjective class (current)

Subjective class (childhood)

Unemployed

Out of labor force

How often: overtime

Occupational group

State employee

Private sector

Trust government

Trust police

Trust parliament

Trust corporations

Trust parties

Trust courts

Stockholm/Goth./Malmö
Anxiety about personal situation: not receiving large enough

gb10b pension - 1 (of no concern at all) to 4 (of major concern)

Anxiety about personal situation: becoming unemployed - 1 (of no concern at all) to 4 (of major concern)

Anxiety about personal situation: becoming seriously ill - 1 (of no concern at all) to 4 (of major concern)

Anxiety about personal situation: becoming a victim of crime -

1 (of no concern at all) to 4 (of major concern)

1 if holding Swedish and other citizenship, 0 otherwise

Subjective family class at present - 1 (blue collar home), 2

(farmer's home), 3 (white-collar home), 4 (entrepreneurial home)

Subjective family class during childhood - 1 (blue-collar home), 2 (farmer's house), 3 (white-collar home), 4 (entrepreneurial home)

1 if unemployed, 0 otherwise

1 if out of labor force (includes old age/retirement, disability/early retirement, being a student, homeworker or other), 0 otherwise

Past 12 months: worked overtime - 1 (never) to 7 (several time a week)

occupational group - 1 (white collar worker), 2 (white collar

worker - supervisor), 3 (white collar worker - leader), 4

(blue-collar worker), 5 (blue collar worker - supervisor), 6 (other

- farmer and self-employed blue collar), 9 (self-employed - no

employees), 10 (self-employed - 1-9 employees), 11

(self-employed, 10 or more employees)

1 if employed by the state, 0 otherwise

1 if employed in the private sector, 0 otherwise

Trust in government - 1 (very low trust) to 5 (very high trust)

Trust in police - 1 (very low trust) to 5 (very high trust)

Trust in national parliament - 1 (very low trust) to 5 (very high trust)

Trust in major companies - 1 (very low trust) to 5 (very high trust)

Trust in political parties - 1 (very low trust) to 5 (very high trust)

Trust in courts - 1 (very low trust) to 5 (very high trust)

1 if living in Stockholm/Gothenburg/Malmö gb10c

gb10d

gb10e

citizen

subclh

subclg

unemployed

lmsit

ma80a

occgr

sector

sector

aa10a

aa10b

aa10e

aa10k

aa10q

aa $10 \mathrm{~m}$

cityrur 
Region

Pref./pers. variables

Risk preference

Admin variables

Year

Yearid
Region in Sweden, 1 (Stockholm), 2 (East-mid Sweden), 3

(Smaland province and islands), 4 (South Sweden), 5 (West

Sweden), 6 (North-mid Sweden), 7 (Mid-North Sweden), 8

(Upper-North Sweden)

Following Butler et al. (2016), is response to a question on

gambling habit, i.e. how often one has gambled on sports, lotto etc. in last 12 months - 1 (never) to 7 (several times a week)

Year of survey

Combination of year and idnr - unique person identifier natgeo

mc10c

year

year, idnr 
Table C.2: Summary statistics - SOM

\begin{tabular}{|c|c|c|c|c|c|}
\hline Statistic & $\mathrm{N}$ & Mean & St. Dev. & Min & Max \\
\hline Trust & 78,890 & 6.553 & 2.219 & 0 & 10 \\
\hline Life satisfaction & 73,047 & 3.262 & 0.617 & 1 & 4 \\
\hline Life satisfaction (rescaled) & 73,047 & 7.540 & 2.056 & 0 & 10 \\
\hline Log of personal income & 14,971 & 9.979 & 0.667 & 8.517 & 11.344 \\
\hline Log of household income & 78,890 & 12.825 & 0.738 & 10.820 & 14.353 \\
\hline Age & 78,890 & 50.599 & 16.954 & 18 & 85 \\
\hline Male & 78,890 & 0.492 & 0.500 & 0 & 1 \\
\hline Unemployed & 78,890 & 0.046 & 0.210 & 0 & 1 \\
\hline Out of labor force & 78,890 & 0.355 & 0.478 & 0 & 1 \\
\hline State empl. & 73,463 & 0.113 & 0.317 & 0 & 1 \\
\hline Priv. sector & 73,463 & 0.593 & 0.491 & 0 & 1 \\
\hline Union member & 76,219 & 0.587 & 0.492 & 0 & 1 \\
\hline Married & 78,890 & 0.518 & 0.500 & 0 & 1 \\
\hline Single HH & 78,890 & 0.190 & 0.392 & 0 & 1 \\
\hline HH with kids & 78,890 & 0.346 & 0.476 & 0 & 1 \\
\hline Educ. $=$ medium & 78,890 & 0.424 & 0.494 & 0 & 1 \\
\hline Educ. = high & 78,890 & 0.374 & 0.484 & 0 & 1 \\
\hline Health & 69,101 & 7.390 & 2.052 & 0 & 10 \\
\hline Risk preference & 78,890 & 3.221 & 2.143 & 1 & 7 \\
\hline Village & 78,890 & 0.214 & 0.410 & 0 & 1 \\
\hline Town & 78,890 & 0.472 & 0.499 & 0 & 1 \\
\hline Stockholm/Goth./Malmö & 78,890 & 0.161 & 0.367 & 0 & 1 \\
\hline Foreigner & 78,751 & 0.031 & 0.174 & 0 & 1 \\
\hline Dual citizen & 78,751 & 0.023 & 0.150 & 0 & 1 \\
\hline Hum. aid. memb. & 63,379 & 0.171 & 0.376 & 0 & 1 \\
\hline Eng. aidorg. & 15,278 & 2.611 & 1.490 & 1 & 6 \\
\hline Donate aidorg. & 41,080 & 2.835 & 1.633 & 1 & 6 \\
\hline Envir. org. memb. & 73,769 & 0.061 & 0.239 & 0 & 1 \\
\hline Choose alt. transp. & 6,872 & 2.575 & 1.203 & 1 & 5 \\
\hline Sort waste & 13,090 & 3.908 & 1.265 & 1 & 5 \\
\hline Env. $>$ growth & 32,211 & 3.341 & 1.069 & 1 & 5 \\
\hline Env. soc. good & 23,097 & 4.226 & 0.815 & 1 & 5 \\
\hline Limit HH energy & 4,885 & 2.922 & 0.761 & 1 & 4 \\
\hline Fav. carb. tax. incr. & 11,779 & 2.651 & 1.237 & 1 & 5 \\
\hline Trust government & 65,251 & 3.023 & 1.052 & 1 & 5 \\
\hline Trust police & 65,337 & 3.473 & 0.926 & 1 & 5 \\
\hline Trust parliament & 54,638 & 3.044 & 0.945 & 1 & 5 \\
\hline Trust corporations & 54,308 & 2.882 & 0.898 & 1 & 5 \\
\hline Trust parties & 63,607 & 2.689 & 0.893 & 1 & 5 \\
\hline Trust courts & 55,514 & 3.341 & 0.974 & 1 & 5 \\
\hline Freq. of praying & 69,712 & 2.358 & 2.147 & 1 & 7 \\
\hline Smoker & 51,393 & 0.272 & 0.445 & 0 & 1 \\
\hline How often: overtime & 35,782 & 3.469 & 2.315 & 1 & 7 \\
\hline How often: gone out & 67,945 & 3.591 & 1.652 & 1 & 7 \\
\hline How often: socialize (friends) & 78,224 & 5.720 & 1.145 & 1 & 7 \\
\hline Anxiety: pension & 4,665 & 2.752 & 0.937 & 1 & 4 \\
\hline Anxiety: unemployment & 4,465 & 2.049 & 1.020 & 1 & 4 \\
\hline Anxiety: illness & 4,689 & 2.850 & 0.906 & 1 & 4 \\
\hline Anxiety: crime & 4,681 & 2.534 & 0.883 & 1 & 4 \\
\hline
\end{tabular}




\section{C.2 Empirical approach}

In the SOM data, we proceed analogously to the ESS and SHP for our regression estimates. Our estimation equation is

$$
y_{i t}=\beta_{0}+\sum_{k=1}^{10} \beta_{k} \mathbb{1}\left(\text { Trust }_{i t}=k\right)+\delta X_{i t}+\eta_{t}+\eta_{r}+\epsilon_{i t},
$$

where $y_{i t}$ is the outcome of interest for individual $i$ in year $t, \eta_{r}$ are region fixed effects, $\eta_{t}$ are year fixed effects, and $X_{i t}$ is a vector of individual controls. Note that in the SOM, the life satisfaction scale runs from 1 to 4 instead of 0 to 10 as is the case in the other two datasets. Consequently, the magnitude of the point estimates cannot directly be compared to those in the ESS or SHP. Hence, to simplify comparability across datasets, we rescale the life satisfaction variable for the specifications in the robustness section such that its values run in equal intervals from 0 to 10 . 


\section{C.3 Trust and income/life satisfaction}

Table C.3: Regression estimates for trust and income/life satisfaction in the SOM data (no corresponding figure in main text)

\begin{tabular}{|c|c|c|c|c|c|}
\hline & $\ln (\mathrm{HH}$ inc. $)$ & $\ln (\mathrm{HH}$ inc. $)$ & $\ln$ (Pers. inc.) & Life satisf. & Life satisf. \\
\hline Trust $=1$ & $0.011(0.027)$ & & $0.023(0.022)$ & $-0.054^{* *}(0.025)$ & \\
\hline Trust $=2$ & $0.069^{* * *}(0.023)$ & & $0.0001(0.039)$ & $0.021(0.035)$ & \\
\hline Trust $=3$ & $0.093^{* * *}(0.013)$ & & $0.037(0.051)$ & $0.062^{* *}(0.031)$ & \\
\hline Trust $=4$ & $0.103^{* * *}(0.014)$ & & $0.031(0.057)$ & $0.081^{* *}(0.039)$ & \\
\hline Trust $=5$ & $0.101^{* * *}(0.016)$ & & $0.017(0.034)$ & $0.113^{* * *}(0.036)$ & \\
\hline Trust $=6$ & $0.143^{* * *}(0.015)$ & & $0.055(0.046)$ & $0.106^{* * *}(0.035)$ & \\
\hline Trust $=7$ & $0.157^{* * *}(0.012)$ & & $0.085^{*}(0.051)$ & $0.133^{* * *}(0.033)$ & \\
\hline Trust $=8$ & $0.168^{* * *}(0.014)$ & & $0.096^{* *}(0.048)$ & $0.185^{* * *}(0.033)$ & \\
\hline Trust $=9$ & $0.185^{* * *}(0.014)$ & & $0.107^{* *}(0.049)$ & $0.260^{* * *}(0.029)$ & \\
\hline Trust $=10$ & $0.152^{* * *}(0.009)$ & & $0.082(0.056)$ & $0.308^{* * *}(0.044)$ & \\
\hline Trust & & $0.016^{* * *}(0.001)$ & & & $0.031^{* * *}(0.002)$ \\
\hline $\ln (\mathrm{HH}$ inc. $)$ & & & & $0.075^{* * *}(0.004)$ & $0.074^{* * *}(0.004)$ \\
\hline Age & $0.021^{* * *}(0.001)$ & $0.021^{* * *}(0.001)$ & $0.039^{* * *}(0.003)$ & $-0.013^{* * *}(0.001)$ & $-0.013^{* * *}(0.001)$ \\
\hline $\mathrm{Age}^{2}$ & $-0.0002^{* * *}(0.00001)$ & $-0.0002^{* * *}(0.00001)$ & $-0.0003^{* * *}(0.00003)$ & $0.0001^{* * *}(0.00001)$ & $0.0001^{* * *}(0.00001)$ \\
\hline Male & $0.052^{* * *}(0.006)$ & $0.053^{* * *}(0.005)$ & $0.239^{* * *}(0.010)$ & $-0.054^{* * *}(0.008)$ & $-0.055^{* * *}(0.008)$ \\
\hline Unemployed & $-0.403^{* * *}(0.019)$ & $-0.404^{* * *}(0.019)$ & $-0.560^{* * *}(0.035)$ & $-0.160^{* * *}(0.014)$ & $-0.158^{* * *}(0.014)$ \\
\hline Health & & & & $0.105^{* * *}(0.004)$ & $0.105^{* * *}(0.003)$ \\
\hline Health*I(year>01) & & & & $0.016^{* * *}(0.003)$ & $0.016^{* * *}(0.003)$ \\
\hline Married & $0.120^{* * *}(0.012)$ & $0.120^{* * *}(0.012)$ & $0.020(0.014)$ & $0.093^{* * *}(0.003)$ & $0.093^{* * *}(0.004)$ \\
\hline Educ. $=$ medium & $0.085^{* * *}(0.007)$ & $0.087^{* * *}(0.006)$ & $0.076^{* * *}(0.008)$ & $-0.058^{* * *}(0.009)$ & $-0.060^{* * *}(0.009)$ \\
\hline Educ. $=$ high & $0.158^{* * *}(0.009)$ & $0.160^{* * *}(0.009)$ & $0.183^{* * *}(0.013)$ & $-0.071^{* * *}(0.011)$ & $-0.072^{* * *}(0.011)$ \\
\hline Single HH & $-0.552^{* * *}(0.006)$ & $-0.553^{* * *}(0.006)$ & $0.031^{* * *}(0.009)$ & $-0.098^{* * *}(0.007)$ & $-0.099^{* * *}(0.007)$ \\
\hline HH with kids & $0.014^{* * *}(0.005)$ & $0.014^{* * *}(0.005)$ & $0.051^{* * *}(0.010)$ & $-0.028^{* * *}(0.004)$ & $-0.027^{* * *}(0.004)$ \\
\hline Foreigner & $-0.136^{* * *}(0.018)$ & $-0.136^{* * *}(0.018)$ & $-0.056(0.045)$ & $-0.066^{* * *}(0.011)$ & $-0.067^{* * *}(0.012)$ \\
\hline Dual citizen & $-0.173^{* * *}(0.019)$ & $-0.174^{* * *}(0.019)$ & $-0.092^{* * *}(0.028)$ & $-0.049^{* *}(0.025)$ & $-0.048^{*}(0.026)$ \\
\hline State empl. & $0.040^{* * *}(0.009)$ & $0.040^{* * *}(0.009)$ & $0.047^{* * *}(0.010)$ & $0.004(0.008)$ & $0.004(0.008)$ \\
\hline Private sector & $0.090^{* * *}(0.009)$ & $0.090^{* * *}(0.009)$ & $0.066^{* * *}(0.012)$ & $-0.012^{* *}(0.006)$ & $-0.013^{* *}(0.006)$ \\
\hline Union member & $0.042^{* * *}(0.010)$ & $0.043^{* * *}(0.010)$ & $0.087^{* * *}(0.010)$ & $-0.009^{* * *}(0.003)$ & $-0.010^{* * *}(0.003)$ \\
\hline White col. - supervisor & $0.117^{* * *}(0.006)$ & $0.117^{* * *}(0.006)$ & $0.190^{* * *}(0.010)$ & $0.040^{* * *}(0.007)$ & $0.040^{* * *}(0.007)$ \\
\hline White col. - leader & $0.296^{* * *}(0.004)$ & $0.296^{* * *}(0.004)$ & $0.405^{* * *}(0.014)$ & $0.067^{* * *}(0.007)$ & $0.068^{* * *}(0.007)$ \\
\hline Blue col. - worker & $-0.057^{* * *}(0.008)$ & $-0.058^{* * *}(0.008)$ & $-0.178^{* * *}(0.011)$ & $0.003(0.008)$ & $0.004(0.008)$ \\
\hline Blue col. - supervisor & $-0.011^{* * *}(0.004)$ & $-0.011^{* *}(0.004)$ & $-0.077^{* * *}(0.012)$ & $0.016(0.012)$ & $0.015(0.012)$ \\
\hline Blue col. - other & $-0.307^{* * *}(0.025)$ & $-0.308^{* * *}(0.025)$ & $-0.503^{* * *}(0.090)$ & $0.052(0.041)$ & $0.052(0.042)$ \\
\hline Self-employed - alone & $-0.191^{* * *}(0.009)$ & $-0.191^{* * *}(0.009)$ & $-0.253^{* * *}(0.036)$ & $0.027^{* * *}(0.009)$ & $0.027^{* * *}(0.009)$ \\
\hline Self-empl. - 1-9 empl. & $-0.028(0.018)$ & $-0.028(0.018)$ & $-0.026(0.027)$ & $0.021^{* *}(0.011)$ & $0.021^{* *}(0.010)$ \\
\hline Self-empl. - $10+$ empl & $0.184^{* * *}(0.033)$ & $0.184^{* * *}(0.033)$ & $0.307^{* * *}(0.040)$ & $0.046^{* *}(0.020)$ & $0.046^{* *}(0.021)$ \\
\hline Subj. class: farmer & $-0.023^{*}(0.014)$ & $-0.023(0.014)$ & $-0.055^{* *}(0.025)$ & $0.022(0.021)$ & $0.022(0.021)$ \\
\hline Subj. class: white col. & $0.238^{* * *}(0.009)$ & $0.239^{* * *}(0.009)$ & $0.083^{* * *}(0.009)$ & $0.026^{* * *}(0.007)$ & $0.025^{* * *}(0.007)$ \\
\hline Subj. class: entrepren. & $0.181^{* * *}(0.015)$ & $0.181^{* * *}(0.015)$ & $0.085^{* * *}(0.022)$ & $0.045^{* * *}(0.010)$ & $0.044^{* * *}(0.010)$ \\
\hline Childh. class: farmer & $-0.016^{*}(0.009)$ & $-0.016^{*}(0.009)$ & $-0.010(0.007)$ & $-0.009^{*}(0.006)$ & $-0.010(0.006)$ \\
\hline Childh. class: white col. & $0.017^{* *}(0.007)$ & $0.018^{* * *}(0.007)$ & $0.006(0.010)$ & $-0.004(0.004)$ & $-0.005(0.004)$ \\
\hline Childh. class: entrepren. & $0.007(0.009)$ & $0.007(0.009)$ & $0.016(0.018)$ & $0.007(0.009)$ & $0.007(0.009)$ \\
\hline Risk preference & $0.006^{* * *}(0.001)$ & $0.006^{* * *}(0.001)$ & $0.006^{* * *}(0.001)$ & $-0.0004(0.001)$ & $-0.001(0.001)$ \\
\hline Village & $0.006(0.009)$ & $0.006(0.009)$ & $0.032^{* *}(0.013)$ & $-0.024^{*}(0.012)$ & $-0.024^{* *}(0.012)$ \\
\hline Town & $0.008(0.008)$ & $0.008(0.008)$ & $0.038^{* *}(0.016)$ & $-0.047^{* * *}(0.009)$ & $-0.048^{* * *}(0.008)$ \\
\hline Stockh./Goth./Malmö & $0.010^{*}(0.005)$ & $0.010^{*}(0.005)$ & $0.065^{* * *}(0.017)$ & $-0.054^{* * *}(0.010)$ & $-0.054^{* * *}(0.010)$ \\
\hline Region FE & Yes & Yes & Yes & Yes & Yes \\
\hline Year FE & Yes & Yes & Yes & Yes & Yes \\
\hline $\mathrm{p}($ Trust $10=$ Trust 7$)$ & 0.65 & & 0.85 & 0.00 & \\
\hline $\mathrm{p}($ Trust $10=$ Trust 8$)$ & 0.11 & & 0.40 & 0.00 & \\
\hline $\mathrm{p}($ Trust $10=$ Trust 9$)$ & 0.00 & & 0.00 & 0.01 & \\
\hline Observations & 64,050 & 64,050 & 12,411 & 53,975 & 53,975 \\
\hline Adjusted $\mathrm{R}^{2}$ & 0.536 & 0.536 & 0.586 & 0.255 & 0.253 \\
\hline
\end{tabular}

$(* * *, * *, *) \Leftrightarrow$ significant at the $1 \%, 5 \%$, and $10 \%$-level, respectively. Standard errors clustered at the region level in parentheses. Life satisfaction takes values ranging from 1 to 4 . " $\mathrm{p}$ (Trust $10=$ Trust 7 )" denotes the $\mathrm{p}$-value of an F-test for equality of coefficients for Trust $=10$ and Trust $=7$. " $\mathrm{p}$ (Trust $10=$ Trust 8 )" and " $p$ (Trust $10=$ Trust 9)" are defined analogously. 


\section{C.4 Trust and cooperative outcomes}

In this section, we analyze the main mechanisms behind our relationship of interest. While not to the same extent of the SHP, the SOM data also provide a relatively large range of cooperative attitudes and behaviors. We first consider three pro-social outcomes concerning membership in a humanitarian/aid organization, the frequency of engagement in the activities of such an organization as well as the frequency of donations to aid organizations, which complements the amounts provided in the SHP as measure of the intensive margin of donations. Table C.4 provides the corresponding estimates. Very much in line with our previous results from the ESS and the SHP, we find a positive relationship between trust and the abovementioned outcomes. Then, we turn to pro-environmental attitudes and behaviors. A defining property of the SOM is the availability of a broad set ofoutcomes related to the environment. We consider three types of pro-environmental behavior comprising membership in an environmental organization as well as the reported frequency of using alternative transport and sorting waste for environmental reasons. We also consider a set of proenvironmental attitudes. These include the degree of agreement with the statements that one should strive for an environmentally friendly society even at the cost of economic growth, and that one should strive for an environmentally friendly society; the attached importance of reducing emissions caused by one's household energy consumption; and support for increasing taxes on carbon-intensive goods, with no specified use of revenues (noting that Sweden already has one of the highest carbon tax rates in the world, see World Bank 2020).

Tables C.4 and C.5 provide our estimates. In line with previous results, they provide consistent evidence that high-trust individuals (i.e. those at trust levels of 9 and 10) engage in more pro-social/pro-environmental activities and have more 
environmentally friendly attitudes than their average trust counterparts (i.e. those with trust levels of 6 or 7 ). 
Table C.4: Regression estimates for pro-social and pro-environmental outcomes and attitudes in the SOM data I

\begin{tabular}{|c|c|c|c|c|c|}
\hline & Hum. aid. memb. & Eng. aidorg. & Donate aidorg. & Envir. org. member & Choose alt. transp. \\
\hline Trust $=1$ & $0.017(0.020)$ & $0.086(0.185)$ & $0.322^{* * *}(0.079)$ & $0.003(0.010)$ & $0.110(0.171)$ \\
\hline Trust $=2$ & $0.007(0.019)$ & $-0.022(0.146)$ & $0.207^{* *}(0.085)$ & $-0.009(0.012)$ & $0.133(0.126)$ \\
\hline Trust $=3$ & $0.022(0.013)$ & $0.242(0.160)$ & $0.290^{* * *}(0.097)$ & $0.001(0.014)$ & $0.214^{* *}(0.091)$ \\
\hline Trust $=4$ & $0.021^{* *}(0.011)$ & $0.120(0.164)$ & $0.367^{* * *}(0.115)$ & $0.0001(0.012)$ & $0.174(0.131)$ \\
\hline Trust $=5$ & $0.039^{* * *}(0.014)$ & $0.227(0.170)$ & $0.387^{* * *}(0.089)$ & $-0.001(0.009)$ & $0.201^{* *}(0.083)$ \\
\hline Trust $=6$ & $0.040^{* * *}(0.011)$ & $0.265(0.174)$ & $0.500^{* * *}(0.097)$ & $-0.002(0.009)$ & $0.286^{* * *}(0.104)$ \\
\hline Trust $=7$ & $0.059^{* * *}(0.014)$ & $0.360^{* *}(0.158)$ & $0.596^{* * *}(0.069)$ & $0.005(0.012)$ & $0.310^{* * *}(0.084)$ \\
\hline Trust $=8$ & $0.080^{* * *}(0.011)$ & $0.407^{* *}(0.173)$ & $0.744^{* * *}(0.065)$ & $0.013(0.011)$ & $0.264^{* * *}(0.081)$ \\
\hline Trust $=9$ & $0.103^{* * *}(0.014)$ & $0.505^{* * *}(0.143)$ & $0.847^{* * *}(0.068)$ & $0.035^{* * *}(0.011)$ & $0.457^{* * *}(0.109)$ \\
\hline Trust $=10$ & $0.101^{* * *}(0.008)$ & $0.486^{* * *}(0.185)$ & $0.747^{* * *}(0.074)$ & $0.025^{* *}(0.012)$ & $0.319^{* * *}(0.113)$ \\
\hline $\ln (\mathrm{HH}$ inc.) & $0.018^{* * *}(0.003)$ & $0.082^{* *}(0.037)$ & $0.104^{* * *}(0.024)$ & $-0.005^{* * *}(0.001)$ & $-0.093^{* * *}(0.029)$ \\
\hline Age & $0.001(0.001)$ & $0.001(0.006)$ & $-0.013^{* * *}(0.003)$ & $0.002^{* * *}(0.0003)$ & $0.002(0.006)$ \\
\hline $\mathrm{Age}^{2}$ & $0.00000(0.00001)$ & $0.0001^{* *}(0.0001)$ & $0.0003^{* * *}(0.00004)$ & $-0.00002^{* * *}(0.00000)$ & $-0.00002(0.0001)$ \\
\hline Male & $-0.071^{* * *}(0.003)$ & $-0.319^{* * *}(0.023)$ & $-0.450^{* * *}(0.014)$ & $-0.006^{*}(0.003)$ & $-0.196^{* * *}(0.039)$ \\
\hline Unemployed & $0.006(0.011)$ & $-0.038(0.074)$ & $-0.101^{* * *}(0.015)$ & $-0.002(0.007)$ & $0.070(0.057)$ \\
\hline Married & $0.016^{* * *}(0.004)$ & $0.200^{* * *}(0.035)$ & $0.231^{* * *}(0.019)$ & $-0.003(0.002)$ & $0.047^{*}(0.026)$ \\
\hline Educ. $=$ medium & $0.036^{* * *}(0.004)$ & $0.193^{* * *}(0.054)$ & $0.157^{* * *}(0.025)$ & $0.010^{* * *}(0.001)$ & $0.063(0.051)$ \\
\hline Educ. = high & $0.103^{* * *}(0.003)$ & $0.412^{* * *}(0.060)$ & $0.365^{* * *}(0.029)$ & $0.045^{* * *}(0.002)$ & $0.200^{* * *}(0.071)$ \\
\hline Single HH & $0.027^{* * *}(0.006)$ & $0.049^{*}(0.029)$ & $0.138^{* * *}(0.038)$ & $0.001(0.003)$ & $0.204^{* * *}(0.060)$ \\
\hline HH with kids & $0.004(0.006)$ & $0.043(0.031)$ & $0.032(0.024)$ & $0.006^{* * *}(0.002)$ & $-0.035(0.046)$ \\
\hline Foreigner & $-0.023(0.015)$ & $0.020(0.071)$ & $-0.105^{* * *}(0.032)$ & $-0.021^{* * *}(0.004)$ & $-0.073(0.131)$ \\
\hline Dual citizen & $0.005(0.015)$ & $0.043(0.361)$ & $0.038(0.066)$ & $-0.022^{* *}(0.010)$ & $-0.095(0.086)$ \\
\hline State empl. & $-0.011^{* * *}(0.004)$ & $-0.037(0.036)$ & $-0.072^{* * *}(0.026)$ & $0.006^{*}(0.003)$ & $0.001(0.074)$ \\
\hline Private sector & $-0.019^{* * *}(0.003)$ & $-0.019(0.015)$ & $0.005(0.028)$ & $-0.005^{* * *}(0.002)$ & $-0.194^{* * *}(0.047)$ \\
\hline Union member & $0.023^{* * *}(0.006)$ & $0.042(0.027)$ & $0.103^{* * *}(0.019)$ & $0.013^{* * *}(0.003)$ & $-0.048(0.031)$ \\
\hline White col. - supervisor & $0.012^{* * *}(0.004)$ & $0.123^{* * *}(0.029)$ & $0.059(0.038)$ & $-0.003(0.002)$ & $-0.097(0.061)$ \\
\hline White col. - leader & $0.024^{* * *}(0.009)$ & $0.204^{* * *}(0.068)$ & $0.151^{* *}(0.076)$ & $-0.008(0.008)$ & $-0.249^{* * *}(0.094)$ \\
\hline Blue col. - worker & $-0.009^{* * *}(0.002)$ & $-0.087(0.054)$ & $-0.117^{* * *}(0.033)$ & $-0.006^{* *}(0.003)$ & $-0.004(0.037)$ \\
\hline Blue col. - supervisor & $0.021^{* * *}(0.006)$ & $0.001(0.063)$ & $0.040(0.031)$ & $-0.001(0.003)$ & $0.059(0.082)$ \\
\hline Blue col. - other & $0.040^{*}(0.024)$ & $0.104(0.137)$ & $-0.011(0.066)$ & $-0.016(0.012)$ & $-0.062(0.199)$ \\
\hline Self-employed - alone & $0.027^{* * *}(0.006)$ & $0.006(0.077)$ & $-0.030(0.042)$ & $0.013^{* *}(0.006)$ & $-0.093(0.092)$ \\
\hline Self-empl. - 1-9 empl. & $0.022(0.014)$ & $0.211^{* *}(0.105)$ & $0.175^{* * *}(0.058)$ & $-0.002(0.006)$ & $-0.094(0.080)$ \\
\hline Self-empl. - 10+ empl & $0.019(0.012)$ & $0.261^{* * *}(0.101)$ & $0.341^{* * *}(0.093)$ & $-0.007(0.006)$ & $-0.202(0.158)$ \\
\hline Subj. class: farmer & $0.030^{* * *}(0.010)$ & $0.043(0.109)$ & $0.184^{* * *}(0.061)$ & $0.010(0.006)$ & $-0.123(0.096)$ \\
\hline Subj. class: white col. & $0.028^{* * *}(0.003)$ & $0.145^{* * *}(0.039)$ & $0.118^{* * *}(0.038)$ & $0.011^{* * *}(0.004)$ & $-0.062(0.039)$ \\
\hline Subj. class: entrepren. & $0.041^{* * *}(0.009)$ & $0.238^{* * *}(0.058)$ & $0.162^{* *}(0.065)$ & $0.015^{* * *}(0.005)$ & $-0.138^{* *}(0.062)$ \\
\hline Childh. class: farmer & $0.014^{* *}(0.007)$ & $0.134^{* * *}(0.034)$ & $0.134^{* * *}(0.031)$ & $0.006^{* *}(0.002)$ & $0.099^{* *}(0.049)$ \\
\hline Childh. class: white col. & $0.032^{* * *}(0.003)$ & $0.041^{* *}(0.016)$ & $0.123^{* * *}(0.017)$ & $0.015^{* * *}(0.002)$ & $0.024(0.031)$ \\
\hline Childh. class: entrepren. & $0.025^{* * *}(0.005)$ & $0.063(0.049)$ & $0.146^{* * *}(0.026)$ & $0.001(0.001)$ & $-0.025(0.035)$ \\
\hline Risk preference & $-0.002^{* *}(0.001)$ & $0.003(0.010)$ & $0.022^{* * *}(0.003)$ & $-0.004^{* * *}(0.0004)$ & $-0.028^{* * *}(0.007)$ \\
\hline Village & $0.007(0.005)$ & $0.017(0.039)$ & $0.016(0.027)$ & $-0.013^{* * *}(0.002)$ & $0.464^{* * *}(0.073)$ \\
\hline Town & $0.004(0.004)$ & $-0.062^{*}(0.035)$ & $0.051^{*}(0.027)$ & $-0.013^{* * *}(0.003)$ & $0.725^{* * *}(0.044)$ \\
\hline Stockh./Goth./Malmö & $0.028^{* * *}(0.004)$ & $0.063(0.054)$ & $0.085^{* *}(0.037)$ & $-0.006^{*}(0.003)$ & $1.052^{* * *}(0.028)$ \\
\hline Region FE & Yes & Yes & Yes & Yes & Yes \\
\hline Year FE & Yes & Yes & Yes & Yes & Yes \\
\hline $\mathrm{p}($ Trust $10=$ Trust 7$)$ & 0.000 & 0.008 & 0.000 & 0.000 & 0.895 \\
\hline $\mathrm{BH}$ q-values & 0.000 & 0.011 & 0.000 & 0.000 & 0.895 \\
\hline $\mathrm{p}$ (Trust $9=$ Trust 6 ) & 0.000 & 0.004 & 0.000 & 0.000 & 0.068 \\
\hline $\mathrm{BH}$ q-values & 0.000 & 0.004 & 0.000 & 0.000 & 0.068 \\
\hline Observations & 52,437 & 11,697 & 33,896 & 60,333 & 5,765 \\
\hline Adjusted $\mathrm{R}^{2}$ & 0.062 & 0.095 & 0.107 & 0.024 & 0.116 \\
\hline
\end{tabular}

$(* * *, * *, *) \Leftrightarrow$ significant at the $1 \%, 5 \%$, and $10 \%$-level, respectively. Standard errors clustered at the region level in parentheses. "Hum. aid. memb." denotes membership in an humanitarian/aid organization - 1 if member, 0 otherwise. "Eng. aidorg." is the reported frequency of donating or helping an aid organization in the last 12 months - 1 (never) to 6 (at least once a week). "Donate aidorg." is coded analogously, but only focuses on monetary donations to an aid organization. "Envir. org. member" denotes membership in an environmental organization - 1 if member, 0 otherwise. "Use alt. transp" is the reported frequency of walking/biking using public transport instead of driving for env. reasons - 1 (never) to 5 (always). " $\mathrm{p}$ (Trust $10=$ Trust 7 )" denotes the p-value of an F-test for equality of coefficients for Trust $=7$ and Trust $=10, " \mathrm{p}$ (Trust $9=$ Trust 6 ) is defined analogously. "BH q-values" refer to Benjamini and Hochberg (1995) $\mathrm{q}$-values adjusted for multiple hypothesis testing and are adjusted versions of the p-values of the F-test for equality of coefficients in the respective lines above the q-values. 
Table C.5: Regression estimates for pro-social/-environmental outcomes/attitudes in the SOM data II

\begin{tabular}{|c|c|c|c|c|c|}
\hline & Sort waste & Env. > growth & Env. soc. good & Limit HH energy & Fav. carb. tax. incr. \\
\hline Trust $=1$ & $-0.044(0.137)$ & $0.016(0.089)$ & $0.015(0.079)$ & $0.076(0.149)$ & $0.206^{*}(0.109)$ \\
\hline Trust $=2$ & $0.079(0.117)$ & $0.075(0.082)$ & $0.078^{*}(0.047)$ & $0.057(0.104)$ & $0.218(0.181)$ \\
\hline Trust $=3$ & $0.211(0.159)$ & $0.075(0.071)$ & $0.092^{*}(0.047)$ & $0.096(0.099)$ & $0.219(0.138)$ \\
\hline Trust $=4$ & $0.232(0.160)$ & $0.039(0.080)$ & $0.146^{* * *}(0.023)$ & $0.055(0.096)$ & $0.372^{* * *}(0.130)$ \\
\hline Trust $=5$ & $0.229^{* *}(0.102)$ & $0.093(0.059)$ & $0.180^{* * *}(0.029)$ & $0.200^{* * *}(0.064)$ & $0.324^{* * *}(0.123)$ \\
\hline Trust $=6$ & $0.236(0.156)$ & $0.115^{* *}(0.057)$ & $0.182^{* * *}(0.018)$ & $0.124^{*}(0.075)$ & $0.379^{* * *}(0.109)$ \\
\hline Trust $=7$ & $0.337^{* *}(0.149)$ & $0.125^{*}(0.069)$ & $0.249^{* * *}(0.025)$ & $0.196^{* *}(0.079)$ & $0.499^{* * *}(0.123)$ \\
\hline Trust $=8$ & $0.371^{* * *}(0.139)$ & $0.198^{* * *}(0.062)$ & $0.305^{* * *}(0.020)$ & $0.255^{* * *}(0.074)$ & $0.583^{* * *}(0.121)$ \\
\hline Trust $=9$ & $0.412^{* *}(0.163)$ & $0.231^{* * *}(0.067)$ & $0.418^{* * *}(0.024)$ & $0.289^{* * *}(0.072)$ & $0.653^{* * *}(0.114)$ \\
\hline Trust $=10$ & $0.438^{* * *}(0.111)$ & $0.211^{* * *}(0.081)$ & $0.461^{* * *}(0.038)$ & $0.335^{* * *}(0.090)$ & $0.714^{* * *}(0.135)$ \\
\hline $\ln$ (HH inc.) & $-0.008(0.018)$ & $-0.153^{* * *}(0.019)$ & $-0.057^{* * *}(0.013)$ & $-0.073^{* *}(0.029)$ & $-0.108^{* * *}(0.015)$ \\
\hline Age & $0.022^{* *}(0.009)$ & $-0.005(0.004)$ & $-0.004^{*}(0.003)$ & $0.018^{* *}(0.008)$ & $-0.008(0.006)$ \\
\hline $\mathrm{Age}^{2}$ & $-0.0001(0.0001)$ & $0.0001(0.00005)$ & $0.00001(0.00003)$ & $-0.0002^{* *}(0.0001)$ & $0.00005(0.0001)$ \\
\hline Male & $-0.170^{* * *}(0.026)$ & $-0.187^{* * *}(0.010)$ & $-0.167^{* * *}(0.013)$ & $-0.183^{* * *}(0.017)$ & $-0.206^{* * *}(0.023)$ \\
\hline Unemployed & $-0.041(0.068)$ & $0.055^{*}(0.030)$ & $-0.003(0.037)$ & $-0.0003(0.048)$ & $0.065(0.115)$ \\
\hline Married & $0.070^{* *}(0.028)$ & $-0.023(0.018)$ & $-0.003(0.014)$ & $-0.008(0.016)$ & $-0.001(0.018)$ \\
\hline Educ. $=$ medium & $0.027(0.055)$ & $-0.031^{* * *}(0.011)$ & $-0.001(0.016)$ & $-0.028(0.032)$ & $0.055(0.049)$ \\
\hline Educ. = high & $0.090(0.067)$ & $0.036^{* * *}(0.014)$ & $0.158^{* * *}(0.023)$ & $0.049(0.039)$ & $0.337^{* * *}(0.050)$ \\
\hline Single HH & $-0.130^{* * *}(0.036)$ & $-0.074^{* * *}(0.022)$ & $-0.016(0.017)$ & $-0.020(0.046)$ & $0.027(0.031)$ \\
\hline HH with kids & $0.081^{* * *}(0.021)$ & $0.050^{* * *}(0.016)$ & $0.014^{*}(0.008)$ & $-0.004(0.038)$ & $-0.007(0.024)$ \\
\hline Foreigner & $0.164^{* *}(0.070)$ & $0.096^{* * *}(0.023)$ & $-0.003(0.025)$ & $-0.083(0.077)$ & $0.089(0.102)$ \\
\hline Dual citizen & $0.185(0.122)$ & $0.070^{* * *}(0.023)$ & $0.038(0.031)$ & $0.122(0.077)$ & $0.118(0.119)$ \\
\hline State empl. & $-0.016(0.032)$ & $-0.064^{* * *}(0.019)$ & $-0.057^{* * *}(0.015)$ & $-0.049(0.042)$ & $-0.069(0.064)$ \\
\hline Private sector & $-0.042(0.029)$ & $-0.123^{* * *}(0.017)$ & $-0.079^{* * *}(0.013)$ & $-0.073^{* * *}(0.027)$ & $-0.156^{* * *}(0.032)$ \\
\hline Union member & $0.055(0.034)$ & $0.056^{* * *}(0.016)$ & $0.019(0.012)$ & $-0.028(0.033)$ & $0.054^{* *}(0.023)$ \\
\hline White col. - supervisor & $0.029(0.021)$ & $-0.035^{* *}(0.017)$ & $-0.064^{* * *}(0.020)$ & $0.012(0.029)$ & $-0.093(0.058)$ \\
\hline White col. - leader & $-0.003(0.047)$ & $-0.167^{* * *}(0.028)$ & $-0.039(0.031)$ & $-0.080(0.053)$ & $-0.129^{* * *}(0.044)$ \\
\hline Blue col. - worker & $-0.054^{* *}(0.026)$ & $-0.020(0.019)$ & $-0.019(0.014)$ & $-0.012(0.024)$ & $-0.012(0.056)$ \\
\hline Blue col. - supervisor & $0.0002(0.056)$ & $-0.015(0.021)$ & $-0.047(0.033)$ & $0.030(0.067)$ & $-0.044(0.045)$ \\
\hline Blue col. - other & $-0.317^{*}(0.183)$ & $0.152(0.103)$ & $-0.064(0.136)$ & $-0.0001(0.124)$ & $0.134(0.240)$ \\
\hline Self-employed - alone & $-0.012(0.076)$ & $0.121^{* * *}(0.028)$ & $0.040(0.031)$ & $0.043(0.102)$ & $0.017(0.078)$ \\
\hline Self-empl. - 1-9 empl. & $0.022(0.059)$ & $0.040(0.042)$ & $-0.097^{*}(0.055)$ & $-0.047(0.094)$ & $0.135^{* * *}(0.049)$ \\
\hline Self-empl. - 10+ empl & $-0.079(0.161)$ & $-0.062(0.070)$ & $-0.106^{* * *}(0.036)$ & $-0.145(0.098)$ & $-0.135(0.087)$ \\
\hline Subj. class: farmer & $-0.071(0.089)$ & $-0.150^{* * *}(0.037)$ & $-0.084(0.055)$ & $-0.049(0.088)$ & $-0.047(0.118)$ \\
\hline Subj. class: white col. & $0.046(0.041)$ & $-0.015(0.017)$ & $0.003(0.017)$ & $-0.014(0.022)$ & $0.103^{* * *}(0.033)$ \\
\hline Subj. class: entrepren. & $-0.056^{*}(0.033)$ & $-0.136^{* * *}(0.034)$ & $-0.019(0.025)$ & $-0.023(0.059)$ & $-0.027(0.041)$ \\
\hline Childh. class: farmer & $0.095^{* * *}(0.033)$ & $0.038^{* *}(0.016)$ & $-0.035(0.026)$ & $0.048(0.041)$ & $0.020(0.026)$ \\
\hline Childh. class: white col. & $0.006(0.021)$ & $-0.044(0.030)$ & $0.010(0.007)$ & $0.026(0.027)$ & $0.097^{* * *}(0.030)$ \\
\hline Childh. class: entrepren. & $0.011(0.037)$ & $-0.060^{* * *}(0.019)$ & $-0.038^{* * *}(0.013)$ & $0.037(0.051)$ & $-0.098(0.065)$ \\
\hline Risk preference & $-0.029^{* * *}(0.010)$ & $-0.016^{* * *}(0.002)$ & $-0.019^{* * *}(0.004)$ & $-0.014^{* *}(0.006)$ & $-0.036^{* * *}(0.010)$ \\
\hline Village & $0.048^{*}(0.027)$ & $-0.001(0.014)$ & $0.009(0.021)$ & $0.058^{*}(0.033)$ & $0.185^{* * *}(0.043)$ \\
\hline Town & $0.090^{* * *}(0.024)$ & $0.019^{*}(0.011)$ & $0.072^{* * *}(0.019)$ & $0.070^{* *}(0.031)$ & $0.333^{* * *}(0.048)$ \\
\hline Stockh./Goth./Malmö & $-0.127^{* * *}(0.022)$ & $0.065(0.043)$ & $0.129^{* * *}(0.012)$ & $0.088^{* *}(0.045)$ & $0.570^{* * *}(0.052)$ \\
\hline Region FE & Yes & Yes & Yes & Yes & Yes \\
\hline Year FE & Yes & Yes & Yes & Yes & Yes \\
\hline$p($ Trust $10=$ Trust 7$)$ & 0.139 & 0.000 & 0.000 & 0.011 & 0.002 \\
\hline BH q-values & 0.154 & 0.000 & 0.000 & 0.014 & 0.003 \\
\hline$p($ Trust $9=$ Trust 6 ) & 0.000 & 0.000 & 0.000 & 0.003 & 0.000 \\
\hline BH q-values & 0.000 & 0.000 & 0.000 & 0.003 & 0.000 \\
\hline Observations & 10,800 & 25,551 & 19,443 & 4,039 & 9,878 \\
\hline Adjusted $R^{2}$ & 0.087 & 0.048 & 0.090 & 0.047 & 0.136 \\
\hline
\end{tabular}

$(* * *, * *, *) \Leftrightarrow$ significant at the $1 \%, 5 \%$, and $10 \%$-level, respectively. Standard errors clustered at the region level in parentheses. "Sort waste" is the reported frequency of sorting waste for environmental reasons - 1 (never) to 5 (always). "Env. > growth" indicates the degree of agreement that one should strive to an environmentally friendly society even at the cost of economic growth - 1 (very bad proposal) to 5 (very good proposal). "Env. soc. good" asks the same, but without the econ. growth qualification. "Limit HH energy" is the reported importance attached to reducing emissions from household energy consumption - 1 (not at all important) to 4 (very important). "Fav. carb. tax. incr." is the opinion towards proposal to increase the $\mathrm{CO}_{2}$ tax on petrol - 1 (very bad proposal) to 5 (very good proposal). "p(Trust $10=$ Trust 7 )" denotes the p-value of an F-test for equality of coefficients for Trust $=7$ and Trust $=10$, "p(Trust 9 = Trust 6) is defined analogously. "BH q-values" refer to Benjamini and Hochberg (1995) q-values adjusted for multiple hypothesis testing and are adjusted versions of the p-values of the F-test for equality of coefficients in the respective lines above the q-values. 


\section{C.5 Robustness tests}

In this section, we present the battery of robustness tests applied to the SOM data. The corresponding estimates are presented in Figures C.1 and C.2 and Tables C.6 and C.7.

As per standard procedure, we start by presenting the analyses testing the robustness of our findings on the trust-income and trust-well-being relationships to the inclusion of additional controls related to other forms of trust, political and religious attitudes (Figure C.1) as well as social activity and negative affect (Figure C.2). Once more, our results are robust to these sensitivity checks.

As for the ESS and SHP data, our findings are also robust to the use of non-linear models, as shown by Tables C.6 and C.7, which provide ordered probit and logit estimates for trust and life satisfaction. That is, also in the case of the SHP data, the observed positive relationship does not depend on the imposed interval scale of the life satisfaction variable in our baseline regressions. Based on the SOM data, and very much in line with the ESS and SHP data, increasing trust by 1 point is projected to increase the probability of being in the highest life satisfaction category by about $2.2 \%$ on average. This estimate is based on a rescaled variable, from 4 to 10 for consistency with ESS and SHP, but rescaling has no impact on the estimates in these ordered specifications. Hence, we conclude that, if anything, the effects are larger in the SOM data, which is to be expected given that the SOM only has 4 answer categories for life satisfaction, compared to the 11 provided in the other datasets. 

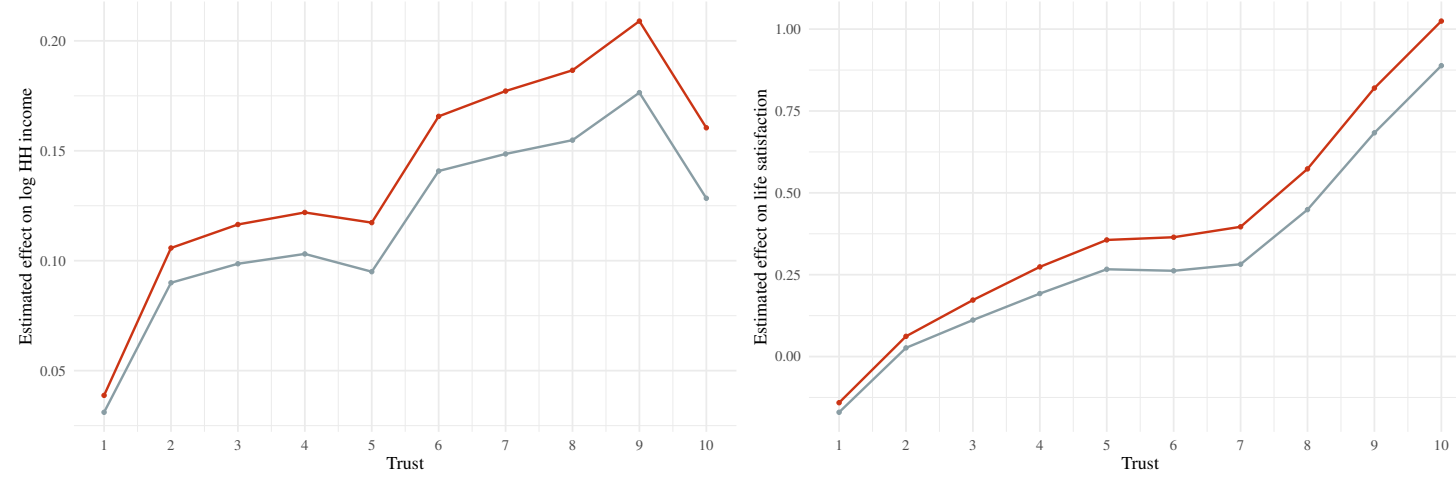

Figure C.1: Trust and income/life satisfaction with (solid) and without (dashed) additional contextual controls in the SOM.

The additional controls include trust in (i) the government, (ii) the police, (iii) parliament, (iv) corporation, (v) political parties, and (vi) courts, as well as the frequency of prayer. The baseline regression specifications is the same as in Table C.3.
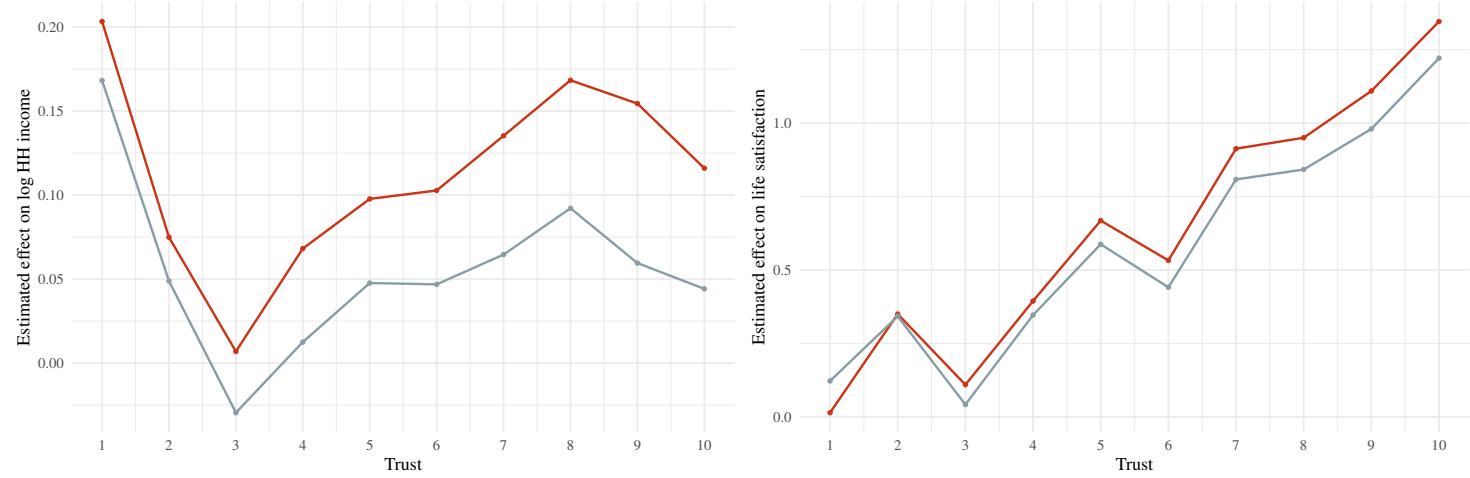

Figure C.2: Trust and income/life satisfaction with (solid) and without (dashed) additional controls for negative affect and social engagement in the SOM.

The additional controls include the degree of anxiety related to (i) pension security, (ii) unemployment, (iii) illness, (iv) crime, how often one performed overtime work, whether the individual is a smoker, and how often the respondent (i) went out and/or (ii) socialized with friends. The baseline regression specifications is the same as in Table C.3. 
Table C.6: Ordered probit estimates for trust and life satisfaction in the SOM data

\begin{tabular}{|c|c|c|c|}
\hline & $\begin{array}{l}\text { Coef. } \\
(1)\end{array}$ & $\begin{array}{c}\text { ME on } \mathrm{p}(\mathrm{y}=10) \text { at mean } \\
(2)\end{array}$ & $\begin{array}{c}\text { Avg. ME on } \mathrm{p}(\mathrm{y}=10) \\
(3)\end{array}$ \\
\hline Trust & $0.0704^{* * *}(0.0026)$ & $0.0250^{* * *}(0.0009)$ & $0.0221^{* * *}(0.0008)$ \\
\hline $\ln (\mathrm{HH}$ inc.) & $0.1260^{* * *}(0.0084)$ & $0.0448^{* * *}(0.0030)$ & $0.0396^{* * *}(0.0026)$ \\
\hline Age & $-0.5006^{* * *}(0.0421)$ & $-0.1781^{* * *}(0.0150)$ & $-0.1574^{* * *}(0.0132)$ \\
\hline $\mathrm{Age}^{2}$ & $0.5068^{* * *}(0.0445)$ & $0.1803^{* * *}(0.0158)$ & $0.1593^{* * *}(0.0140)$ \\
\hline Male & $-0.1240^{* * *}(0.0115)$ & $-0.0441^{* * *}(0.0041)$ & $-0.0390^{* * *}(0.0036)$ \\
\hline Unemployed & $-0.3280^{* * *}(0.0270)$ & $-0.1167^{* * *}(0.0096)$ & $-0.1031^{* * *}(0.0085)$ \\
\hline Married & $0.2179^{* * *}(0.0131)$ & $0.0775^{* * *}(0.0047)$ & $0.0685^{* * *}(0.0041)$ \\
\hline Educ. $=$ medium & $-0.1405^{* * *}(0.0163)$ & $-0.0500^{* * *}(0.0058)$ & $-0.0442^{* * *}(0.0051)$ \\
\hline Educ. = high & $-0.1675^{* * *}(0.0196)$ & $-0.0596^{* * *}(0.0070)$ & $-0.0526^{* * *}(0.0061)$ \\
\hline Single HH & $-0.2162^{* * *}(0.0174)$ & $-0.0769^{* * *}(0.0062)$ & $-0.0680^{* * *}(0.0055)$ \\
\hline HH with kids & $-0.0659^{* * *}(0.0131)$ & $-0.0234^{* * *}(0.0047)$ & $-0.0207^{* * *}(0.0041)$ \\
\hline Foreigner & $-0.1607^{* * *}(0.0318)$ & $-0.0572^{* * *}(0.0113)$ & $-0.0505^{* * *}(0.0100)$ \\
\hline Dual citizen & $-0.1136^{* * *}(0.0353)$ & $-0.0404^{* * *}(0.0126)$ & $-0.0357^{* * *}(0.0111)$ \\
\hline State empl. & $0.0084(0.0189)$ & $0.0030(0.0067)$ & $0.0026(0.0060)$ \\
\hline Private sector & $-0.0299^{* *}(0.0134)$ & $-0.0106^{* *}(0.0048)$ & $-0.0094^{* *}(0.0042)$ \\
\hline Union member & $-0.0279^{* *}(0.0125)$ & $-0.0099^{* *}(0.0045)$ & $-0.0088^{* *}(0.0039)$ \\
\hline White col. - supervisor & $0.0954^{* * *}(0.0177)$ & $0.0339^{* * *}(0.0063)$ & $0.0300^{* * *}(0.0056)$ \\
\hline White col. - leader & $0.1658^{* * *}(0.0279)$ & $0.0590^{* * *}(0.0099)$ & $0.0521^{* * *}(0.0087)$ \\
\hline Blue col. - worker & $0.0091(0.0169)$ & $0.0032(0.0060)$ & $0.0029(0.0053)$ \\
\hline Blue col. - supervisor & $0.0323(0.0252)$ & $0.0115(0.0090)$ & $0.0102(0.0079)$ \\
\hline Blue col. - other & $0.1033(0.0737)$ & $0.0368(0.0262)$ & $0.0325(0.0232)$ \\
\hline Self-employed - alone & $0.0560 *(0.0317)$ & $0.0199 *(0.0113)$ & $0.0176^{*}(0.0100)$ \\
\hline Self-empl. - 1-9 empl. & $0.0468(0.0352)$ & $0.0167(0.0125)$ & $0.0147(0.0111)$ \\
\hline Self-empl. - 10+ empl & $0.1126^{* *}(0.0527)$ & $0.0401^{* *}(0.0187)$ & $0.0354^{* *}(0.0166)$ \\
\hline Subj. class: farmer & $0.0574(0.0419)$ & $0.0204(0.0149)$ & $0.0181(0.0132)$ \\
\hline Subj. class: white col. & $0.0574^{* * *}(0.0166)$ & $0.0204^{* * *}(0.0059)$ & $0.0180^{* * *}(0.0052)$ \\
\hline Subj. class: entrepren. & $0.1070^{* * *}(0.0264)$ & $0.0381^{* * *}(0.0094)$ & $0.0336^{* * *}(0.0083)$ \\
\hline Childh. class: farmer & $-0.0215(0.0184)$ & $-0.0076(0.0065)$ & $-0.0068(0.0058)$ \\
\hline Childh. class: white col. & $-0.0081(0.0141)$ & $-0.0029(0.0050)$ & $-0.0025(0.0044)$ \\
\hline Childh. class: entrepren. & $0.0179(0.0209)$ & $0.0064(0.0074)$ & $0.0056(0.0066)$ \\
\hline Risk preference & $-0.0030(0.0026)$ & $-0.0011(0.0009)$ & $-0.0010(0.0008)$ \\
\hline Village & $-0.0573^{* * *}(0.0186)$ & $-0.0204^{* * *}(0.0066)$ & $-0.0180^{* * *}(0.0058)$ \\
\hline Town & $-0.1090^{* * *}(0.0169)$ & $-0.0388^{* * *}(0.0060)$ & $-0.0343^{* * *}(0.0053)$ \\
\hline Stockh./Goth./Malmö & $-0.1227^{* * *}(0.0218)$ & $-0.0437^{* * *}(0.0077)$ & $-0.0386^{* * *}(0.0068)$ \\
\hline Threshold 1 (SE) & -2.5619 & $(0.0554)$ & \\
\hline Threshold 2 (SE) & -1.341 & $(0.0518)$ & \\
\hline Threshold 3 (SE) & 0.9526 & $(0.0515)$ & \\
\hline $\mathrm{N}$ & 53986 & & \\
\hline Region dummies & Yes & Yes & Yes \\
\hline Year dummies & Yes & Yes & Yes \\
\hline
\end{tabular}

$(* * *, * *, *) \Leftrightarrow$ significant at the $1 \%, 5 \%$, and $10 \%$-level, respectively. Heteroskedasticity robust standard errors in parentheses. Age, age squared, and log household income have been standardized (mean 0 and standard deviation of 1 ) before estimation. The thresholds refer to the values of the latent variable at which the outcome changes according to the fitted model ( 3 thresholds separating 4 ordered response categories). 
Table C.7: Ordered logit estimates for trust and life satisfaction in the SOM data

\begin{tabular}{|c|c|c|c|}
\hline & $\begin{array}{l}\text { Coef. } \\
(1)\end{array}$ & $\begin{array}{c}\text { ME on } \mathrm{p}(\mathrm{y}=10) \text { at mean } \\
(2)\end{array}$ & $\begin{array}{c}\text { Avg. ME on } \mathrm{p}(\mathrm{y}=10) \\
(3)\end{array}$ \\
\hline Trust & $0.1228^{* * *}(0.0046)$ & $0.0257^{* * *}(0.0010)$ & $0.0226^{* * *}(0.0008)$ \\
\hline $\ln (\mathrm{HH}$ inc.) & $0.2215^{* * *}(0.0149)$ & $0.0464^{* * *}(0.0031)$ & $0.0407^{* * *}(0.0027)$ \\
\hline Age & $-0.9615^{* * *}(0.0746)$ & $-0.2015^{* * *}(0.0156)$ & $-0.1769^{* * *}(0.0137)$ \\
\hline $\mathrm{Age}^{2}$ & $0.9740^{* * *}(0.0788)$ & $0.2042^{* * *}(0.0165)$ & $0.1792^{* * *}(0.0145)$ \\
\hline Male & $-0.2143^{* * *}(0.0201)$ & $-0.0449^{* * *}(0.0042)$ & $-0.0394^{* * *}(0.0037)$ \\
\hline Unemployed & $-0.6021^{* * *}(0.0498)$ & $-0.1262^{* * *}(0.0104)$ & $-0.1108^{* * *}(0.0092)$ \\
\hline Married & $0.3693^{* * *}(0.0228)$ & $0.0774^{* * *}(0.0048)$ & $0.0679^{* * *}(0.0042)$ \\
\hline Educ. $=$ medium & $-0.2448^{* * *}(0.0287)$ & $-0.0513^{* * *}(0.0060)$ & $-0.0450^{* * *}(0.0053)$ \\
\hline Educ. $=$ high & $-0.2802^{* * *}(0.0343)$ & $-0.0587^{* * *}(0.0072)$ & $-0.0515^{* * *}(0.0063)$ \\
\hline Single HH & $-0.3971^{* * *}(0.0310)$ & $-0.0832^{* * *}(0.0065)$ & $-0.0730^{* * *}(0.0057)$ \\
\hline HH with kids & $-0.1154^{* * *}(0.0228)$ & $-0.0242^{* * *}(0.0048)$ & $-0.0212^{* * *}(0.0042)$ \\
\hline Foreigner & $-0.2653^{* * *}(0.0571)$ & $-0.0556^{* * *}(0.0120)$ & $-0.0488^{* * *}(0.0105)$ \\
\hline Dual citizen & $-0.2020^{* * *}(0.0634)$ & $-0.0423^{* * *}(0.0133)$ & $-0.0372^{* * *}(0.0117)$ \\
\hline State empl. & $0.0227(0.0330)$ & $0.0048(0.0069)$ & $0.0042(0.0061)$ \\
\hline Private sector & $-0.0484^{* *}(0.0234)$ & $-0.0101^{* *}(0.0049)$ & $-0.0089^{* *}(0.0043)$ \\
\hline Union member & $-0.0505^{* *}(0.0219)$ & $-0.0106^{* *}(0.0046)$ & $-0.0093^{* *}(0.0040)$ \\
\hline White col. - supervisor & $0.1539^{* * *}(0.0305)$ & $0.0323^{* * *}(0.0064)$ & $0.0283^{* * *}(0.0056)$ \\
\hline White col. - leader & $0.2696^{* * *}(0.0476)$ & $0.0565^{* * *}(0.0100)$ & $0.0496^{* * *}(0.0087)$ \\
\hline Blue col. - worker & $0.0092(0.0296)$ & $0.0019(0.0062)$ & $0.0017(0.0055)$ \\
\hline Blue col. - supervisor & $0.0514(0.0440)$ & $0.0108(0.0092)$ & $0.0095(0.0081)$ \\
\hline Blue col. - other & $0.1986(0.1293)$ & $0.0416(0.0271)$ & $0.0365(0.0238)$ \\
\hline Self-employed - alone & $0.1037^{*}(0.0552)$ & $0.0217^{*}(0.0116)$ & $0.0191^{*}(0.0102)$ \\
\hline Self-empl. - 1-9 empl. & $0.0780(0.0611)$ & $0.0163(0.0128)$ & $0.0143(0.0112)$ \\
\hline Self-empl. - 10+ empl & $0.2161^{* *}(0.0914)$ & $0.0453^{* *}(0.0192)$ & $0.0398^{* *}(0.0168)$ \\
\hline Subj. class: farmer & $0.1005(0.0726)$ & $0.0211(0.0152)$ & $0.0185(0.0133)$ \\
\hline Subj. class: white col. & $0.0959^{* * *}(0.0291)$ & $0.0201^{* * *}(0.0061)$ & $0.0176^{* * *}(0.0054)$ \\
\hline Subj. class: entrepren. & $0.1830^{* * *}(0.0459)$ & $0.0384^{* * *}(0.0096)$ & $0.0337^{* * *}(0.0084)$ \\
\hline Childh. class: farmer & $-0.0484(0.0321)$ & $-0.0101(0.0067)$ & $-0.0089(0.0059)$ \\
\hline Childh. class: white col. & $-0.0157(0.0245)$ & $-0.0033(0.0051)$ & $-0.0029(0.0045)$ \\
\hline Childh. class: entrepren. & $0.0244(0.0361)$ & $0.0051(0.0076)$ & $0.0045(0.0066)$ \\
\hline Risk preference & $-0.0060(0.0046)$ & $-0.0013(0.0010)$ & $-0.0011(0.0008)$ \\
\hline Village & $-0.1015^{* * *}(0.0323)$ & $-0.0213^{* * *}(0.0068)$ & $-0.0187^{* * *}(0.0059)$ \\
\hline Town & $-0.1937^{* * *}(0.0295)$ & $-0.0406^{* * *}(0.0062)$ & $-0.0356^{* * *}(0.0054)$ \\
\hline Stockh./Goth./Malmö & $-0.2158^{* * *}(0.0380)$ & $-0.0452^{* * *}(0.0080)$ & $-0.0397^{* * *}(0.0070)$ \\
\hline Threshold 1 (SE) & -4.9059 & $(0.1028)$ & \\
\hline Threshold 2 (SE) & -2.4285 & $(0.0921)$ & \\
\hline Threshold 3 (SE) & 1.6614 & $(0.0911)$ & \\
\hline $\mathrm{N}$ & 53986 & & \\
\hline Region dummies & Yes & Yes & Yes \\
\hline Year dummies & Yes & Yes & Yes \\
\hline
\end{tabular}

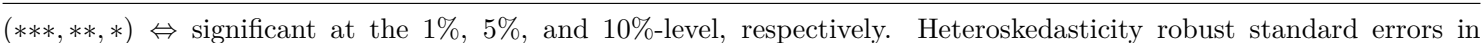
parentheses. Age, age squared, and log household income have been standardized (mean 0 and standard deviation of 1) before estimation. The thresholds refer to the values of the latent variable at which the outcome changes according to the fitted model (3 thresholds separating 4 ordered response categories). 